\author{
BY \\ BRIAN HANNA \\ BACHELOR OF SCIENCE IN BIOLOGY, RYERSON UNIVERSITY 2013 \\ A THESIS \\ PRESENTED TO RYERSON UNIVERSITY
}

IN PARTIAL FULFILLMENT OF THE

REQUIREMENTS FOR THE DEGREE OF

MASTER OF APPLIED SCIENCE

IN THE PROGRAM OF

ENVIRONMENTAL APPLIED SCIENCE AND MANAGEMENT

TORONTO, ONTARIO, CANADA, 2016

CBRIAN HANNA 2016 
This page left intentionally blank 


\section{AUTHOR'S DECLARATION}

I hereby declare that I am the sole author of this thesis. This is a true copy of the thesis, including any required final revision, as accepted by my examiners.

I authorize Ryerson University to lend this thesis to other institutions or individuals for the purpose of scholarly research.

I further authorize Ryerson University to reproduce this thesis by photocopying or by other means, in total or in part, at the request of other institutions or individuals for the purpose of scholarly research.

I understand that my thesis may be made electronically available to the public. 


\title{
Effects Of Ibuprofen And Tetracycline On Extracellular Polymer Production
}

\author{
Brian Hanna \\ Master of Applied Science, Environmental Applied Science and Management
}

Ryerson University 2016

\begin{abstract}
Extracellular polymer substances (EPS) comprised of proteins, carbohydrates, and other biomolecules, are important for microbiological communities. The EPS provides benefits to wastewater treatment communities (WWTC) such as antibiotic resistance, and community structure. Therefore EPS can be viewed as a valuable health marker of WWTC and therefore it is important to determine effects of contaminants entering wastewater treatment plants (WWTPS) on EPS. WWTC were exposed to the non-steroidal anti-inflammatory drug (NSAID) Ibuprofen at $16 \mathrm{ng} / \mathrm{mL}$ and $100 \mathrm{ng} / \mathrm{mL}$, and the antibiotic tetracycline at $50 \mathrm{ng} / \mathrm{mL}$ to determine how EPS and growth were affected. EPS was analyzed using high performance liquid chromatography (HPLC), Bradford protein analysis, and Anthrone carbohydrate analysis. It was determined that EPS content was lower at both Ibuprofen concentrations, enhanced with tetracycline, and comparable to control when both were present. Changes could not be linked to protein or carbohydrate concentration. Growth inhibition occurred in the presence of both drugs but not each individually, suggesting that Ibuprofen may increase tetracycline sensitivity through EPS inhibition.
\end{abstract}




\section{Acknowledgements}

First and foremost I would like to thank my supervisor Professor Kimberley Gilbride, for not only helping me finish and push through when times were hard, but for helping me start my Masters at Ryerson University. I could not have completed this without her continuous support over the past 2.5 years.

I would also like to thank all the professors at Ryerson who made themselves available to me whenever I had questions, Professor Michael Arts, Professor Martina Hausner, Dr. Otini Kroukamp, and all my amazing professors. Of course I would like to thank the professors who helped me discover my passion for environmental science, especially Professor Vadim Bostan, and Professor Lynda McCarthy. You helped me strive to learn more at times when I questioned the importance of my academic career.

The days and nights were always made enjoyable thanks to all the members of the Gilbride and Wolfaardt lab, and even on the worst of days I was able to experience happiness through the many friends I made.

Finally but not least, I must thank my loving family for encouraging my love of science from a young age and bringing me to Canada where I could aspire to be more than I could have ever dreamed; Especially my mother Cecilia for her constant inspiration, and my father Edward for his stern but loving encouragement. 
List of Tables

1. Introduction

$\begin{array}{ll}\text { 2. Background } & 5\end{array}$

2.1. Wastewater treatment plants (WWTPs) 5

2.1.1. Purpose of WWTPs $\quad 6$

$\begin{array}{lll}\text { 2.1.2. } & \text { Types of WWTPs } & 7\end{array}$

2.2. Wastewater Treatment Communities (WWTCs) 8

2.3. Extracellular polymeric substances (EPS) 10

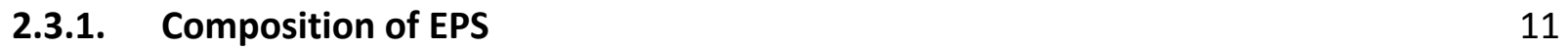

2.3.2. Functions of EPS in WWTPs 12

2.3.3. EPS Extraction Techniques 14

2.4. Emerging Contaminants $\quad 14$

\begin{tabular}{ll} 
2.4.1. & Removal Rates in WWTPs \\
\hline
\end{tabular}

$\begin{array}{lr}\text { 2.5. Ibuprofen } & 18\end{array}$

2.5.1. History $\quad 19$

2.5.2. Removal Rates and Psuedopersistence 20

2.6. Tetracycline $\quad 21$

$\begin{array}{ll}\text { 2.6.1. History } & 21\end{array}$

2.6.2. Removal Rates and Pseudo-persistence 22

2.7. Global Policies $\quad 23$

2.7.1. Gaps in Knowledge $\quad 25$ 
2.8. Pharmaceutical Mixtures 26

2.8.1. Conceptual Questions Vs. Environmental Relevance 26

2.8.2. Previous Links Between Ibuprofen and Tetracycline $\quad 27$

$\begin{array}{llr}\text { 2.9. } & \text { Research Objectives } & 28\end{array}$

3. Materials and Methods 29

3.1. Bacterial strains $\quad 29$

$\begin{array}{ll}\text { 3.2. Wastewater samples } & 29\end{array}$

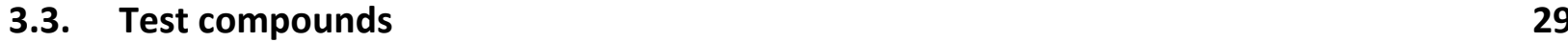

3.4. Growth Inhibition Tests $\quad 30$

3.5. EPS Extraction and Analysis $\quad 30$

3.6. Protein Quantification 31

3.7. Carbohydrate Analysis 32

3.8. Analysis - Calculating the Area of the Chromatograms 32

3.9 Statistical analysis 33

3.9.1 Sample Characteristics $\quad 33$

3.9.2 ANOVA analysis $\quad 34$

4. Results and Discussion $\quad 35$

4.2. Growth Inhibition Tests

4.2.1. Pseudomonas putida BBC443

$\begin{array}{lll}\text { 4.2.2. Wastewater Treatment Community } & 37\end{array}$

4.3. Extracellular Polymer Substances

4.3.1. Chromatograms $\quad 39$

4.4. Possible model explaining effect of Ibuprofen and tetracycline on WWTC 49

4.4.1. Protein and Carbohydrate Concentrations of EPS $\quad 51$

4.5. Soluble Microbial Products Analysis $\quad 53$

5. Conclusions and Future Work

$\begin{array}{ll}\text { Appendix A - Chromatograms } & 58\end{array}$ 
Appendix B - Protein Standards

Appendix C - Statistics Tables

Appendix D - Method for Calculation of chromatogram area

Appendix E - Normal Q-Q plots

References

79 
List of Tables

Table 1 Prepared BSA standards 32

Table 2 Post Hoc Bon Ferroni corrected T-tests statistical analysis of pairwise comparisons for groups of interest 49

Table 3 ANOVA table of area under chromatograms for the contaminant groups 65

Table 4 ANOVA table for area under peak one for chromatograms of contaminant groups... 66

Table 5 ANOVA table for area under peak two for chromatograms of contaminant groups .. 67

Table 6 Bonferroni Post Hoc Control vs (50 ng/mL Tetracycline +100 ng/mL Ibuprofen) ....... 67

Table 7 Bonferroni Post Hoc Control vs Tetracycline and Ibuprofen Group........................... 68

Table 8 Bonferroni Post Hoc Control vs 50 ng/mL tetracycline group................................ 68

Table 9 Bonferroni Post Hoc 50 ng/mL tetracycline +100 ng/mL lbuprofen vs 50 ng/mL

Tetracycline $+16 \mathrm{ng} / \mathrm{mL}$ Ibuprofen 69

Table 10 Bonferroni Post Hoc Ibuprofen as one group vs Ibuprofen $100 \mathrm{ng} / \mathrm{mL}$ 69

Table 11 ANOVA analysis of Carbohydrate concentrations of EPS samples produced by WWTC exposed to various concentrations of Tetracycline and Ibuprofen. 69 
List of Figures

Figure 1 Cross sectional model for sludge within WWTPs (Sheng et al., 2010)

Figure 2 Possible pathways to water systems as a result of medical use (Mudgal et al., 2013)

Figure 3 Structure of Ibuprofen

Figure 4 Structure of Tetracycline

Figure 5 Growth rate of Pseudomonas putida measured in OD600 when exposed to varying concentrations of the contaminants Ibuprofen and Tetracycline 36

Figure 6 Growth rate of Wastewater Community measured in OD600 when exposed to varying concentrations of the contaminants Ibuprofen and Tetracycline 38

Figure 7 Chromatogram of Extracellular Products when wastewater community is exposed to $50 \mathrm{ng} / \mathrm{mL}$ of Tetracycline compared to control, measured at $215 \mathrm{~nm}$ 40 Figure 8 Chromatogram of Extracellular Products when wastewater community is exposed to $16 \mathrm{ng} / \mathrm{mL}$ and $100 \mathrm{ng} / \mathrm{mL}$ of Ibuprofen compared to control, measured at $215 \mathrm{~nm}$ 43

Figure 9 Chromatogram of Extracellular Products when wastewater community is exposed to combinations of Tetracycline and Ibuprofen compared to control, measured at $215 \mathrm{~nm}$ 44 Figure 10 Chromatogram of Extracellular Products when wastewater community is exposed to Ibuprofen, Tetracycline, and Combination compared to each other, measured at $215 \mathrm{~nm} 45$ Figure 11 Area of chromatograms of EPS production by WWTCs 46 Figure 12 Graph showing average areas of chromatograms of WWTC EPS exposed to varying concentrations of Ibuprofen and Tetracycline error bars represent the Standard deviation.. 48 
Figure 13 Conceptual model for the interaction between EPS and contaminants Ibuprofen

and Tetracycline 50

Figure 14 Measured concentrations of Protein in wastewater samples exposed to Tetracycline and Ibuprofen in $\mathrm{mg} / \mathrm{L}$ 52

Figure 15 Carbohydrate concentrations of EPS samples produced by WWTC exposed to varying concentrations of Tetracycline and Ibuprofen 52

Figure 16 Chromatogram of WWTC sample control 58

Figure 17 Chromatogram of WWTC exposed to $100 \mathrm{ng} / \mathrm{mL}$ Ibuprofen 59

Figure 18 Chromatogram of WWTC exposed to $16 \mathrm{ng} / \mathrm{mL}$ Ibuprofen 60

Figure 19 Chromatogram of WWTC sample exposed to $50 \mathrm{ng} / \mathrm{mL}$ Tetracycline 61 Figure 20 Chromatogram of WWTC exposed to $50 \mathrm{ng} / \mathrm{mL}$ tetracycline and $100 \mathrm{ng} / \mathrm{mL}$ Ibuprofen 62

Figure 21 Chromatogram of WWTC sample exposed to $50 \mathrm{ng} / \mathrm{mL}$ Tetracycline and $16 \mathrm{ng} / \mathrm{mL}$ Ibuprofen 63

Figure 22 Protein Standard Mix 15-600 kDa run through Zorbax Bio series gf-250 column at 1 $\mathrm{mL} / \mathrm{min}$. From left to right, Thyroblobulin Bovine $670 \mathrm{kDa}, \mathrm{y}$-globulins from bovine blood 150 kDa, Chicken egg albumin 44.3 kDa, Ribonuclease A 13.7 kDa 64

Figure 23 Step One - Open Chromatogram in GIMP 2.0 Program ...................................... 71

Figure 24 Step 2 - Open the Histrogram window ...................................................... 71

Figure 25 Step 3 - Press U key to use "Fuzzy Select" tool ................................................ 72

Figure 26 Step 4 - With "Fuzzy Select" tool, click anywhere within the graph boundaries, total pixels in graph will be displayed in Histogram 72 
Figure 27 Step 5 - Select the pencil brush tool

Figure 28 Step 6 - Close off the boundaries of the chromatogram using the pencil tool (Shift click to draw straight lines)....... 73

Figure 29 Step 7 - Using the "Fuzzy Select" tool once again, click under the line of the chromatogram, total pixels under the graph will be shown in the Histogram 74

Figure 30 Normal Q-Q plot for the Area of the Chromatograms belonging to the Control Group 75

Figure 31 Normal Q-Q plot for the Area of the Chromatograms belonging to the Groups containing both Tetracycline and Ibuprofen 76

Figure 32 Normal Q-Q plot for the Area of the Chromatograms belonging to the Tetracycline Group

Figure 33 Normal Q-Q plot for the Area of the Chromatograms belonging to the Ibuprofen Groups. 78 
List of Abbreviations

$\begin{array}{ll}\text { AOB } & \text { Ammonia-Oxidizing Bacteria } \\ \text { BOD } & \text { Biological Oxygen Demand } \\ \text { BTEX } & \text { Benzenes, Toluene, Ethylbenzenes, Xylenes } \\ \text { CA } & \text { Canada } \\ \text { CAS } & \text { Conventional Activated Sludge } \\ \text { CER } & \text { Cation Exchange Resin } \\ \text { COD } & \text { Chemical Oxygen Demand } \\ \text { EPS } & \text { Extracellular Polymer Substances } \\ \text { EU } & \text { Europe }\end{array}$

FBR Fixed Bioreactors

HPSEC High Pressure Size Exclusion Chromatography

ICL In Commerce List

MBBR Moving Bed Bioreactors

MBR Membrane Bioreactors

NSAIDS Non-Steroidal Anti-Inflammatory Drugs

PAO Polyphosphate Accumulating Organisms 
PEC Predicted Environmental Concentration

PNEC Predicted No Effect Concentration

SMP Soluble Microbial Products

SRT Sludge Retention Time

US United States

UV Ultraviolet

WWTC Wastewater Treatment Communities

WWTPS Wastewater Treatment Plants 
This page left intentionally blank 


\section{Introduction}

In large urban areas, Canadian wastewater treatment plants (WWTPs) are responsible for treating as much as 150 Mega litres per day of raw sewage. The main purpose of these plants is to remove organic waste in the form of nitrogen, sulfur, and phosphorus before the effluent is released into the surrounding environment. These treatment plants are however receiving many different types of pollutants that they were not originally intended to handle, such as antibiotics, hormonal drugs, and personal care products. As time goes on more drugs will be introduced into the environment, many which may have unintended consequences. As a result, it is important to reduce usage, improve degradation and elimination, and study the effects of the drugs on the wastewater treatment process. This research will focus on the effects of tetracycline and Ibuprofen on the secondary treatment process in the WWTPs. This is especially important when you take into consideration that increasing amounts of pharmaceuticals are entering WWTPs each year as exemplified by the fact that Canadian sales of prescription drugs increased by $\$ 12$ billion between 2006 and 2011 (Guerra et al., 2014).

Recent studies show that the residues of many of these pharmaceuticals, designed to act upon cellular processes in humans, show toxic effects in the environment. For instance a group of drugs called Azoles used to clinically treat fungal infections have been shown to have a causal relationship to a reduction in egg numbers in female fish (Celander, 2011). In addition to having an effect on its own, Azoles in combination with benzenes, toluene, ethylbenzenes, and xylenes (BTEXs) causes greater bioaccumation of said BTEXs (Celander, 2011). In another study with a mixture of the NSAID (nonsteroidal anti-inflammatories, NSAID) diclofenac and other 
drugs, it was shown that the reproductive age of water fleas was significantly reduced, and the fecundity increased (Vasquez et al., 2014). Changes within algae have also been seen, where mixtures including Ibuprofen and antibiotics induced quantitative changes in proteins involved in photosynthesis (Vasquez et al., 2014). These examples show that individual drugs alone and in combinations can have unintended side effects at all levels of the trophic system.

While extreme care is taken in preventing harmful drug interactions in humans, it is impossible to prevent these drug interactions in a wastewater treatment scenario, where each of these drugs can have many differing effects on gene expression, metabolism, changing levels of ions, etc. (Vasquez et al., 2014). Furthermore, combinations of drugs may produce additive or synergistic effects that have not been studied yet. Additive here refers to an effect equal to the sum of the effects seen when the individual drugs are examined, and synergistic being an effect greater than both combined.

Numerous different drugs may be found in the influent water of treatment plants, such as NSAIDs (Deblonde et al., 2011; Irsch, 2003; Lishman et al., 2006; Pasquini et al., 2013; Verlicchi et al., 2012), antibiotics, lipid regulators, and hormonal drugs (Avella et al., 2010; Deblonde et al., 2011; Irsch, 2003; Michael et al., 2013; Pasquini et al., 2013). While the cumulative effect of all these compounds is interesting, preliminary studies need to assess the effect of individual drugs before studying drug mixtures. This study will focus on the effect of two drugs, tetracycline and Ibuprofen, from two different pharmaceutical groups, antibiotics and NSAIDS respectively. These drugs were chosen primarily for the wealth of supporting research already available, as well as their ubiquitous use in human and veterinary medicine. 
Ibuprofen was also chosen in order to further examine some novel effects seen when wastewater communities were exposed to it, namely its ability to inhibit the production of one of the community's defense and structural components (known as extracellular polymer substances, EPS).

Furthermore, studying the effect of these two drugs together should provide insight into how these communities cope with drug combinations, as well as how the presence of one drug can enhance or inhibit the effect of the other. This can provide information that can later be analyzed to determine the EPS products produced and determine what specific components are linked to greater survival of the community.

The goal of this research is to study the effect of tetracycline and Ibuprofen on the microbial populations of a wastewater secondary treatment system by measuring the effect on growth and the concentration and composition of EPS produced in the presence of these two pharmaceuticals. Examining current literature suggests that Ibuprofen inhibits the EPS production in bacteria thereby reducing their protective layer while antibiotics such as tetracycline have been show to increase EPS production (Avella et al., 2010; Pasquini et al., 2013).

It is hypothesized that Ibuprofen and tetracycline will have opposite effects on the production of EPS, with Ibuprofen causing inhibition, and tetracycline causing a spike. In combination it is wondered if the individual effects of the drugs will cancel each other out or be enhanced in the presence of the other. 
Therefore the short term objectives of this research are to measure the:

1) Effect of tetracycline or Ibuprofen alone or in combination on the growth of a model organism, Psuedomonas putida BBC443

2) Effect of tetracycline or Ibuprofen alone or in combination on the growth of a wastewater microbial population

3) Effect of tetracycline or Ibuprofen alone or in combination on the production of EPS and soluble microbial products (SMP) in a batch reactor system

The EPS and SMP was measured and quantified using High Performance Liquid Chromatography (HPLC) and Bradford and Dubois assays were used to determine the changes in protein and carbohydrate concentrations respectively. These methods were chosen for their nondestructive nature, ensuring that results measured were minimally affected by cell lysis. 


\section{Background}

\subsection{Wastewater treatment plants (WWTPs)}

Wastewater Treatment Plants (WWTPs) come in many shapes and sizes, from lagoons used to treat wastewater in small towns (Hoque et al., 2014), to large plants capable of treating over 150 million liters per day (City of Guelph, 2009). Population growth, urbanization, and increased access to treatment systems mean an increase in global effluent loads over the next fifty years, with nitrogen and phosphorous effluents alone expected to rise from 6 to 17 million tons, and 1.3 to 3.3 million tons respectively (OECD, 2012).

While the processes behind WWTPs are expected to become more efficient, this increased efficiency is not expected to be on par with increased nutrient rates (OECD, 2012). What this means is that barring other types of contaminants entering WWTPs, the plants will be enduring increasing challenges to remove xenobiotics in the coming years; something that needs to be taken into consideration when determining how to deal with the new contaminants and their effects on the processes that occur within these plants. This is especially important, considering that WWTPs are often the only treatment processes for sewage before it is released into the environment. If they are incapable of removing contaminants, this could lead to a positive feedback loop where incoming contaminants can have greater effects. 


\subsubsection{Purpose of WWTPs}

The main purpose of a WWTP is the removal of macropollutants such as organic matter, nitrogen, phosphorus, and suspended solids (Pasquini et al., 2013). The total load of these contaminants is expected to almost triple within the next 50 years (OECD, 2012), putting stress on already aging infrastructure.

WWTPs usually consist of primary, secondary, and sometimes tertiary treatment.

The primary treatment stage consists of physical removal of solid materials from the wastewater and this stage is common to most wastewater treatment systems (Batt et al., 2007). It results in the settlement of suspended solids (referred to as sludge) and the overall reduction of biochemical oxygen demand (BOD) of the effluent by at least $20 \%$ (OECD, 2012).

The effluent then is transported to the secondary treatment reactors which are dependent on biological activity of a microbial community to remove dissolved organic materials (Avella et al., 2010), with an aim of reducing BOD by $~ 70 \%$ and chemical oxygen demand (COD) by $\sim 75 \%$ (OECD, 2012). Furthermore, many pathogens are removed in this step.

Anaerobic digestion often follows secondary treatment where, under anaerobic conditions, fermentation of sludge components, production of methanogenic substrates and methanogenesis occurs. The advantage is a reduction of sludge produced during the aerobic processes. 
Finally, tertiary processes can be employed that best suit the geography/contaminants found in the wastewater, and includes further nitrogen and phosphorus removal, a reduction in the microbial concentration and removal of organic pollutants with activated carbon filters.

Finally, additional treatments of the effluent before released in the environment can include ozonation, powdered activated carbon, or ultraviolet (UV) exposure, among others (OECD, 2012).

\subsubsection{Types of WWTPS}

There exist many different types of WWTPs, all utilizing the benefits of microbial degradation. These include lagoon systems, conventional activated sludge (CAS), membrane bioreactors (MBR), and moving or fixed bed bioreactors (MBBR and FBR respectively) (Michael et al., 2013).

\subsubsection{Lagoons}

Lagoon based sewage treatment are pond-like water bodies that are responsible for receiving and treating wastewater, usually for small municipalities (Hoque et al., 2014). They are usually implemented due to their low cost to build, operate and maintain, in addition to this there is some evidence that they are efficient at removing a wide variety of micro-pollutants due to the complex processes that occur within the lagoons; however their efficiency in winter seasons is still under investigation. 


\subsubsection{Conventionally Activated Sludge (CAS)}

Activated sludge plants are by far the most common types of centralized wastewater treatment (CAS). They depend on the use of microbiological activity in a highly oxygenated environment to degrade organic matter (Michael et al., 2013). The sludge produced in these plants is a mix of living organisms, and the products that they need to survive and are considered high in nutrients. The sludge can be further processed into biosolids than can be incinerated for energy or used as agricultural fertilizer (Irsch, 2003; Michael et al., 2013). Due to the high affinity of many drugs to bind to this sludge, biosolids provide another route of dissemination for emerging contaminants to reach the environment (K. A. Gilbride et al., 2011; Guerra et al., 2014; McEneff et al., 2014; Prosser et al., 2015; Zenker et al., 2014).

\subsubsection{Membrane Bioreactors (MBR)}

Membrane Bioreactors are a combination between activated sludge and membrane filtration technologies, enabling the bacterial flocs to be contained in a small amount of space (Le-Clech et al., 2006). They have a smaller footprint than CAS systems, while producing high quality effluent, disinfectant capabilities, and less biosolid production. However they tend to be more expensive to maintain, and as time goes on the filters become less effective due to membrane fouling (Le-Clech et al., 2006).

\subsection{Wastewater Treatment Communities (WWTCs)}

Wastewater treatment communities are extremely diverse systems, consisting of archaea, bacteria, protozoa, metazoan, autotrophs, fungi, archaea, viruses and even predatory heterotrophs (Lee et al., 1996; Martín-González et al., 2006; Moussa et al., 2005; Zhang et al., 
2011). From this we can see that these are full ecosystems, presumably at risk to perturbations due to changing environmental conditions like any ecosystem.

The bacteria in the system are most commonly found in aggregates, flocs, and biofilms bound by EPS (Lee et al., 1996; Sheng et al., 2010). Typically this biomass consists of 33\% and $14 \%$ active bacteria at sludge retention times (SRT) of 30 and 100 days respectively (Moussa et al., 2005). What this means is that as SRT increases, the growth of bacteria saturates while sludge volumes continue to increase. This saturation seems to occur at around 40 days where levels of nitrification, phosphate removal, and predation no longer increase (Moussa et al., 2005). Low oxygen content, as well as removal of surface proteins can cause aggregates to deflocculate, which in turn reduces the quality of the final effluent (Miao et al., 2004). This effect on effluent quality is due to the use of gravity clarifiers which will remove flocs before effluent is released (Richard et al., 2003). SRTs can vary between plants, but on average most plants will manage a SRT of 3-6 days, with a minority reaching as high as 10 or more days (Lishman et al., 2006).

The bacterial population plays a very important part of the WWT community since they remove most of the BOD by metabolizing or degrading the organic matter. Furthermore, In particular, some bacteria are polyphosphate accumulating organisms (PAO) (Acevedo et al., 2014) responsible for most of the phosphate removal, and ammonia-oxidizing bacteria (AOB) that remove ammonia that is toxic to biota downstream ( Zhang et al., 2011). These groups remove contaminants in different ways, PAOs are responsible for removing phosphate by physically storing them in their cells (T. Zhang et al., 2011), while ammonia is removed 
chemically by AOBs and nitrite-oxidizing bacteria (NOBs) in a two-step process(Acevedo et al., 2014). Within AOBs there are two main groups of bacteria, the dominant genera being Nitrosomona, and Nitrosospira (rare due to slow growth rate); these bacteria complete the first rate limiting step of converting ammonia to nitrite (Zhang et al., 2011). NOBs then oxidize nitrite to nitrate.

As mentioned before, most of the bacteria are present in flocs and other aggregates, many however are found free floating on their own in the treatment system which reduces effluent quality (Lee et al., 1996; Martín-González et al., 2006). Thankfully this ecosystem self corrects this issue with the aid of a wide array of predatory protozoa and metazoan (Lee et al., 1996; Martín-González et al., 2006), among these are different types including ciliated, flagellated, amoeba, nematodes, and rotifers. This grazing community is known to be susceptible to contaminants such as heavy metals, however these tests are usually only done with one contaminant; known interactions between contaminants are few and far between (MartínGonzález et al., 2006). As these organisms are susceptible to bioaccumulation and responsible for aiding in the removal of free floating bacteria, they have been used as biomarkers for the overall health of a Wastewater treatment community (WWTC).

\subsection{Extracellular polymeric substances (EPS)}

Extracellular polymeric substances (EPS) include polysaccharides, proteins, glycoproteins, glycolipids and nucleic acids. It is the term given to the wide variety of compounds produced by the bacteria that live in close proximity to each other such as in biofilms or dense populations such as WWTPs. These compounds can make up as much as $50 \%-90 \%$ of the total 
organic matter in sludge (Avella et al., 2010; Pasquini et al., 2013; Sheng et al., 2010). In addition to EPS, there is also soluble EPS, otherwise referred to as the soluble microbial products (SMP) (Le-Clech et al., 2006; Pasquini et al., 2013).

The over expression of EPS and SMP can be considered signs of stress on the WWTP, as these substances are released by bacteria and are capable of acting as buffers within the system against nutrient stress (Pasquini et al., 2013; Sheng et al., 2010). Usually EPS production is directly related to the growth of the bacteria. During the exponential growth phase, EPS content is steadily increasing. Once the stationary phase has been reached EPS production begins to decrease (Sheng et al., 2010).

\subsubsection{Composition of EPS}

The composition of EPS is composed of up to $90 \%$ proteins and polysaccharides (Pasquini et al., 2013). In some cases the protein fraction alone can represent as much as 75\%, followed by carbohydrates and DNA (Pal et al., 2008); however humic acids have been found to account for as much as $20 \%$ of the total amount (Sheng et al., 2010). This leaves a very small amount left for lipids, nucleic acids, uronic acids, and some inorganic compounds. The different constituents and their ratios found in EPS can vary greatly in their reported numbers. This is due to a variety of extraction methods, bioreactor types, and tools used to observe the bacteria (Frolund et al., 1996; Sheng et al., 2010). For example, SMP are defined as the soluble cellular compounds that may be released by the cell either through diffusion, cell lysis, or purposefully secreted. As such, if a harsh extraction method is used on the bacteria that could cause the cell 
to lyse, reported concentrations of SMP can vary even within the same sampling source (LeClech et al., 2006).

\subsubsection{Functions of EPS in WWTPs}

In WWTPs EPS will cover the surface or be found within the spaces of microbial aggregates (Sheng et al., 2010), which indicates that substrates, or contaminants such antibiotics must pass through EPS before they can reach the cell. It is also known that the diffusion coefficients of EPS are generally lower than water, this in addition, to the fact that it surrounds the bacteria found in WWTPs further strengthens the concept that they act as a literal wall to contaminants. The figure below shows a cross sectional model of sludge aggregates:

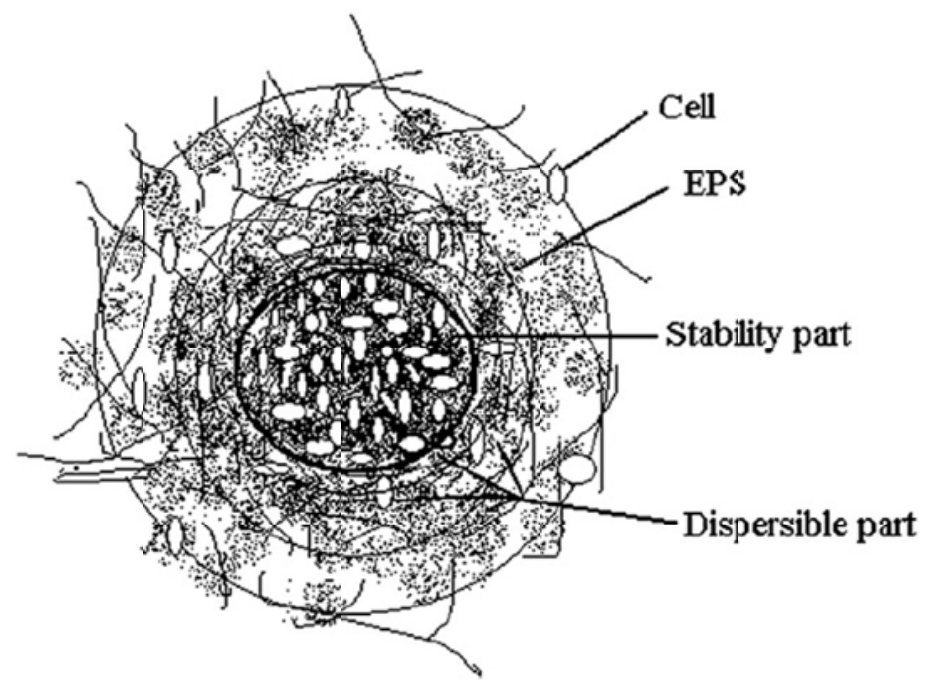

Figure 1 Cross sectional model for sludge within WWTPs (Sheng et al., 2010)

Figure 1 shows that EPS can be broken down into two distinct sections, a soluble or dispersible section that surrounds a much more stable section that keeps the majority of cells together in a larger floc. 
As mentioned EPS consists of mostly proteins and carbohydrates, which help make it a major structural component in biofilms (Pasquini et al., 2013; Sheng et al., 2010). In addition to its structural characteristics, it serves important roles when it comes to adsorption, and nutrient consumption for wastewater bacteria.

Due to the variety of proteins and carbohydrates found in EPS, there will be an equally large variety in functional groups found, such as hydroxyl and carboxyl groups that can bind with heavy metals and other contaminants (Ha et al., 2010; Joshi et al., 2009; Pereira et al., 2011; Sheng et al., 2010). This is also not an insignificant effect as studies have shown that floc is capable of absorbing as much as $60 \%$ of BTEX contamination (Sheng et al., 2010). In these cases it was shown that the BTEXs were adsorbed mostly to the EPS itself, and not to the bacterial cells. This is an important example that shows the benefits of EPS produced by wastewater bacteria in being able to sequester harmful contaminants that could otherwise leave treatment plants in the effluent.

The EPS produced by the bacteria can be used by other bacteria as food sources, as enzymes required for the breakdown of the proteins and carbohydrates are found in high abundance in WWTPs (Sheng et al., 2010). Notable that this can tapped into in times of stress, however it is also seen that degradation of EPS can lead to a loss of quality in the effluent flowing out of WWTPs. This again shows the importance of maintaining healthy EPS production in these microbial communities. 


\subsubsection{EPS Extraction Techniques}

Determining the constituents of wastewater sludge can be done using a variety of methods, however differing methods will provide different results due to factors such as disruption of exopolymers, and promotion of cell lysis (Frolund et al., 1996). In particular, any method that causes cell lysis to occur would affect the results, as it would be difficult to differentiate between the internal and external components of the cells. Therefore a method must be chosen carefully to minimize the likelihood of cell lysis.

The best method found in the literature for this purpose is the use of a Cation Exchange Resin (CER). The method detailed by Frolund (1995) utilizes a resin through which chemical and physical processes strips away the EPS from the cells in the activated sludge. It does this by removing cations that keep the EPS together, such as calcium and magnesium (Sheng et al., 2010), and through shearing processes that occur when the mixture is being spun.

Not only does the method prove to be less likely to cause cell lysis, but it also enables twice as much EPS proteins and carbohydrates to be extracted than other methods such as heating to $80^{\circ} \mathrm{C}$ or the sodium hydroxide method (Frolund et al., 1996). The CER method has been used successfully by many others in the analysis of EPS (Avella et al., 2010; Pasquini et al., 2013), and has become the standard for EPS extractions (Sheng et al., 2010).

\subsection{Emerging Contaminants}

There is no solid definition for the term "emerging contaminants"; different authors will provide their own. In general terms, however, they can be thought of as contaminants that are 
seeing a rising interest in research. Even if they have been present in the environment for several decades, such as Ibuprofen, the drug may be classified as an emerging contaminant (Metcalfe et al., 2014; Osachoff et al., 2014; Stuart et al., 2012). The US EPA defines emerging pollutants as new chemicals without regulatory status and which impact on environment and human health that are poorly understood (Deblonde et al., 2011).

Scientific research has shown that pharmaceuticals that have been measured in the environment are mostly in the $\mathrm{ng} / \mathrm{L}-\mu \mathrm{g} / \mathrm{L}$ range (Vasquez et al., 2014), and as such acute toxicity does not play a large factor when assessing risk to human health (Hughes et al., 2013; Michael et al., 2013). However concentrations are definitely believed to be environmentally detrimental as we are seeing chronic effects in organisms exposed to these contaminants, such as fish and invertebrates (Kim et al., 2007; Mudgal et al., 2013; Sanchez et al., 2011), and many contaminants are known to accumulate in the tissues of these organisms along with plants (Zenker et al., 2014).

Over 270 known pharmaceuticals are already detectable in the environment, with several being found in concentrations that are harmful to aquatic life as high up in the trophic level as large fish (Hughes et al., 2013; Pasquini et al., 2013; Sanchez et al., 2011; Zenker et al., 2014). Three to four thousand of these are drugs being produced in quantities of over 1,000,000 pounds a year, with over 700 new industrial chemicals being introduced each year (EPA, 2007; Petrie et al., 2013; Woodruff et al., 2011).

A main source of pharmaceutical contaminants in wastewater systems is due to both human and veterinary use, and excretion after use (Mudgal et al., 2013). Before even discussing 
contamination due to excretion post ingestion, it is important to realize that unused medicinal products can account for as much as $8 \%$ of all medication sold for human use (Mudgal et al., 2013), among these are left over products for the treating of cardiovascular disease, asthma, the nervous system and, of course, antibiotic treatments. In the case of agricultural use, antibiotics are commonly used as prophylactics in order to prevent illness (Landers et al., 2012).

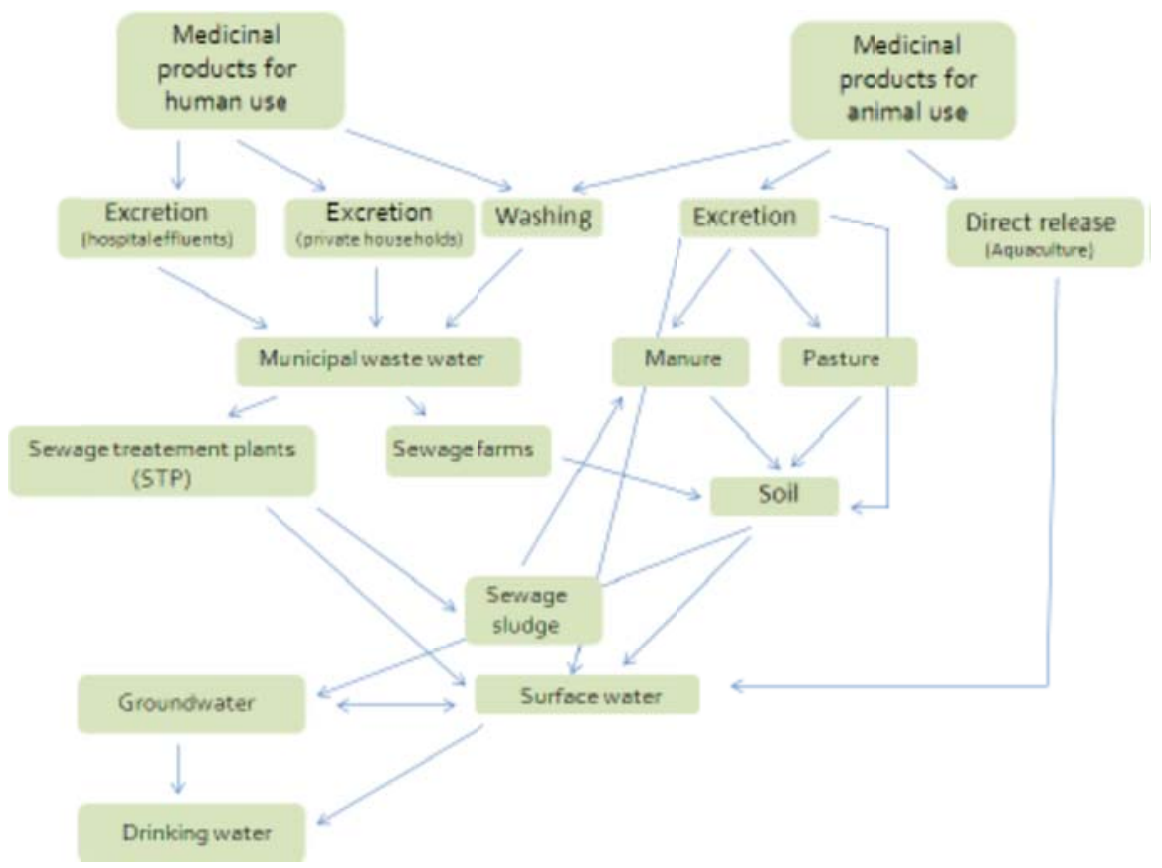

Figure 2 Possible pathways to water systems as a result of medical use (Mudgal et al., 2013)

While the previously mentioned unused category accounts for a significant proportion of these contaminants, by far the greatest source is from emissions after use through animal or human waste (Mudgal et al., 2013). Once a dose has been administered as much as $90 \%$ of will be excreted as an active substance in the urine (Alcock et al., 1998; Holtz, 2006), while feces can also contain as much as $75 \%$ depending on the drug (Mudgal et al., 2013). According to one study which analyzed over 200 human pharmaceuticals, $64 \%$ of each was excreted in urine, and 
$35 \%$ in feces (Lienert et al., 2007). However the products released from excretion were highly variable, for example, on average $42 \%$ of active substances were released as metabolites. In some cases the resulting intermediates can vary greatly, such as with Amoxicillin where, 80$90 \%$ is released unchanged whereas with Carbamazepine only $3 \%$ is released unchanged (Lienert et al., 2007).

The effects of these contaminants should be of great concern, especially since many of them enter wastewater treatment facilities on their path to the environment. Possible emissions pathways related to medicinal products can be seen in Figure 2 .

In this environment there can be hundreds to thousands of different chemicals in influent water (Osachoff et al., 2014) that need to be removed. Since WWTPs were not designed to eliminate these compounds, their direct effect on the functioning of the microbial community within the system needs to be examined in great depth.

\subsubsection{Removal Rates in WWTPs}

Simply attempting to increase biodegradation in wastewater plants isn't enough, as some compounds are not susceptible to biodegradation, likewise elimination through the use of adsorption to biosolids is not sufficient to guarantee transfer into wastewater sludge (Pasquini et al., 2013). For antibiotics and many personal care products (PCPs), removal has been documented to be around $50-100 \%$. Specifically, NSAIDs where removed at around $60 \%$ with the exception of Ibuprofen which sees removal rates near 75-100\% (Deblonde et al., 2011; Fent et al., 2006; Luo et al., 2014; Metcalfe et al., 2014) and diclofenac with far lower removal rates (<30\%) (Deblonde et al., 2011; Michael et al., 2013). Antibiotics are removed at various 
rates with tetracyclines being reported from 12 to $100 \%$ removal (Deblonde et al., 2011;

Michael et al., 2013).

It can be seen that there are extremely large variations in removal rates for these drugs, which can be attributed to WWTP processes, geography, community composition, and seasonal changes where drugs such as Ibuprofen and carbamazepine are found in higher concentrations during the fall (Hoque et al., 2014). Regardless of the factor, it shows a clear difference in removal rates from one drug to the next, even within the same class of pharmaceutical. There are also some unique drugs such as sucralose is not degraded at all in most systems (Hoque et al., 2014; Pasquini et al., 2013). This shows that there may be a future need to determine how to remove these contaminants from our waters, as some are extremely persistent.

\subsection{Ibuprofen}

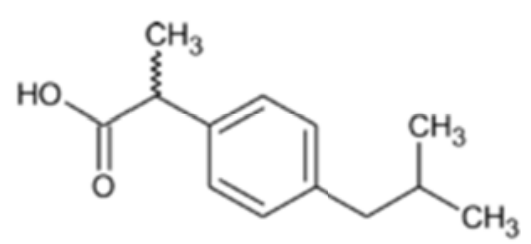

(Brozinski et al., 2013)

Figure 3 Structure of Ibuprofen

In the UK alone over 22 million prescriptions are written every year for NSAIDs, and over 70 million in the United States (Russell, 2001). Ibuprofen specifically can be prescribed for chronic conditions such as rheumatoid arthritis osteoarthritis, and other non-rheumatoid arthropathies. Treatment usually lasts 90-100 days with high dosage and regular medical attention (Moore, 2007). Data is much harder to find in Canada, but could be estimated at 
10million a year based on populations sizes and prescriptions in the two previously mentioned countries. It should be noted that these numbers only pertain to prescribed doses, and that over the counter sales of Ibuprofen and other drugs are likely to represent a greater share of the total doses worldwide (Mudgal et al., 2013).

Ibuprofen is a propionic acid derivative, to deal with general pain in the body (Moore, 2007). It does this by binding to cyclooxygenase (COX) as many other NSAIDs do (McGettigan et al., 2013; Moore, 2007; Russell, 2001; Yin et al., 2014), however COX can be found in two forms (COX-1 and COX-2) which many NSAIDs will indiscriminately bind to. COX-1 is responsible for general upkeep of many aspect of the body such as production of prostaglandins that regulate processes such as gastroenterological protection, blood flow, kidney functions, and more (Russell, 2001), COX-2 on the other hand causes pain and inflammation. The inhibition of COX-2 is the goal of NSAIDs, however many unintended side effects may arise due to unwanted inhibition of COX-1. While Ibuprofen also inhibits COX-1, it is extremely popular not only due to low cost but due to the fact that it has a short half-life of 1-2 hours (Moore, 2007). As a result of this short half-life Ibuprofen can be consumed for acute pain, and be $99 \%$ removed from the body after only 8-16 hours, serving the purpose of treating pain without extended COX-1 inhibition.

\subsubsection{History}

In 1983, Ibuprofen became the very first prescription NSAID to be made available over the counter due to a very high safety record. In the UK it was marketed under the brand name Nurofen, however, once available in the USA in 1984, it was marketed under the brand name 
Advil. The maximum OTC allowance is set to $1200 \mathrm{mg}$ per day, however when it is prescribed the dose can increase to between $1200 \mathrm{mg}$ and $3600 \mathrm{mg}$ per day (Moore, 2007). Currently it is one of the top most used pharmaceuticals around the world due to its low cost and effectiveness, with usage in the US as high as 2,300,000 Kg per year (Gilbride et al., 2007). With sales of this drug expected to increase between $5-6 \%$ per year in the US, the total load of this drug is only expected to rise (Limited, 2012). This already high use, partnered with its ubiquitous nature, makes Ibuprofen a great candidate for further research, especially considering any novel effects it might have in WWTPs.

\subsubsection{Removal Rates and Psuedopersistence}

In 2014, a Canadian study showed that Ibuprofen could be found with $100 \%$ frequency in Canadian WWTPs. The concentrations found in the influent water ranged from between $2500 \mathrm{ng} / \mathrm{L}$ and $45,000 \mathrm{ng} / \mathrm{L}$, with removal rates of up to $90 \%$ (Guerra et al., 2014). This is in line with what is seen in studies from other parts of the world (Miège et al., 2009; Pasquini et al., 2013; Stuart et al., 2012). However it is still significantly higher than what may be found in European countries such as Germany, where concentrations of the drug can be as much as $8 \mathrm{x}$ lower (Irsch, 2003). This suggests that the WWTP bacteria are indeed capable of breaking down large quantities of Ibuprofen. However, due to a constant influx from the sewer systems, concentrations remain high on a day to day basis causing the drug to be pseudo-persistent. Furthermore, the Canadian study also showed that Ibuprofen could be found in $100 \%$ of bio solid samples (Guerra et al., 2014). 


\subsection{Tetracycline}

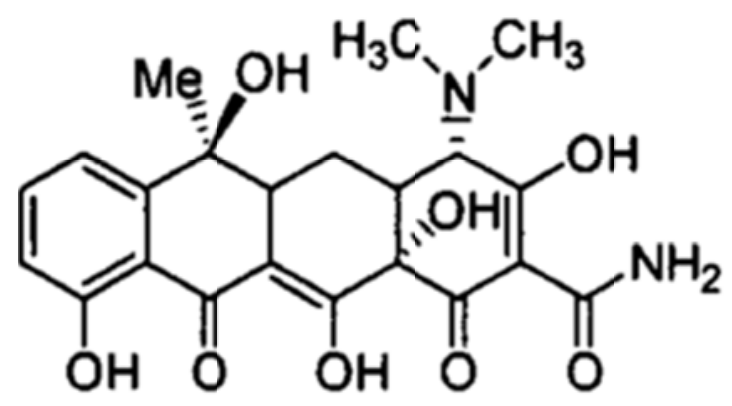

(Nelson, 2002)

Figure 4 Structure of Tetracycline

Tetracycline is a broad scale antibiotic group consisting of several antibiotics: Doxycycline, Clomocycline, Minocycline, and Tetracycline among others (Mudgal et al., 2013) which can target both prokaryotic and eukaryotic cellular processes, and is effective against parasites, fungi, and bacteria (Nelson, 2002). All tetracyclines share the same mode of action in bacteria, the inhibition of protein synthesis by binding to the $30 \mathrm{~S}$ ribosomal subunit, thereby preventing binding of aminoacyl-tRNA (Mudgal et al., 2013). The wide range of targets for this antibiotic make it very relevant in the context of WWTPs, as it has already been discussed how they are home to extremely diverse communities of microscopic organisms. Around $25-75 \%$ of tetracycline antibiotics are excreted into the environment through urine and feces in their original form (Pan et al., 2015).

\subsubsection{History}

Tetracycline was first discovered in 1947 by Benjamin M. Duggar, a scientist who was searching for new antibiotics produced naturally by bacteria. In this case he discovered the first 
broad spectrum antibiotic Tetracycline from soil bacteria Actinomycetales (Nelson, 2002).

Today it is one of the most frequently detected groups of antibiotics found in wastewater all across the globe (Michael et al., 2013). According to an EU study the median concentration of tetracyclines in natural waters is roughly a factor of 10 below the hazardous concentration $(1.30 \mu \mathrm{g} / \mathrm{L})$ for $5 \%$ of species (HC5), with the exception of Oxytetracycline which is found at a median concentration of $1.34 \mu \mathrm{g} / \mathrm{L}$ (Mudgal et al., 2013). However this is only a median concentration and detections are often found that are above the predicted no effect concentration (PNEC) when all assessments are applied. Combined these data suggest that the tetracycline family are already a potential risk to the aquatic environment; before taking into account the cumulative effect of the different groups, something which can't be ignored as they all have the same mode of action to bind the 30 S subunit.

In terms of human health concerns it cannot be ignored that the persistent presence of tetracycline as well as any other antibiotic adds to the risk of antibiotic resistances developing. This factor should be considered even if tetracycline concentrations are not viewed high enough to directly affect human health.

\subsubsection{Removal Rates and Pseudo-persistence}

Depending on the geographical location, tetracycline can be found in influent water at concentrations between $35 \mathrm{ng} / \mathrm{L}$ to $50,000 \mathrm{ng} / \mathrm{L}$ or higher, with removal efficiencies between $12-100 \%$ (Michael et al., 2013). According to a study on the environmental risks of medicinal products by the European commission, tetracycline has been found at concentrations as high $850,000,000 \mathrm{ng} / \mathrm{L}$ in wastewaters, with the median being $370 \mathrm{ng} / \mathrm{L}$ (Mudgal et al., 2013). The 
removal efficiency is dependent on original concentration, as well as the detection methods used at the individual wastewater treatment plants. However removal rates of metabolite compounds are not as easily measured due to a wide variety of derivatives being available. In fact, metabolites of one drug can sometimes be found at concentrations 3 times as high as their parent compounds (Zhang et al., 2014). The main method of removal for tetracyclines is sorption into sludge, this is due to how easily it can bind to calcium and other ions that may be found in EPS (Michael et al., 2013).

\subsection{Global Policies}

Each region has its own policy for the handling of environmental contaminants, however these policies vary greatly in many factors such as what are considered contaminants, the testing required, what constitutes dangerous levels, and to whom the burden of proof is placed.

A few things that appear to be common among Europe (EU), the United States (US), and Canada (CA) are:

- All drugs are regulated on an individual basis (Holtz, 2006; Klaper et al., 2011). This means that the interaction with other compounds is not taken into account when regulation limits are determined.

- They do not account for bio-magnification, instead there is a heavy emphasis on acute toxicity (Klaper et al., 2011)

- Most protections are placed on drinking water, especially in the US, neglecting the WWTP completely (Klaper et al., 2011). This means that very few regulations on removal efficiencies of emerging contaminants have been implemented. 
In terms of regulation between Europe, the US and Canada, there seems to be a very clear ranking of strictness when it comes to regulation, whether or not these differences are significant is not clear. The EU places first, USA second, with Canada being the least restrictive. The reason that the EU places first is mainly due to policies that force companies to perform acute toxicity testing on all new drugs, their possible metabolites, and even the capsules that the drugs will be packaged in (Holtz, 2006). It is worth mentioning that EU policies were made with consultation by Canadian scientists, indicating that similar policies may be implemented in Canada in the near future. It should also be noted that this is testing only for drugs intended for human use.

There is a two tier testing guideline for the drugs in the EU, with tier A looking at aquatic fate, including within sewage sludge. This tier A guideline is designed to determine the drugs predicted no effect concentration (PNEC) within the environment. This testing only comes into play if the predicted environmental concentration (PEC) is over $0.01 \mu \mathrm{g} / \mathrm{L}$ of pharmaceutical, or if the drug is an endocrine disruptor. If it is found that the PEC is greater than the PNEC, then tier B testing is done that further examines risk as well as looks at which drugs metabolites are performed. If the PEC is less than the PNEC, then the environmental assessment is concluded.

Within the USA there is similar policy being drafted, however the PEC required to start testing is $10 \mathrm{x}$ higher at $0.1 \mu \mathrm{g} / \mathrm{L}$ of pharmaceutical. The PEC is calculated based on the estimated sales and dosages of the drugs. In Canada, however, there is no such policy in effect yet, although the EU policy was created with the help of Canadian scientists (Holtz, 2006). Instead Canadians have what is called an In Commerce List (ICL) which contains three 
mandatory items; CAS name, CAS registration number, and the alternate name, however, with no information available regarding how it would be used, chemical structures, or estimated annual volumes (According to https://www.ec.gc.ca/inrenwri/default.asp?lang=En\&n=C00A589F-1\&offset=11\&toc=show). Environment Canada lists their first task as to obtain accurate identification of each substance, and the basic information needed to determine potential hazards. Canada states that there will be special attention given to mixtures of unknown composition, which accounts for $50 \%$ of the $\sim 9000$ items on the list. Of that, they claim, cosmetic and pharmaceutical products account for $83 \%$ of all new substance notifications they receive.

\subsubsection{Gaps in Knowledge}

Currently most research is done on the direct effects of pharmaceuticals in the environment and is conducted using only one compound at a time (Fent et al., 2006; Vasquez et al., 2014). However, even in the case of singular drug compounds not all modes of action are known, even in human targets, and much less in lower taxa (Fent et al., 2006; Vasquez et al., 2014). There is also a strong bias towards examining the acute effects of these drugs as opposed to the chronic effects (Fent et al., 2006). In addition to this, there is a lack of information showing effects of mixture of medicinal products by themselves and in combination with other organics such as endocrine disruptors (Mudgal et al., 2013).

There is quite a bit of information regarding the effects of certain mixtures on bacteria and zooplankton, however even in these cases, the mixtures are overwhelmingly done with the same group of pharmaceuticals (Vasquez et al., 2014); Meaning that the research looks at 
groups of several antibiotics, or NSAIDs, as opposed to a large variety of different groups. In cases where antibiotics and NSAIDs were combined, changes in fertility, protein regulation, were observed (Vasquez et al., 2014). In one interesting case it was noted that there was a $17 \%$ shift in sex ratio towards male Hyalla (Borgmann et al., 2007) in the presence of 7 common pharmaceuticals (acetaminophen, diclofenac, gemfibrozil, Ibuprofen, naproxen, salicylic acid, and triclosan. While it was the only significant effect seen in that case, it was observed at environmental concentrations (10-100 ng/L) and it goes to show that drugs can have wildly different effects in secondary targets that cannot be inferred from human trials.

As well it can be shown that some drug/taxa combinations are completely neglected. A meta-study which analyzed articles regarding over 270 chemicals and 40 countries found that there were no studies done examining the effects of antibiotics on fish, antidepressants on aquatic plants, or cardiovascular drugs on bacteria, within the studies that they analyzed (Hughes et al., 2013).

\subsection{Pharmaceutical Mixtures}

\subsubsection{Conceptual Questions Vs. Environmental Relevance}

When determining the 'how to design' an experiment to test the effect of pharmaceuticals, it is important to choose whether you want to answer conceptual questions or focus on environmental relevance. A meta study (2014) categorized the difference between these two kinds of studies that have been seen in the literature (Vasquez et al., 2014). Studies that aimed to answer conceptual questions tend to be pushing high concentrations of a few pharmaceuticals in order to observe effects on a specific mode of action. On the other hand, in 
order to determine environmental relevance, studies looked at the concentration of between 4 and 12 pharmaceuticals at environmentally relevant concentrations. In general it was harder to perform data analysis on studies aiming to be environmentally relevant due to the wide variety of contaminants and concentrations.

In addition to categorizing these different types of experiments, the study also laid out the types of cocktail experiments previously completed. What was noted was that in most cases when a study used a cocktail, it represented only one type of drug, such as several different antibiotics (Vasquez et al., 2014; Wunder et al., 2013). When experiments were done with various groups of drugs, the research is rare and never studied the effect on bacterial populations in WWTPs.

\subsubsection{Previous Links Between Ibuprofen and Tetracycline}

According Wong et al. 1984, a combination of Ibuprofen and Tetracycline was found to have statistically better results in treating acne than either of the drugs alone, or a placebo (Wong et al., 1984). A follow up study also found that this result could be replicated with minocycline, another antibiotic (Funt, 1985). In addition to these cases, a study from Actis et al. (2014) found that patients who took NSAIDs such as Ibuprofen could suffer from negative side effects relating to the gastroenterological setting (a system heavily reliant on bacterial activity) (Actis et al., 2014).

While this may not be directly related to wastewater treatment processes, it does show an interesting link between NSAIDs and a stronger response to antibiotics; an important factor being looked at in this research. 


\subsection{Research Objectives}

This study will aim to determine the effects of Ibuprofen and Tetracycline alone or in combination on WWTC; Characteristics being analyzed are growth rate, EPS and SMP, and proteins and carbohydrates.

HPLC will be utilized in order to determine profiles of EPS produced. Proteins and carbohydrates will be quantified using the colorimetric assays Bradford BSA and Anthrone Method respectively. 


\section{Materials and Methods}

\subsection{Bacterial strains}

The bacterial strain Pseudomonas putida BBC443 was used as a reference strain for the growth and HPLC tests. It was grown and maintained on $100 \%$ LB agar plates until needed.

\subsection{Wastewater samples}

The samples were collected from the Toronto Humber Wastewater Treatment plant. Samples $(500 \mathrm{ml})$ were obtained from four of the aeration tanks, mixed and transported to the lab for immediate use. Once in the lab samples were centrifuged at 4500x g for 10 mins, and the pellet resuspended in LB broth twice in order to wash the sample of contaminants that could be found in the wastewater. This LB solution was used to seed the samples used in the experiment.

\subsection{Test compounds}

Two test compounds were selected. Tetracycline (Sigma-Aldrich) was selected to represent antibiotics and Ibuprofen (Life Brand) to represent NSAIDS. Concentrations used were $50 \mathrm{ng} / \mathrm{ml}$ tetracycline, and $16 \mathrm{ng} / \mathrm{ml}, 100 \mathrm{ng} / \mathrm{mL}$ Ibuprofen. The concentrations chosen represented environmentally relevant amounts found in wastewater for tetracycline (Avella et al., 2010) and Ibuprofen (Pasquini et al., 2013). A second higher concentration of Ibuprofen was also tested to verify results previously described (Pasquini et al., 2013) In addition to this, mixtures of the compounds were examined as well. 


\subsection{Growth Inhibition Tests}

Growth inhibition tests of wastewater treatment community were carried out at $30^{\circ} \mathrm{C}$ with shaking in $250 \mathrm{ml}$ conical flasks containing $100 \mathrm{ml}$ of Lysogenic-Broth (LB Broth). Growth was measured both in the presence of each compound and in combination at various concentrations (16 ng/mL - $100 \mathrm{ng} / \mathrm{mL}$ Ibuprofen, and $50 \mathrm{ng} / \mathrm{mL}$ tetracycline).

A reference growth inhibition test was carried out using $P$. putida. The bacteria were pre-grown in LB medium overnight to an OD600 reading of $\sim 2.5$. Cultures were then diluted 1:100 in warm LB medium supplemented with the various concentrations of the compounds and growth was monitored at $30^{\circ} \mathrm{C}$ for $P$. putida and $25^{\circ} \mathrm{C}$ for the wastewater sample. Growth was measured at OD600 over a 24 hour period.

\subsection{EPS Extraction and Analysis}

To measure the effect of the compounds on EPA production, samples of the cultures were collected at 12 hour growth. The biomass was separated from the supernatant by centrifugation (15 $\mathrm{min}$ at $4500 \mathrm{~g}$ ). The supernatant containing Soluble Microbial Products (SMP) was directly analyzed and the settled biomass was subjected to EPS extraction using a DOWEX resin (Frolund et al., 1996), an extraction time of 4 hours was used (Avella et al., 2010; Pasquini et al., 2013). The resin was first rinsed in a prepared PBS buffer $\left(2 \mathrm{mM} \mathrm{Na}_{3} \mathrm{PO}_{4}, 4 \mathrm{mM} \mathrm{NaH}_{2} \mathrm{PO}_{4}\right.$, $9 \mathrm{mM} \mathrm{NaCl}$, and $1 \mathrm{mM} \mathrm{KCl}$ at $\mathrm{pH}$ 7), after which the EPS previously centrifuged was resuspended in equal amounts of buffer. This sample was then magnetically stirred for 4 hours in an ice bath, after which the resin was removed via centrifugation. The remaining solution contained the EPS macromolecules. 
The EPS and SMP samples were analyzed using High Pressure Size Exclusion

Chromatography (HPSEC) according the procedures used by Avella (2010) and Pasquini (2013).

A Perkin Elmer series 785 UV/Vis detector, equipped with a Zorbax Bio series column (GF-250, $25 \mathrm{~cm} \times 4.6 \mathrm{~mm}$, Agilent Technologies) at room temperature was used. The mobile phase was $\mathrm{NaCl} 0.2 \mathrm{M}$ with a flow rate of $1 \mathrm{~mL} / \mathrm{min}$. The detection was carried out at $215 \mathrm{~nm}$. Prior to injection, all samples were filtered with 0.45 um filters.

Calibration was performed with a protein standard (5730 to 670 kDa, Sigma-Aldrich, France). This was compared to standards found in literature for proteins and carbohydrates on the same column using the same flow rates and mobile phase. EPS was extracted in duplicate, and each extract injected in duplicate using an injection volume of $10 \mu \mathrm{L}$.

\subsection{Protein Quantification}

Protein quantification was done using Bradford Protein Standard 96 well plate technique. A standard curve was plotted using 8 known concentrations of BSA ranging from 0 to $125 \mathrm{mg} / \mathrm{mL}$. Samples and standards were measured at $595 \mathrm{~nm}$ in a 96 well plate, each well containing $20 \mu \mathrm{L}$ of standard/sample and $200 \mu \mathrm{L}$ of Bradford reagent. The SMP samples were analyzed directly after first centrifugation, while EPS samples were analyzed after being treated with the CER.

The BSA standards were prepared as detailed below in table 1 
Table 1 Prepared BSA standards

\begin{tabular}{|l|l|l|}
\hline Tube & Solution & Concentration BSA $(\mu \mathrm{g} / \mathrm{mL})$ \\
\hline 1 & $3 \mu \mathrm{L}$ BSA $(5 \mathrm{mg} / \mathrm{mL}$ stock) $>117 \mu \mathrm{L}$ PBS & 125 \\
\hline 2 & $80 \mu \mathrm{L}$ tube $1->20 \mu \mathrm{L}$ PBS & 100 \\
\hline 3 & $60 \mu \mathrm{L}$ tube $2->15 \mu \mathrm{L}$ PBS & 80 \\
\hline 4 & $45 \mu \mathrm{L}$ tube $3->15 \mu \mathrm{L}$ PBS & 60 \\
\hline 5 & $30 \mu \mathrm{L}$ tube $4->15 \mu \mathrm{L}$ PBS & 40 \\
\hline 6 & $15 \mu \mathrm{L}$ tube $5->15 \mu \mathrm{L}$ PBS & 20 \\
\hline 7 & $10 \mu \mathrm{L}$ tube $6->10 \mu \mathrm{L}$ PBS & 10 \\
\hline 8 & $20 \mu \mathrm{L}$ PBS & 0 \\
\hline
\end{tabular}

\subsection{Carbohydrate Analysis}

Carbohydrate testing was done using the colorimetric Anthrone Method. Anthrone solution was prepared by adding $0.5 \mathrm{~g}$ of Anthrone to $10 \mathrm{ml}$ of EtOH, this was then added to $250 \mathrm{ml} 75 \%$ $\mathrm{H}_{2} \mathrm{SO}_{4}$. The samples of EPS and SMP were then placed on ice. In vials solutions were made consisting of $1 \mathrm{~mL}$ sample, $2 \mathrm{~mL} \mathrm{H}_{2} \mathrm{SO}_{4}$, and $4 \mathrm{~mL}$ Anthrone Solution. The vials were then heated to $100^{\circ} \mathrm{C}$ for 15 minutes before being measured at $578 \mathrm{~nm}$.

\subsection{Analysis - Calculating the Area of the Chromatograms}

The produced chromatograms compared based on shape, size, and location of peaks recorded. The areas under the curves of the graphs were also compared against each other in 
order to determine if there was a significant difference in concentrations of each relative peak from one sample to the next.

The areas of the graphs were calculated with the aid of an open source image editing software called GIMP 2 using the following method. First the total units ${ }^{2}$ of all graphs were calculated, secondly all pixels in the graph where recorded using the histogram feature. From these two values the pixels/unit ${ }^{2}$ of the graphs could be calculated. Finally the pixels under the lines of the chromatograms were measured; from here the unit $^{2}$ of the graph could be calculated. The full equation used can be seen below

(Pixels under Chromatogram)

Area in Unit ${ }^{2}$ of Chromatogram $=$

(Total Pixels in graph / (X axis units * Y axis units))

A visual demonstration can be seen in Appendix C.

\subsection{Statistical analysis}

\subsubsection{Sample Characteristics}

A Shapiro-Wilk's test ( $p>0.05$ ) (Shapiro et al., 1965) and a visual inspection of normal QQ plots and box plots was performed in order to determine if the chromatogram areas were normally distributed or not among the control groups, Tetracycline groups, Ibuprofen groups, and groups containing both Ibuprofen and Tetracycline. 


\subsubsection{ANOVA analysis}

Comparative analysis was done using single factor ANOVA tests in order to determine if there was any statistical difference between the groups of contaminants tested. Following this multiple T-tests with modified Bonferroni corrections were used to determine if the statistical difference between individual groups was significant.

The ANOVA tests were carried out on the total areas of the chromatograms that were calculated using the method in 3.8

A list of ANOVA tables and Bonferroni corrected t-tests can be found in appendix C. 


\section{Results and Discussion}

\subsection{Summary of Results and Discussion}

It was observed that Ibuprofen and Tetracycline had opposite effects on the production of EPS by WWTC. Tetracycline was viewed as a stressor and as a result led to a significantly higher concentration of EPS produced; Ibuprofen on the other hand had the opposite effect of lowering the amount of EPS detected. In both cases the individual contaminants did not illicit an inhibition in the growth rate of the WWTC; however when both were present in the same sample there was a significant decrease in the growth rate as compared to the control even when measured EPS was not significantly different that found in the control sample. The results show that significant effects can already be seen in WWTC when exposed to contaminants at environmental concentrations, and just as importantly that when two contaminants at "harmless" concentrations are examined in combination there may be significant impact on the WWTC.

\subsection{Growth Inhibition Tests}

Xenobiotic compounds are often found to affect the growth of organism either directly or indirectly (Avella et al., 2010). In this study, the effect of tetracycline and Ibuprofen on growth was tested both on an antibiotic sensitive strain of $P$. putida (BBC443) and a WWTP bacterial community. A comparison of growth rate or overall biomass production was used to assess the effect on growth.

\subsubsection{Pseudomonas putida BBC443}


Figure 5 shows the growth of $P$. putida in the presence of various concentrations of Ibuprofen and Tetracycline. Under control conditions the bacteria reached maximal growth within 12 hours with a maximum OD600 of 2.4. In the presence of Ibuprofen at either concentration $P$. putida showed no observed difference in growth rate or overall biomass when compared to the control sample without Ibuprofen. In the presence of tetracycline, however, there was a noticeable decrease in both the growth rate and overall biomass (OD=1.7).

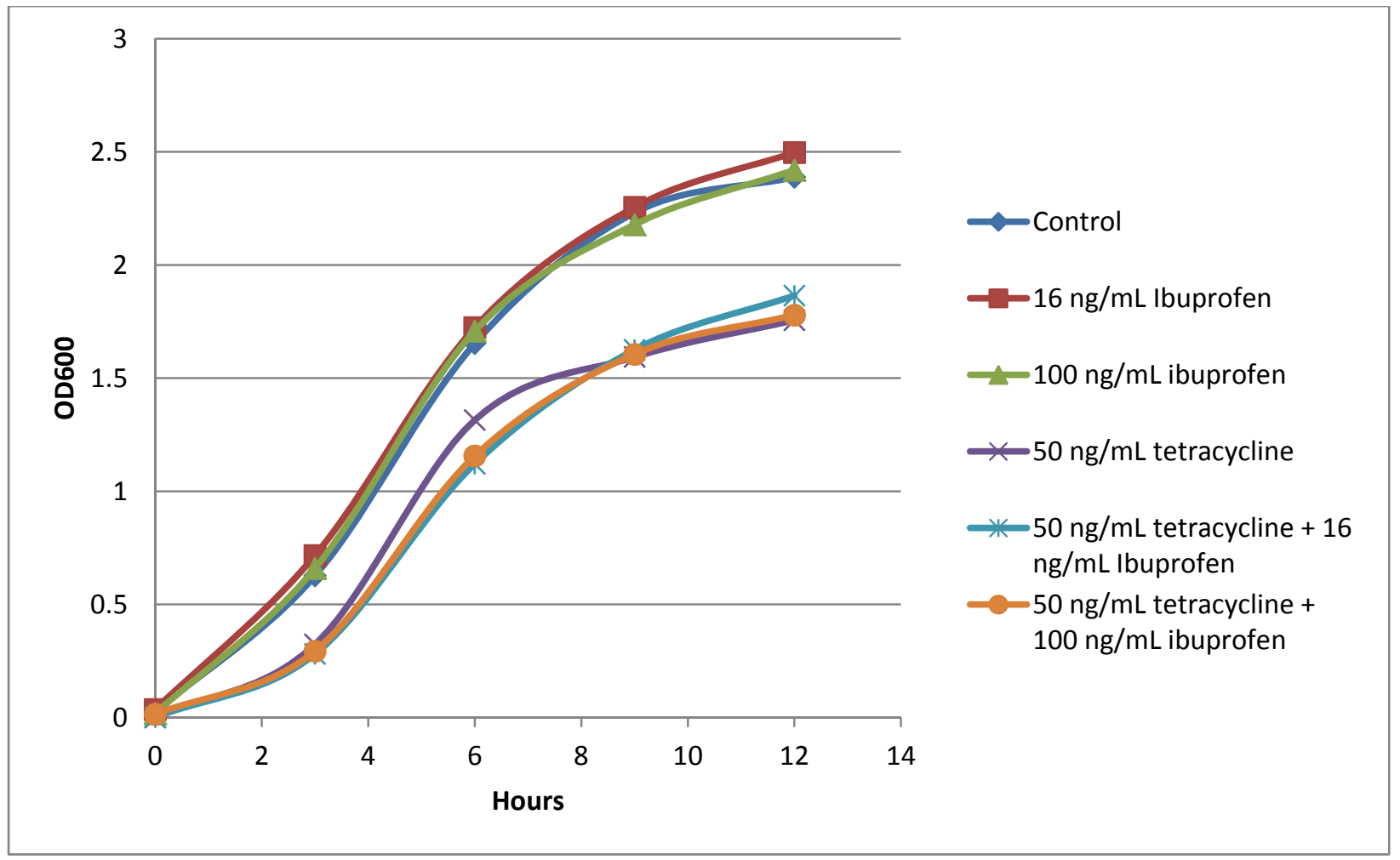

Figure 5 Growth rate of Pseudomonas putida measured in OD600 when exposed to varying concentrations of the contaminants Ibuprofen and Tetracycline

Since $P$. putida does not carry a resistance gene to tetracycline it was expected that it would not grow in the presence of tetracycline. However the concentration used $(50 \mathrm{ng} / \mathrm{mL})$ represents an environmentally relevant concentration found in wastewater and is below the minimum inhibitory concentration. These results here suggest that although the concentration 
does not completely inhibit the growth of the organism it still causes an effect as shown by the decrease in biomass after 12 hours. Furthermore, cultures of $P$. putida grown in the presence of mixtures of Ibuprofen and Tetracycline did not differ when compared to those of tetracycline alone. For the purpose of this discussion "inhibitory concentration" refers to a concentration that would prevent any growth.

Overall, tetracycline, even at sub inhibitory concentrations, affected the growth of the tetracycline sensitive strain of $P$. putida. However, Ibuprofen, at both concentrations showed no effect on the growth of the organism.

\subsubsection{Wastewater Treatment Community}

Growth inhibition tests were then performed on the total microbial community of the WWTP. As with the reference strain of $P$. putida, Ibuprofen did not inhibit the growth of the total community either. However it was observed that tetracycline also did not negatively impact the growth or the biomass production. This observation suggests that the community mostly likely contained tetracycline resistance organisms, and they may be responsible for maintaining the rate of growth of the entire community.

According to several studies the fact that WWTPs are the final destination of wastewater, from hundreds to thousands of households, as well as dozens of hospitals, they provide a perfect environment for the evolution of antimicrobial resistance that may be later spread to the environment (Coutu et al., 2013; Michael et al., 2013; Zhang et al., 2014). Antibiotic resistance could also spread within the community due to horizontal gene transfer, so that even if a certain species of bacteria does not individually develop resistance it can be 
gained through the process of plasmid transfer (Schlüter et al., 2007). Sub-inhibitory concentrations of antibiotics therefore could contribute selective pressure on maintaining antibiotic resistance genes in the community, although they do not cause an overall decrease in biomass production.

Interestingly, although neither Ibuprofen nor Tetracycline alone caused a decrease in the overall growth of the community compared to the control, when they were both present together a slight but significant decrease in growth rate was observed at 12 hours as shown in Figure 6.

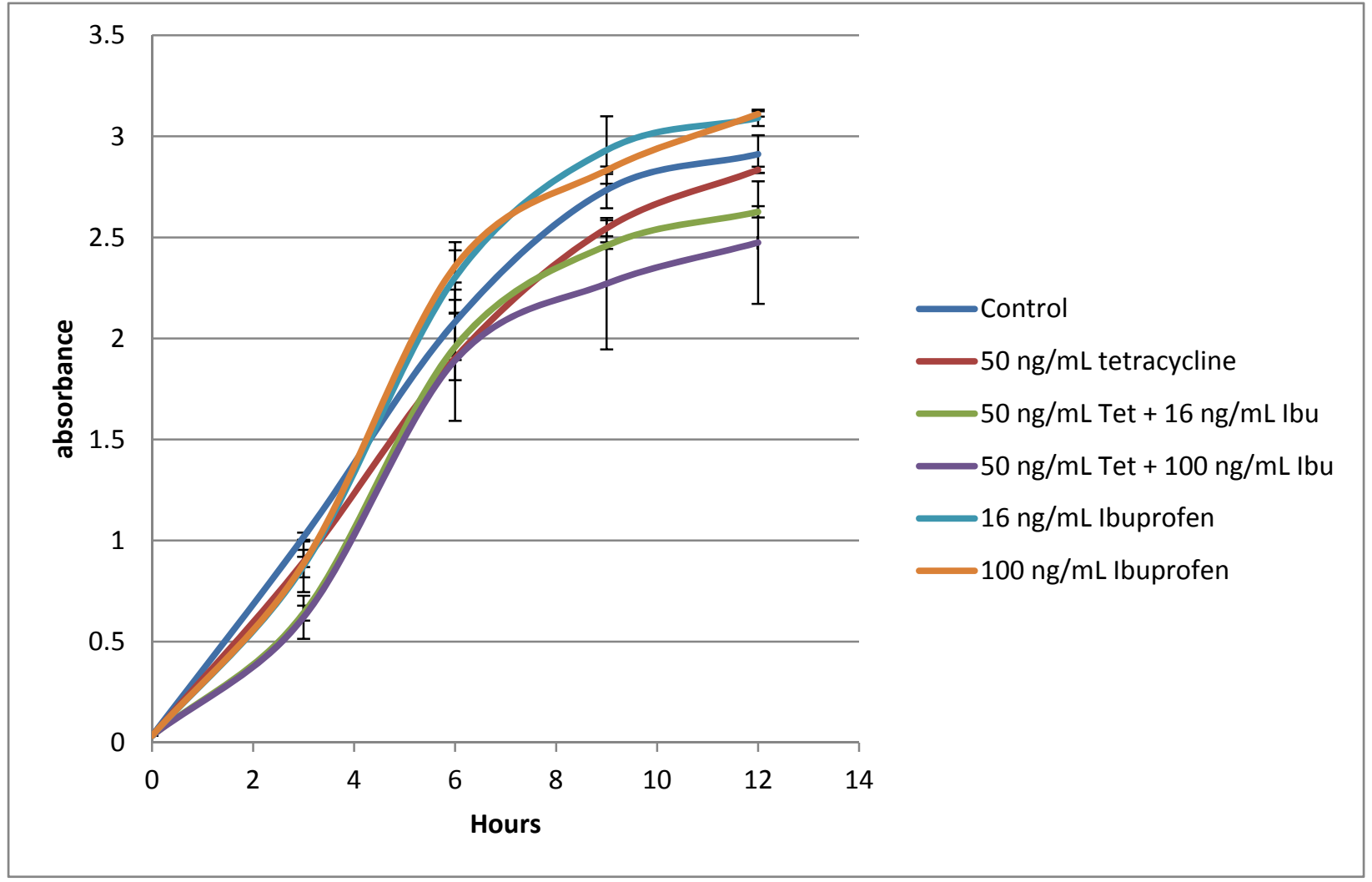

Figure 6 Growth rate of Wastewater Community measured in OD600 when exposed to varying concentrations of the contaminants Ibuprofen and Tetracycline

This significance was determined by a lack of overlap between the standard deviation error bars that were calculated. This reduction in growth rate only when both contaminants 
are present could be due to additive effects caused by the combination of compounds, even if they do have different modes of action.

\subsection{Extracellular Polymer Substances}

As already mentioned EPS is a vital component of a healthy bacterial community, providing structure, nutrition, and antibiotic resistance mostly due to physical characteristics such as diffusion coefficients (Pasquini et al., 2013; Sheng et al., 2010). Also as the EPS is responsible for most of the adsorption of other contaminants such as heavy metals and BTEXs, disruption in normal EPS production can have unseen adverse effects on the community. Thus observing changes in EPS is a vital part of gauging the health of the community.

\subsubsection{Chromatograms}

Chromatography is a method for determining the size of substrates within a solution; in this case it is being used to determine the size of proteins and carbohydrates found within the samples of our WWTC exposed to the contaminants Ibuprofen and Tetracycline. All of the chromatograms shown below were exported into text files then into Excel for easier comparisons. Raw chromatograms for each group can be seen in Appendix A. The protein standards graph can be found in Appendix B.

\subsubsection{Control vs Tetracycline}

Figure 7 shows the chromatograms from the control and the community exposed to tetracycline. Comparing the shapes of the control chromatogram vs the shape of the $50 \mathrm{ng} / \mathrm{mL}$ tetracycline chromatogram it can be noted that both contain a sharper peak at approximately 2.5 -3.5 mL elution volume and a second spread out peak at approximately $4-4.5 \mathrm{~mL}$ elution 
volume, a sharper peak is defined here as a peak that had a higher absorbance value over the same time period versus another peak. This sharpness indicates a greater concentration of macromolecules in the sample tested.

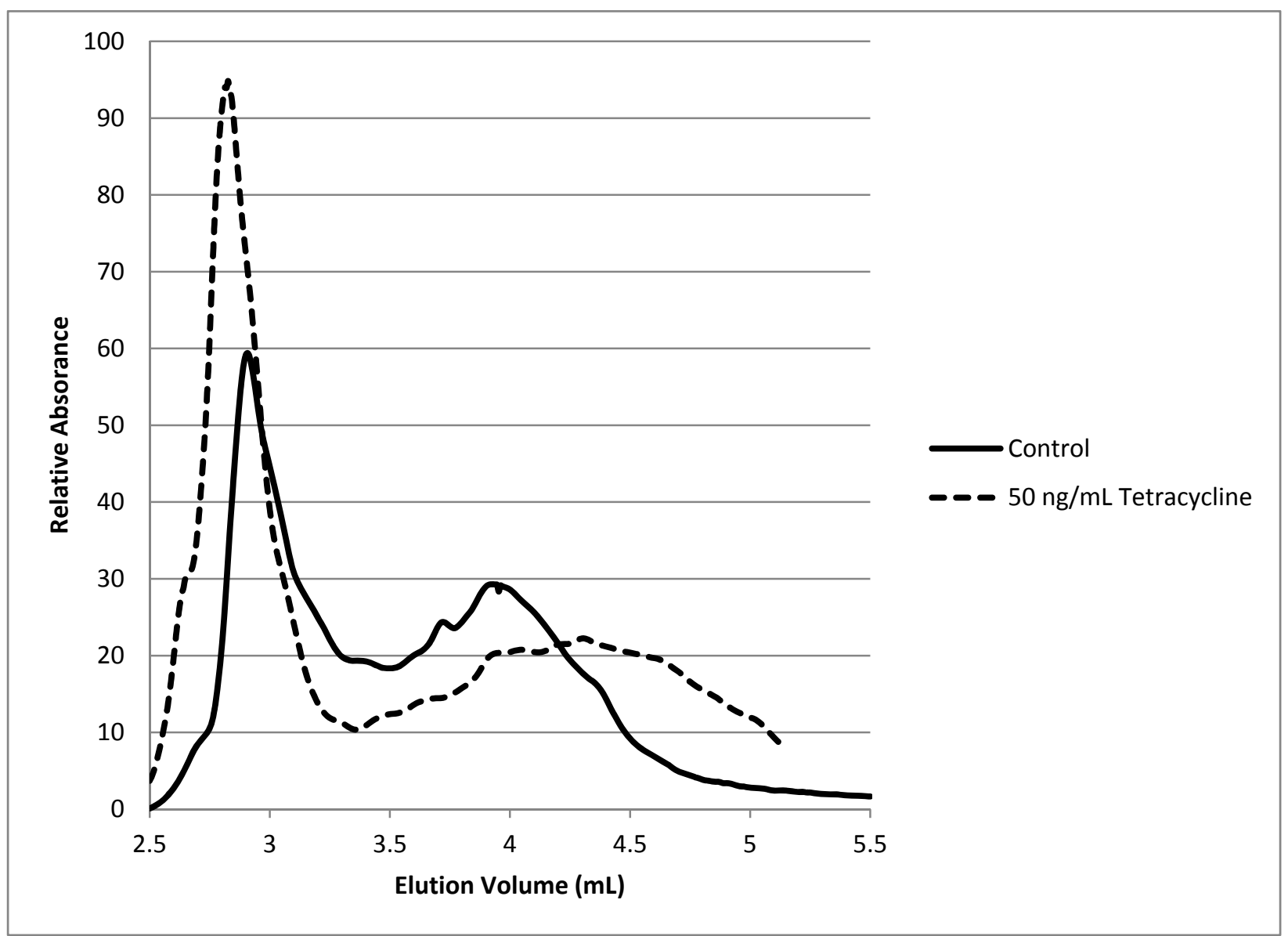

Figure 7 Chromatogram of Extracellular Products when wastewater community is exposed to $50 \mathrm{ng} / \mathrm{mL}$ of Tetracycline compared to control, measured at $215 \mathrm{~nm}$

The first peak represents the larger molecular weight EPS fraction while the smaller less intense peak represents lower molecular weight EPS material. The first and most obvious comparison to be made is in the height of the first peak, where the sample exposed to tetracycline shows a significantly higher absorbance. 
This peak corresponds to proteins in the $130 \mathrm{kDa}$ to $400 \mathrm{kDa}$ range according to the protein standards, and carbohydrates around $200 \mathrm{kDa}$ in size according to the literature (Avella et al., 2010; Pasquini et al., 2013). The increase in peak height in the presence of tetracycline was expected as previous studies showed that other antibiotics had elicited an increase in EPS material.

The second peaks correspond to proteins and carbohydrates in the sub $5 \mathrm{kDa}$ range. In previous studies the second peak containing the smaller macromolecules had higher absorbance than the first peak, however we have noted a smaller one; the concentration used previously was $10 \mathrm{mg} / \mathrm{L}$ which is 200 fold higher than the concentration of $50 \mathrm{ng} / \mathrm{mL}$ used in this study. In our case the reduction of smaller forms of EPS may be due to more EPS remaining in the larger fraction when the community is exposed to the tetracycline.

Overall, these results show that tetracycline does indeed cause the bacterial community to produce more EPS when exposed to an antibiotic, indicating that even though it does not cause growth inhibition (Figure 6) it still results in a change in the response of the community.

An increase in EPS when exposed to a stressor such as the antibiotic tetracycline makes sense due to the decreased diffusion coefficient of EPS vs water (Avella et al., 2010; Pal et al., 2008; Pasquini et al., 2013; Sheng et al., 2010). In other words, in order for the bacteria to protect itself from this contaminant it may require a greater barrier to act as a first line of defense.

\subsubsection{Control vs Ibuprofen}


Chromatograms in Figure 8 represent EPS production with and without Ibuprofen at 16 $\mathrm{ng} / \mathrm{mL}$ and $100 \mathrm{ng} / \mathrm{mL}$. Ibuprofen at either concentration gave a significantly different profile from the control although there was no significant difference according to ANOVA and Bonferroni corrected t-tests between the two Ibuprofen concentrations (Fig. 8). In this case the communities exposed to Ibuprofen produced less EPS that was slightly lower in molecular weight (optimal elution at $3 \mathrm{~mL}$ verse $2.8 \mathrm{~mL}$ ). This was determined with the aid of molecular weight standards, which can be seen in Appendix B, the longer it takes for a compound to elute, the smaller its molecular weight.

Only one previous study observed the effects of Ibuprofen on EPS in WWTC communities (Pasquini et al., 2013), however, in that case the minimum concentration tested was $100 \mathrm{ng} / \mathrm{mL}$, while we have observed this effect at $16 \mathrm{ng} / \mathrm{mL}$. This lower concentration represents concentrations of Ibuprofen detected in wastewater treatment systems around the world (ranges between $2500 \mathrm{ng} / \mathrm{L}$ and 45,000 ng/L (Guerra et al., 2014)). This is the first study to demonstrate that environmentally relevant concentrations of this NSAID cause changes in WWTC structure. This is an unexpected result as there is no known mode of action for Ibuprofen on prokaryotes (the main constituent of WWTP communities and producer of EPS), since the main target of Ibuprofen is the inhibition of COX-2 (and unintentionally COX-1) which are eukaryotic proteins. 


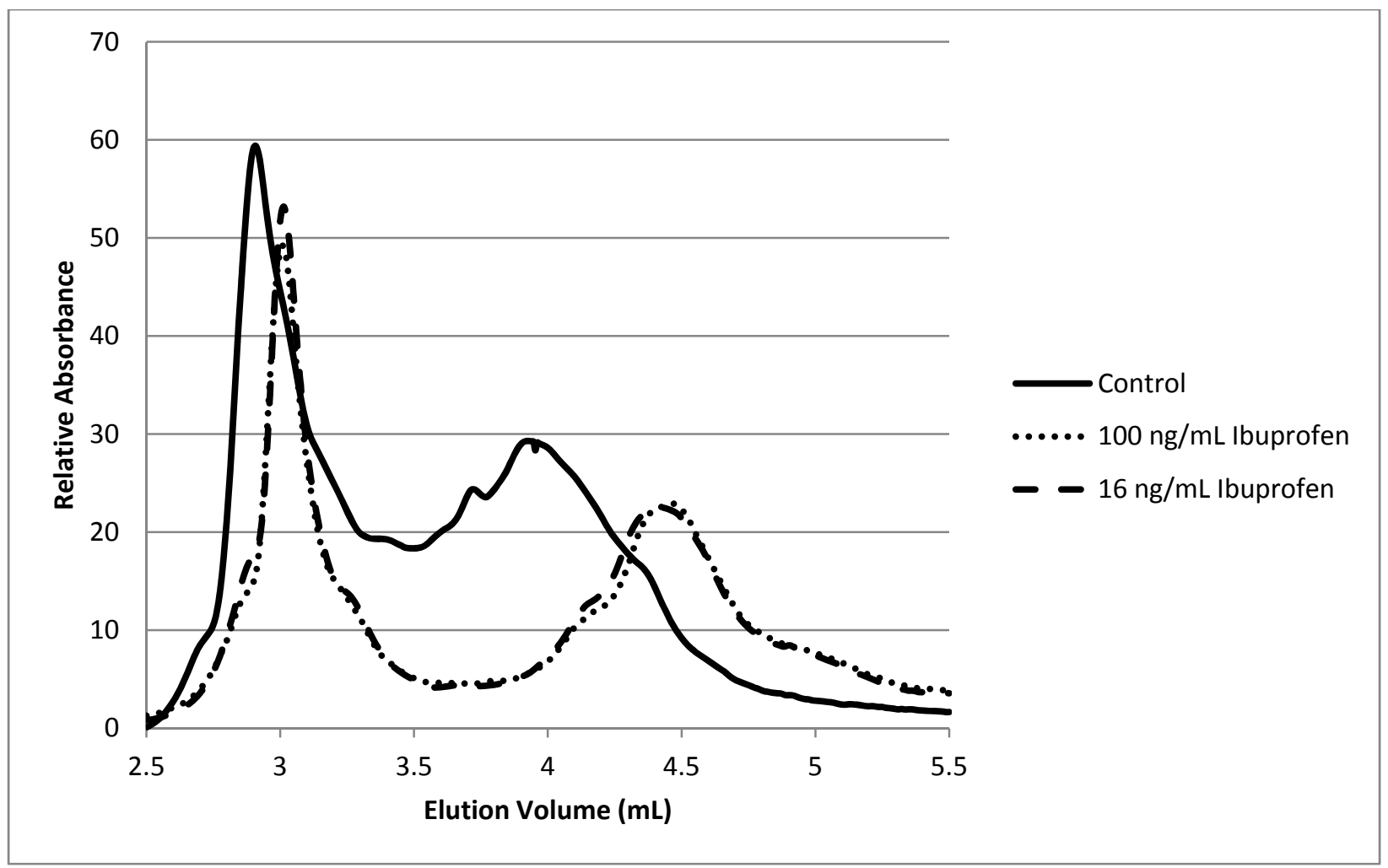

Figure 8 Chromatogram of Extracellular Products when wastewater community is exposed to $16 \mathrm{ng} / \mathrm{mL}$ and $100 \mathrm{ng} / \mathrm{mL}$ of Ibuprofen compared to control, measured at $215 \mathrm{~nm}$

A recent study that suggests NSAIDs (Carprofen, Bromfenac, and Vedaprofen) may inhibit DNA replication by preventing the binding of DNA polymerase III, however Ibuprofen was not one of the three tested NSAIDs examined in that study (Yin et al., 2014) and further research would be needed in order to establish any links. Further research would be required in order to determine if Ibuprofen has the same affect at the three previously mentioned NSAIDs, or if there is some other mechanism in action.

\subsubsection{Control vs Tetracycline + Ibuprofen Combinations}

In this study, a combination of tetracycline and Ibuprofen was also tested on the WWTC, something none of the previous studies had performed. When observing the chromatograms 
in Figure 9 it appears at first glance that there is a significant difference between the control group and the groups containing both contaminants.

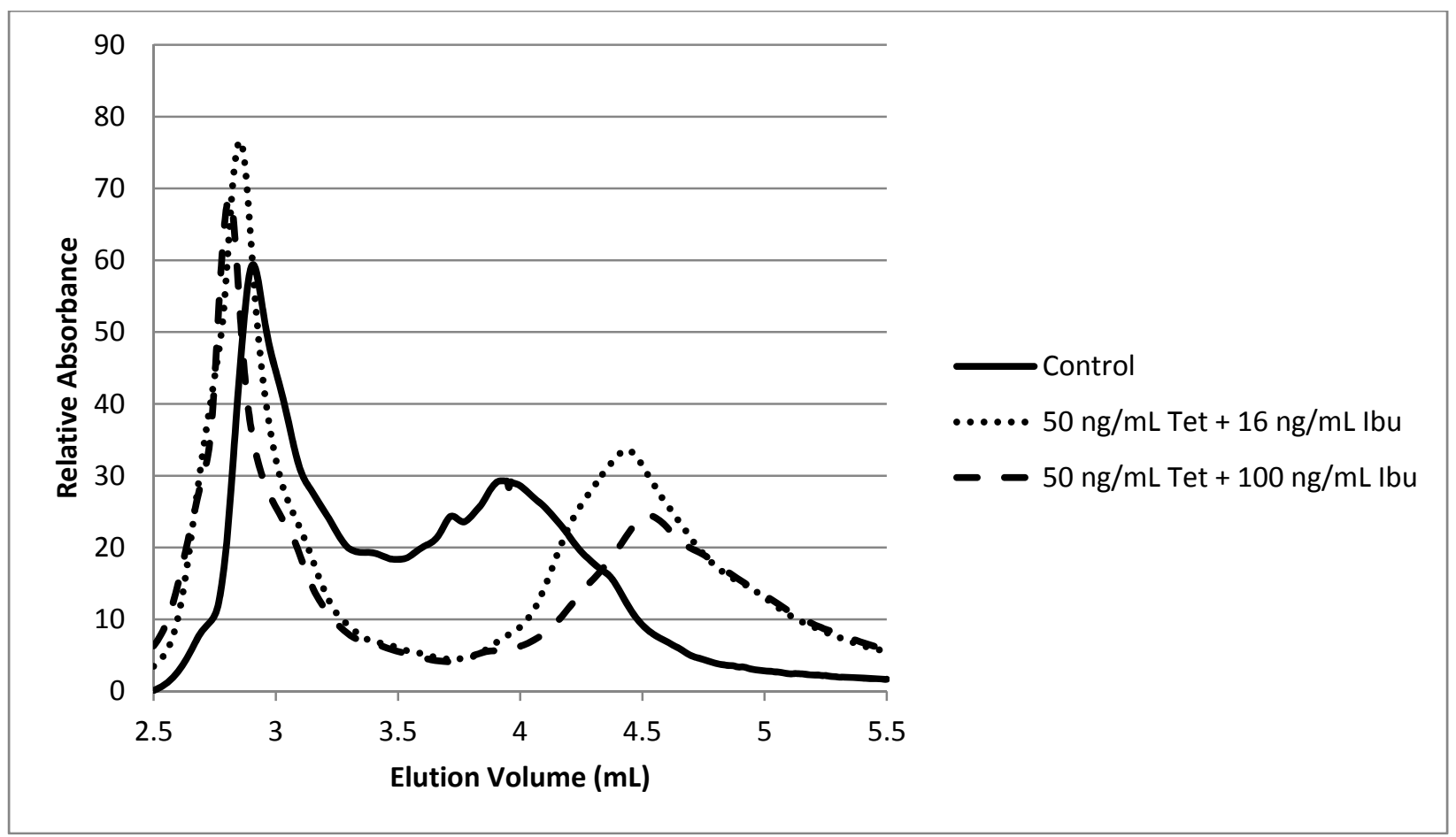

Figure 9 Chromatogram of Extracellular Products when wastewater community is exposed to combinations of Tetracycline and Ibuprofen compared to control, measured at $215 \mathrm{~nm}$

However even though ANOVA analysis determined that there was variance between all sample groups tested, post hoc Bonferroni determined that there was no significant difference between the groups in Figure 9. This was an interesting result since both compounds individually caused effects in EPS structure but together appeared to cancel out the effects.

Furthermore, the lack of difference in EPS structure between the control and the community exposed to both compounds was not reflected in the growth curves seen in Figure 6 where we noted a significant difference between the growth rate of the samples exposed to both contaminants and the control. It appears that the growth rate of the WWTC is affected by 
the combination of the two contaminants yet the change in the production of EPS was negligible.

\subsubsection{Tetracycline vs Ibuprofen vs Tetracycline + Ibuprofen}

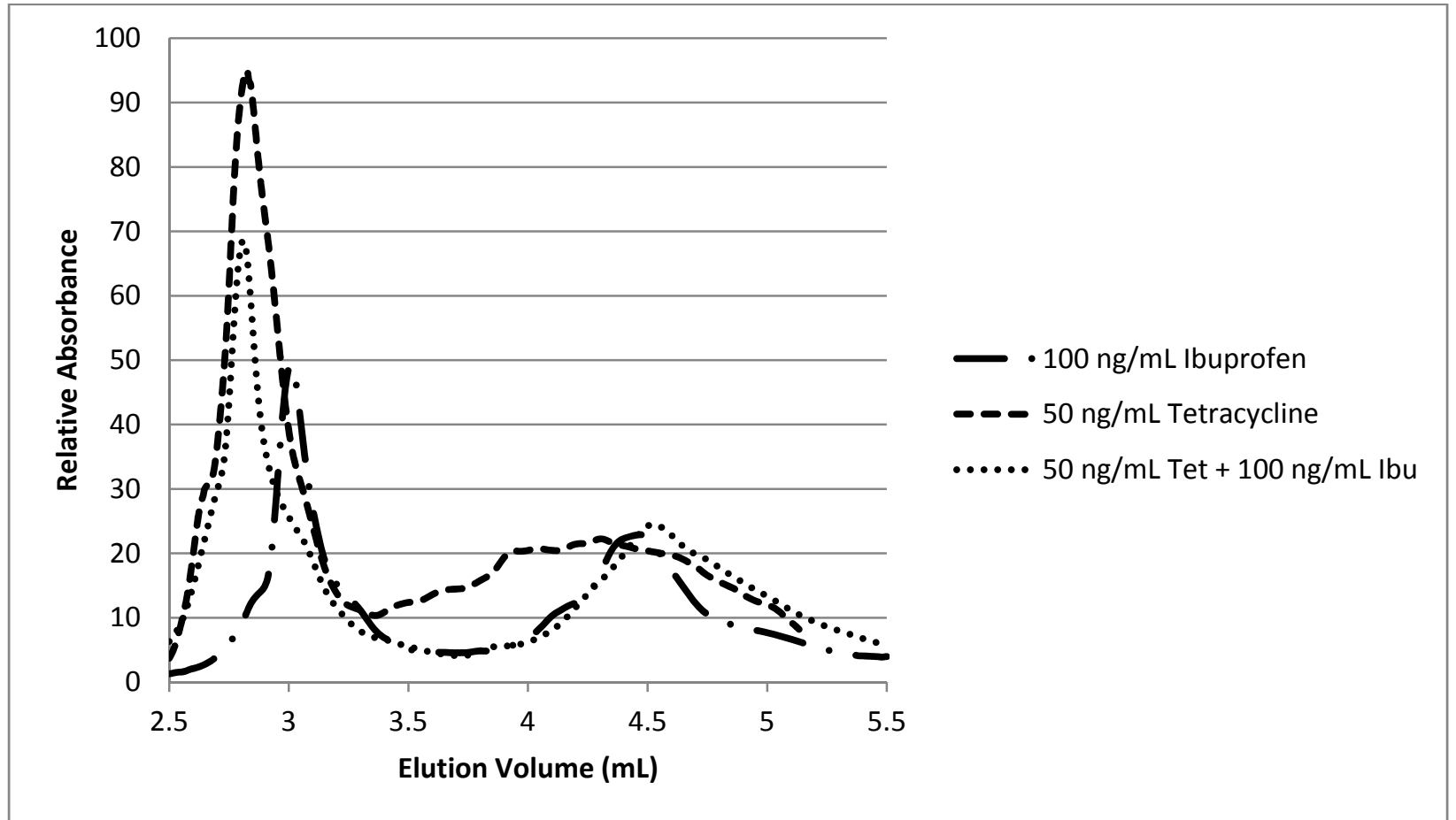

Figure 10 Chromatogram of Extracellular Products when wastewater community is exposed to Ibuprofen, Tetracycline, and Combination compared to each other, measured at $215 \mathrm{~nm}$

The effect of the contaminants on the WWTC is most effectively demonstrated when the chromatograms of EPS produced when the community was exposed to tetracycline alone, Ibuprofen alone, or to both, are displayed side by side for the purpose of comparing the differences between the groups.

As seen in Figure 10 there is a significant difference between all three groups when compared to each other. The community exposed to tetracycline alone had the largest amount of EPS, almost double that of the community exposed to Ibuprofen alone. The community 
exposed to both contaminants contained an intermediate level of EPS, in the middle of the two extremes.

\subsubsection{Sample Characteristics}

A Shapiro-Wilks test ( $p>.05)$ (Shapiro et al., 1965) and visual inspection of their normal Q-Q plots and box plots showed that the four main groups of samples had Shapiro-Wilk $p$ values of greater than 0.05 confirming the null hypothesis that the data is normally distributed.

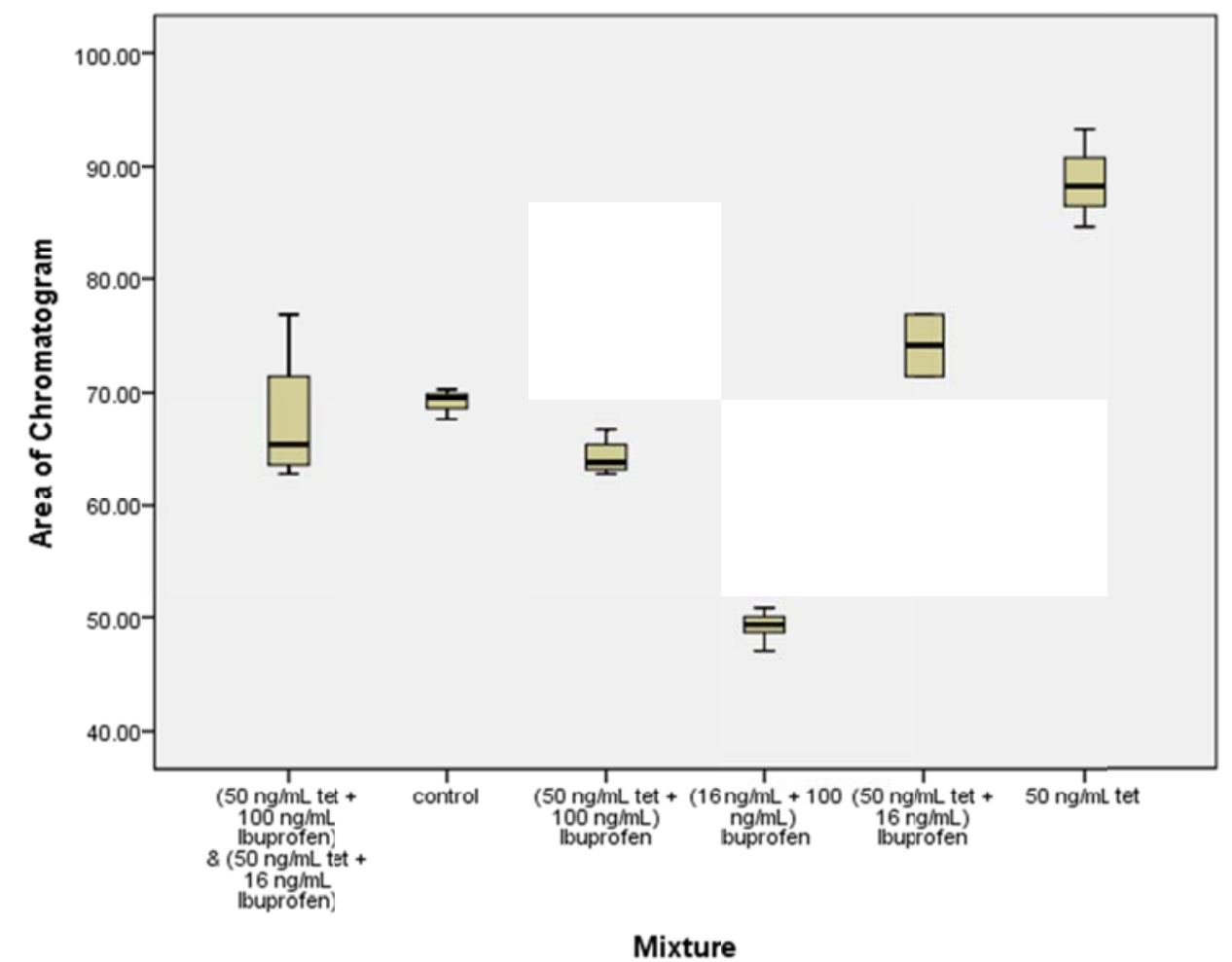

Figure 11 Area of chromatograms of EPS production by WWTCs

With a skewness of $-1.106(\mathrm{SE}=1.225)$ for the control group, a skewness of $1.133(\mathrm{SE}=$ $0.845)$ and kurtosis of $0.151(\mathrm{SE}=1.741)$ for the groups containing both Ibuprofen and Tetracycline, a skewness of $-0.728(\mathrm{SE}=0.845)$ and kurtosis of $0.648(\mathrm{SE}=1.741)$ for the groups containing Ibuprofen, and the groups containing Tetracycline only had a skewness of 0.467 (SE $=1.225)$. The box plot can be seen in Fig. 11, for $Q-Q$ plots please see appendix E. 


\subsubsection{Areas of Chromatograms}

Chromatograms were also examined based on total area under the curve to establish a quantitative approach to analyzing the EPS concentration, as opposed to visual comparison. The areas under the curves of the chromatograms were measured using a method involving image editing software. The software used is an open source free program available for download (https://www.gimp.org/); the method follows the same principles as an older method in which the graph is physically cut out of paper and weighed on a scale (http://quiz2.chem.arizona.edu/vip/chromatography/GC/analysis.htm). The main difference is that the computer method allows a more precise measurement (significant to 6 digits), and the method is not susceptible to user error caused by inconsistent cuts with scissors. The results produce a value for the area under the curves that can be compared between the different scenarios.

The bar graphs in Figure 11 show the total area under the curves and the area under each of the 2 peaks seen in the chromatograms. The results of these measurements showed that even though the peak height of the first peak was significant higher than the height of the second peak, the areas of the second peaks were in most cases significantly higher than the first; Except for samples where tetracycline was present. 


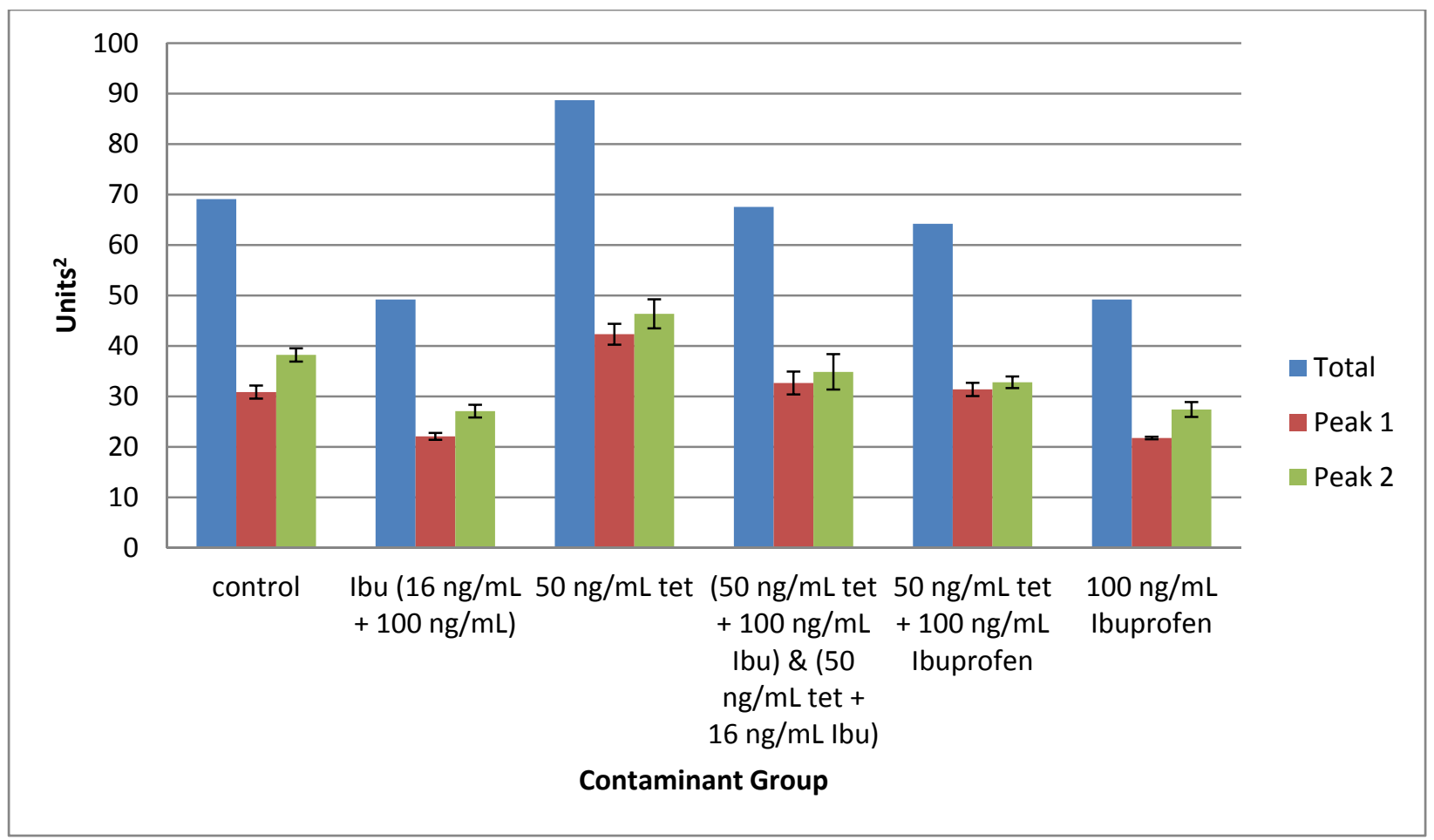

Figure 12 Graph showing average areas of chromatograms of WWTC EPS exposed to varying concentrations of Ibuprofen and Tetracycline error bars represent the Standard deviation

Careful notice should be taken however to not confuse peak area with concentration of the proteins or carbohydrates present in that peak. While the first peaks in all graphs can be compared with each other when discussing concentration, the first peak and second peak of the same graph cannot be compared in the same way. The reason for this is because the peaks represent molecules of different sizes and there is not a linear relationship with absorbance between different sized species.

Further analysis can be done to determine total proteins and carbohydrates of the individual peaks by collecting the elution volumes after chromatography in separate containers. Unfortunately the column selected for this experiment does not suit that application as it has a much narrower column diameter than those used in previous studies (Avella et al., 2010; Pasquini et al., 2013). The tradeoff however is that the narrower column used in this 
experiment provides greater resolution between the different peaks. This was confirmed as chromatograms obtained with our $4.5 \mathrm{~mm}$ diameter column showed far greater peak separation than the chromatograms obtained with the same column type at $9 \mathrm{~mm}$ diameter as seen in research by Avellas and Pasquini (Avella et al., 2010; Pasquini et al., 2013).

Table 2 Post Hoc Bon Ferroni corrected T-tests statistical analysis of pairwise comparisons for groups of interest

\begin{tabular}{|l|l|}
\hline Comparison & Significance $(\mathrm{p}<0.05)$ \\
\hline Ibuprofen $16 \mathrm{ng} / \mathrm{mL}$ vs Ibuprofen $100 \mathrm{ng} / \mathrm{mL}$ & Not significant \\
\hline Control vs (Tetracycline and Ibuprofen groups) & Not significant \\
\hline Control vs Tetracycline $50 \mathrm{ng} / \mathrm{mL}$ & Significant \\
\hline Control vs Ibuprofen groups & Significant \\
\hline Tetracycline $50 \mathrm{ng0} \mathrm{ng} / \mathrm{mL}$ vs Ibuprofen groups & Significant \\
\hline (Tetracycline $50 \mathrm{ng} / \mathrm{mL}+100 \mathrm{ng} / \mathrm{mL}$ Ibuprofen) vs $100 \mathrm{ng} / \mathrm{mL}$ & Significant \\
Ibuprofen & \\
\hline
\end{tabular}

The above table shows the findings of the Post Hoc analysis on the groups of interest discussed in this section, tables can be seen in Appendix B.

\subsection{Possible model explaining effect of Ibuprofen and tetracycline on WWTC}

One of the main characteristics of EPS in wastewater communities is the protection of floc organisms against antibiotics by means of lowered diffusion coefficients (Pasquini et al., 2013; Sheng et al., 2010). This means that EPS serves as an actual physical barrier against antibiotics or other contaminants. 
As a result, the natural response of the community in the presence of tetracycline in order to prevent a significant drop in growth may be to increase the amount of EPS which allows the bacteria to handle that threat.

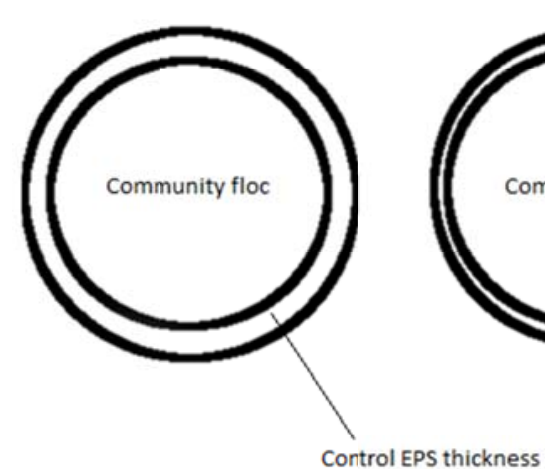

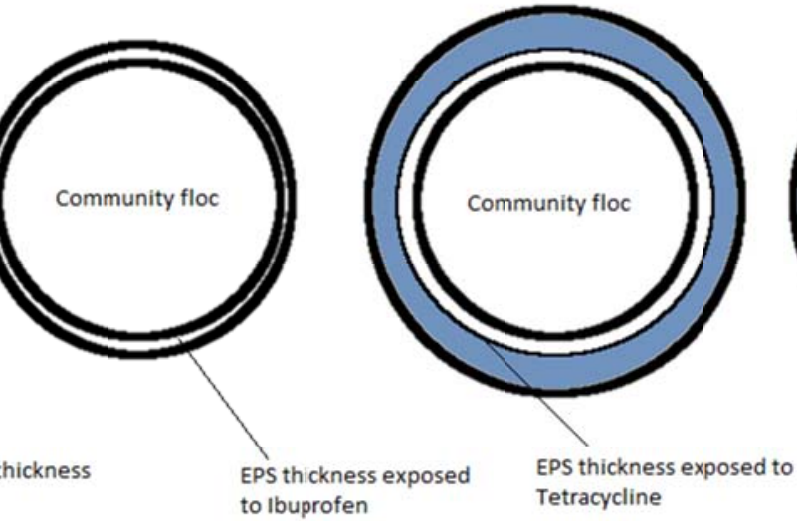

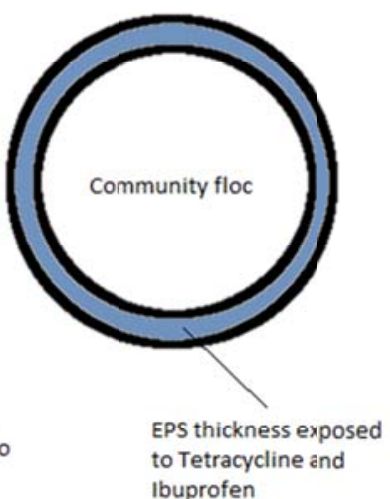

Tetracycline Penetration of EPS

Figure 13 Conceptual model for the interaction between EPS and contaminants Ibuprofen and Tetracycline

A visual explanation can be viewed in Figure 12, where the blue circle represents the penetration of tetracycline into the thick layer of EPS.

When Ibuprofen is present alone there wasn't a reduction in growth rate as Ibuprofen has no mode of action for killing bacteria however there was a reduction in the amount of EPS (Figure 12B) suggesting that in some way it can affect the functioning of the community. As mentioned previously (Yin et al., 2014), NSAIDs have been found to be effective against bacteria in some cases although the study did not examine Ibuprofen specifically. Furthermore the NSAIDs used were tested at $\mu \mathrm{g} / \mathrm{mL}$ concentrations $\left(10^{3}\right.$ times higher than concentrations used in this experiment) and therefore the results may not be relevant. 
Finally once the WWTC is exposed to both Ibuprofen and Tetracycline there is a drop in the growth rate as seen in Figure 6, even though the levels of EPS are comparable to what is found in the control as seen in Figure 9 that is the EPS per OD unit is greater in the sample containing both contaminants. A visual representation may be seen in Figure 12 . As can be seen, the EPS levels are comparable to control, and as a result the same concentration of Tetracycline is now capable of penetrating the EPS layer and reaching the cells. This explanation is supported by the reduction in growth rate seen (Figure 6). Although sludge aggregates are usually surrounded by and filled with EPS; the less EPS there is, the more likely that antibiotics can penetrate to the cells regardless of how low the diffusion coefficient is.

\subsubsection{Protein and Carbohydrate Concentrations of EPS}

The concentrations of protein in each sample were measured in order to determine if changes seen with the EPS response could be linked to protein concentration. The results obtained are shown in Figure 13. Although, in general it appeared more protein was present in the community exposed to Ibuprofen only, and it appeared less than the control when Tetracycline was present, no significant difference between the groups could be found. Overall the variance within the sample groups was quite large and as a result it could not be concluded that the changes seen in the EPS were a result of a change in protein concentrations. 


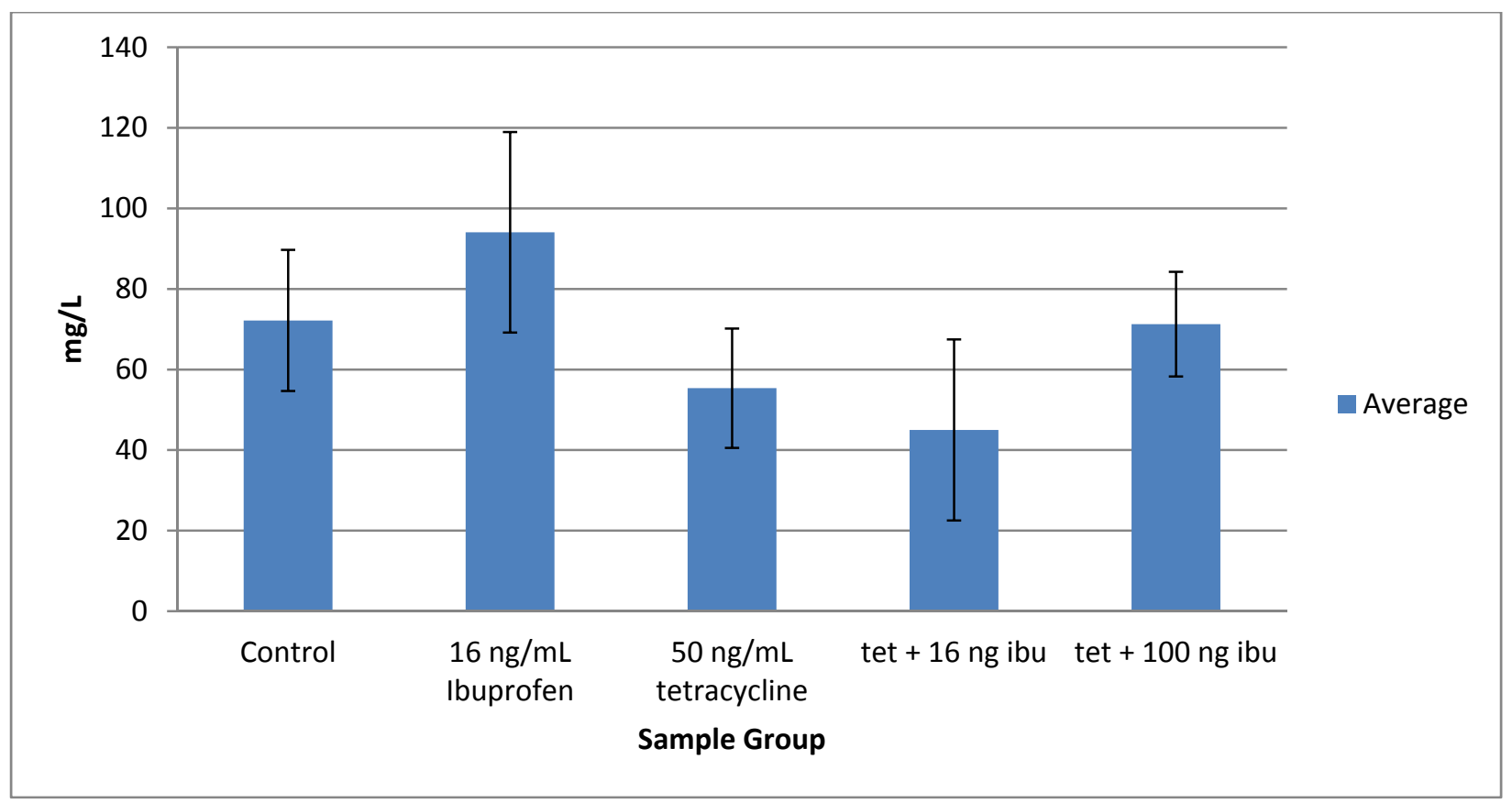

Figure 14 Measured concentrations of Protein in wastewater samples exposed to Tetracycline and Ibuprofen in $\mathrm{mg} / \mathrm{L}$

In addition to protein, the concentrations of carbohydrates were measured using a colorimetric method known as the Anthrone method; results can be seen in Figure 14.

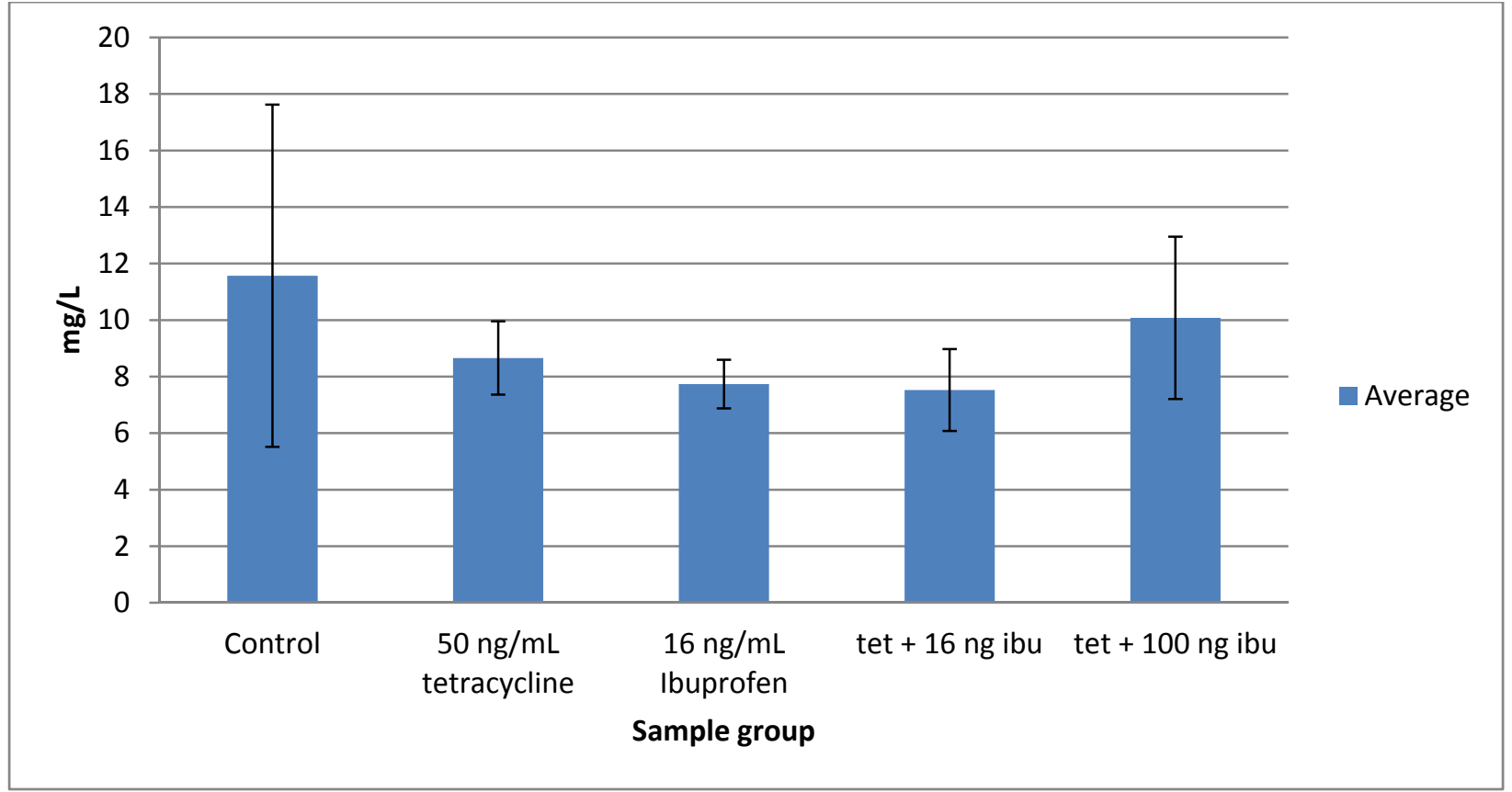

Figure 15 Carbohydrate concentrations of EPS samples produced by WWTC exposed to varying concentrations of Tetracycline and Ibuprofen 
There was also no significant difference between the groups in regards to carbohydrate concentration (Figure 15). It is important to remember that while EPS is comprised of up to $90 \%$ proteins and carbohydrates, a recent literature review has shown that up to $20 \%$ of the EPS may be humic acids (Sheng et al., 2010). As such, further research should be carried out to determine if other EPS constituents are affected by Tetracycline and Ibuprofen.

In terms of protein to carbohydrate ratio it was found that the samples had far greater concentrations of protein (average 6:1), this is expected at ratios found in literature usually fall between values of 1.5 to 3 (Sheng et al., 2010). Ratios reported here are higher than literature values most likely due to the high variance of results obtained, while done in triplicate the values obtained varied highly.

\subsection{Soluble Microbial Products Analysis}

The SMP produced by the communities was also screened for the protein and carbohydrate content after exposure of the community to the compounds, as mentioned before the SMP consists of extracellular products that are much smaller, and therefore soluble in solution without the need for a CER. Unlike the EPS samples that were resuspended in PBS buffer, SMP samples still remained in the LB buffer once centrifuged. As a result the contents of the LB media caused extremely high absorbance readings so that any differences due to exposure to the compounds were masked. Furthermore the presence of the LB also prevented meaningful results from being obtained in quantitative tests such as Anthrone Method and Bradford. Furthermore, there are few values in the literature for SMP which suggests other researchers have experience the same phenomenon. Future work should investigate whether there is a 
more accurate way to measure protein and carbohydrate concentrations in the SMP to determine whether the EPS reduction seen with Ibuprofen are due to less production of EPS or degradation of the existing EPS into the soluble phase.

\section{Conclusions and Future Work}

EPS production is a defining characteristic of many bacteria, especially of those found in wastewater treatment plants. It is responsible for providing structure, nutrition, antibiotic resistance, and adsorption of contaminants such as heavy metals and BTEXs. This in addition to the fact that EPS is produced more in times of stress indicate that it should be treated as an important metric when determining the health and susceptibilities of a wastewater community. If the WWTC is not capable of maintaining EPS it is creating vulnerabilities to future contaminants, as well as reducing its ability to survive in times of hardship.

The main research questions posed by this study were to determine whether or not two extremely common pharmaceuticals could illicit effects on the growth rates of $P$. putida $B B C 443$, and WWTCs. And secondly to determine the effects these compounds might have on the production of EPS at varying concentrations when one or both these compounds were present.

The results obtained in regards to $P$.putida showed that tetracycline did have an inhibitory effect on growth; however the strain of $P$. putida tested does not have a resistance to tetracycline which can explain the inhibition of growth rate. This decrease in growth was not affected by the addition of Ibuprofen. In fact the addition of Ibuprofen did not appear to have any effect on the growth rate of $P$. putida regardless of concentration tested. 
When looking at the growth rates of WWTCs it was determined that unlike in the case of $P$. putida, Tetracycline had no significant effect on the growth rate. This could be reasoned due to the fact that WWTCs are extremely diverse microbial communities, and as a result of being exposed to antibiotics on a consistent basis they are extremely prone to developing antibiotic resistance that can be transferred from one species of bacteria to another via plasmid transfer. However once Ibuprofen was added to the mix there was an inhibitory effect on growth rate which was statistically significant. These results could not be explained solely on the data obtained from a growth curve, and as a result the EPS production of the WWTC was examined via the use of HPLC.

Once HPLC was performed on the EPS constituents, it was found that both concentrations of Ibuprofen examined elicited a significant decrease in EPS production. This result was consistent with what was previously seen in the literature, however the lowest concentration looked at previously was $100 \mathrm{ng} / \mathrm{mL}$ or roughly twice the highest environmentally relevant concentration. I showed that the inhibitory effect on EPS by Ibuprofen continued at much lower and environmentally relevant concentrations of $16 \mathrm{ng} / \mathrm{mL}$, indicating that even current concentrations of this contaminant could be having effects in nature.

The effect of Tetracycline on EPS was also examined by HPLC and the results obtained were similar to what was seen in previous literature. One study which looked at several antibiotics, but not tetracycline, showed that there was an increase in EPS production in the presence of antibiotics (Pasquini et al., 2013). This increase in EPS was again explained as a result of stress on the WWTC, the production of a physical barrier for protection. A second study (Avella et al., 
2010) which looked at Tetracycline examined a concentration of $10 \mathrm{mg} / \mathrm{mL}, 200$ fold higher than used in this study of $0.05 \mathrm{mg} / \mathrm{mL}$. Again showing that even at environmentally relevant concentrations WWTCs are being affected by the contaminant concentrations currently found through monitoring.

By far the most interesting result however was that when Ibuprofen and Tetracycline were present together, the levels of EPS were not different than the control. Furthermore, each compound on their own did not show a negative impact the growth rate of WWTCs, yet in combination there was a reduction the growth rate of the community. Since contaminants are regulated on a case by case basis, and neither compound caused growth inhibition these results could have not been predicted.

Current opinion is that EPS is produced as a defense against antibiotics; therefore in conditions where the WWTC are only exposed to a single antibiotic they will produce enough EPS to stave off the antibiotic. However, in combination with Ibuprofen, an NSAID, these effects may be masked since Ibuprofen is shown to decrease EPS production. Overall, combinations need to be studied since outcomes cannot be predicted based on the data generated for single compounds.

In this study the individual chromatogram peaks could not be analyzed for protein or carbohydrate content as the column used traded the benefit of elution collection for peak resolution. Examining the individual peaks should be of interest for future research as it can be used to determine the actual molecular structure of the eluted compounds. 
I believe that the main applications of this study should be in regards to the decision making of policy and regulation for current and new drugs. When recalling how contaminants are examined before regulation occurs in all three regions (EU, US, CA), it was said that most drugs are regulated on an individual basis which means that drug interactions are not taken into consideration. However these results clearly show that drugs of completely different groups can have additive effects on complex WWTCs found in urban settings. It brings concern to a major question: "how could it be responsible to determine the safety of one drug, much less one group of drugs in isolation when two extremely popular drugs from completely different pharmaceutical groups can elicit additive negative effects?"

Again it is important to emphasize that the results obtained in this study were found when testing pharmaceuticals at environmentally relevant concentrations. With global population and water stress to peak by 2050 the situation can only get worse if steps are not taken to address these issues today. 
Appendix A - Chromatograms

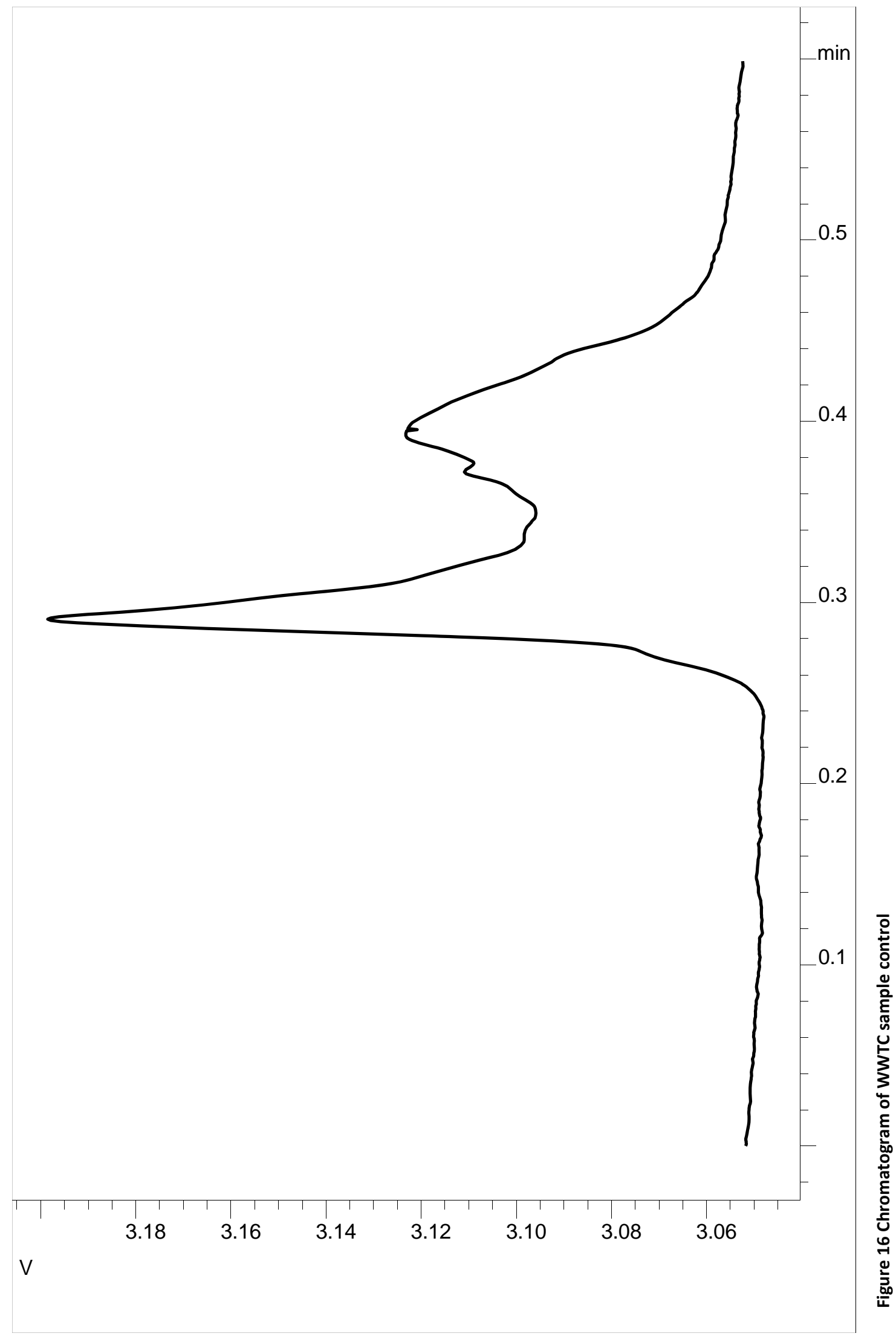




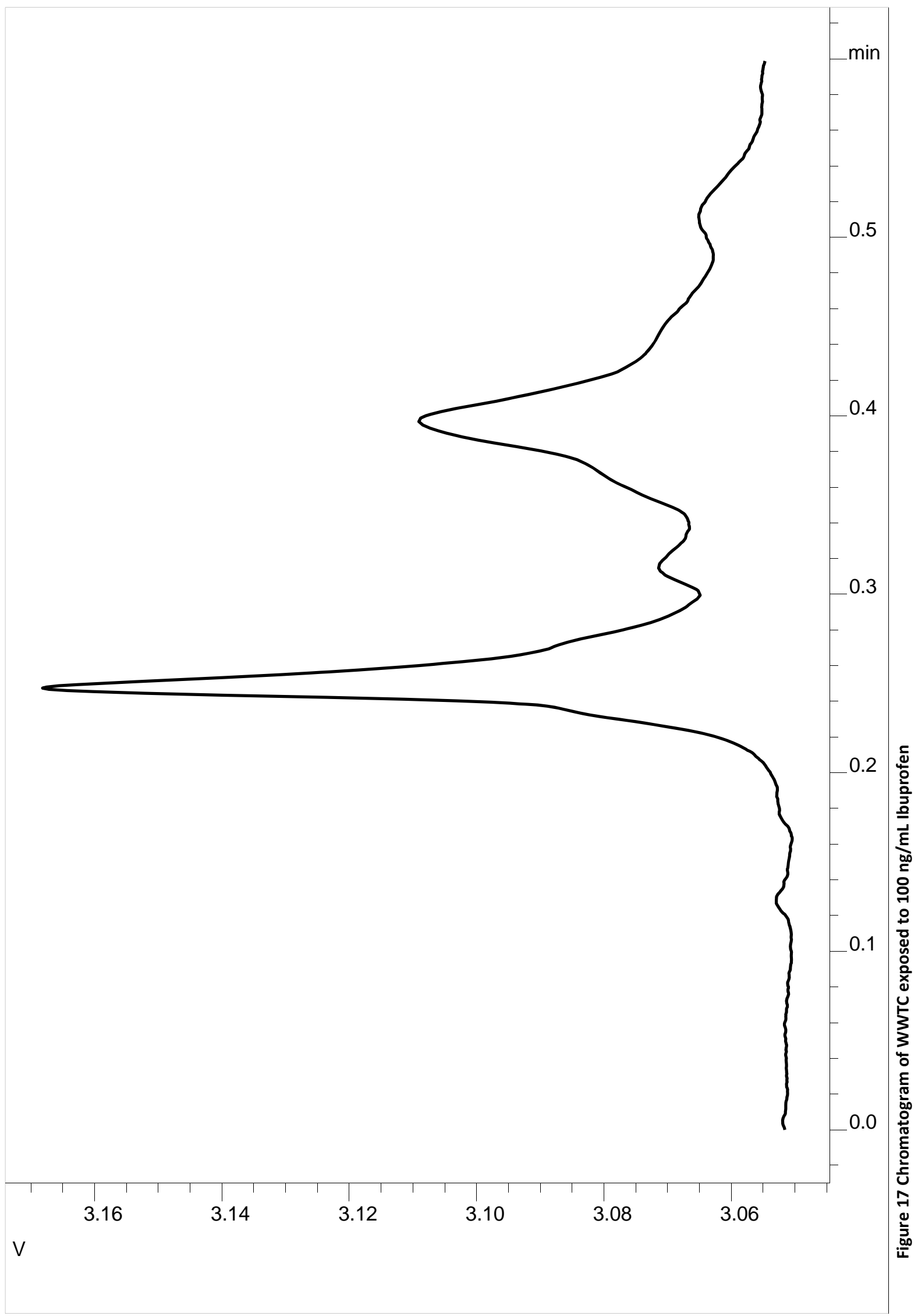




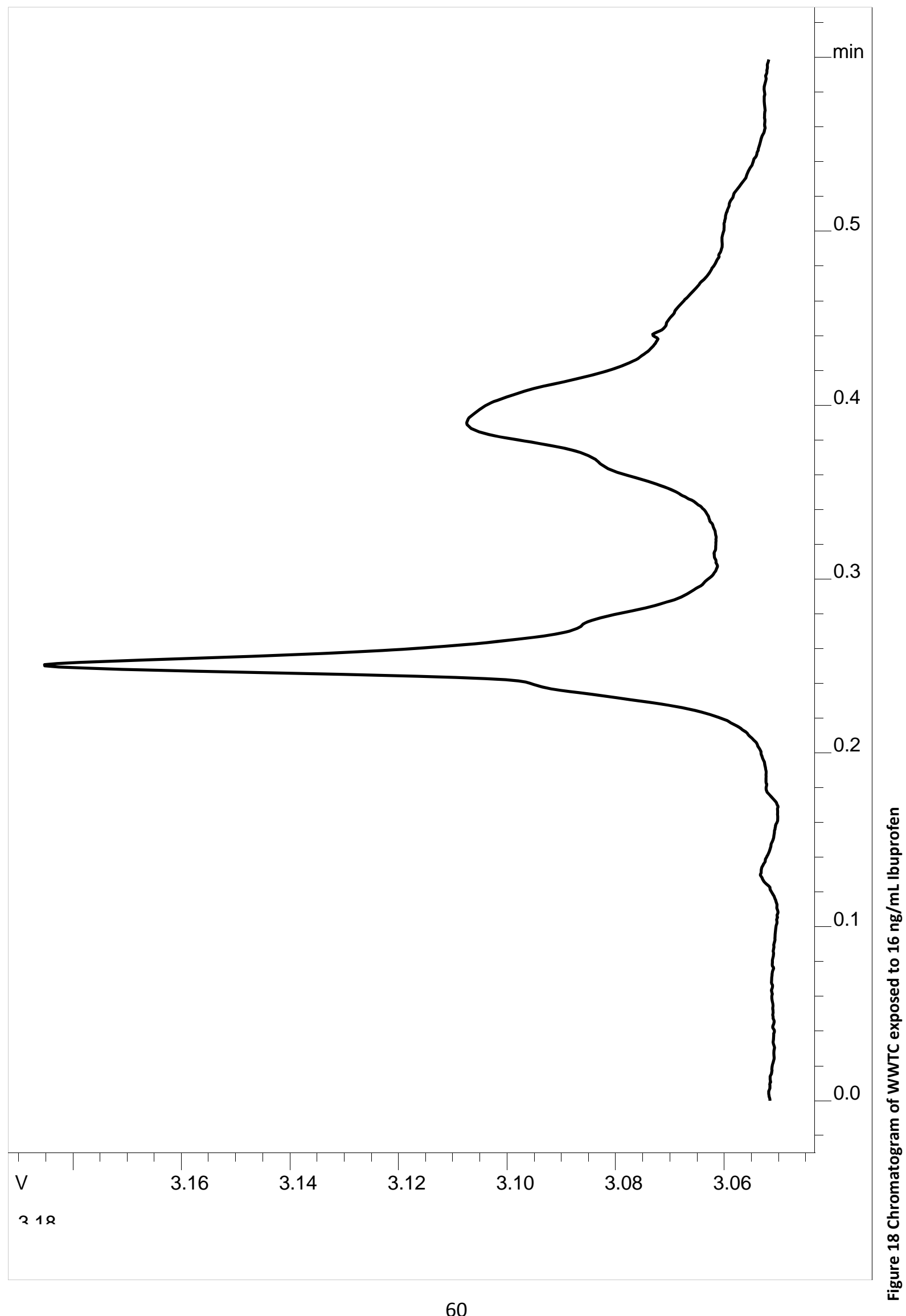




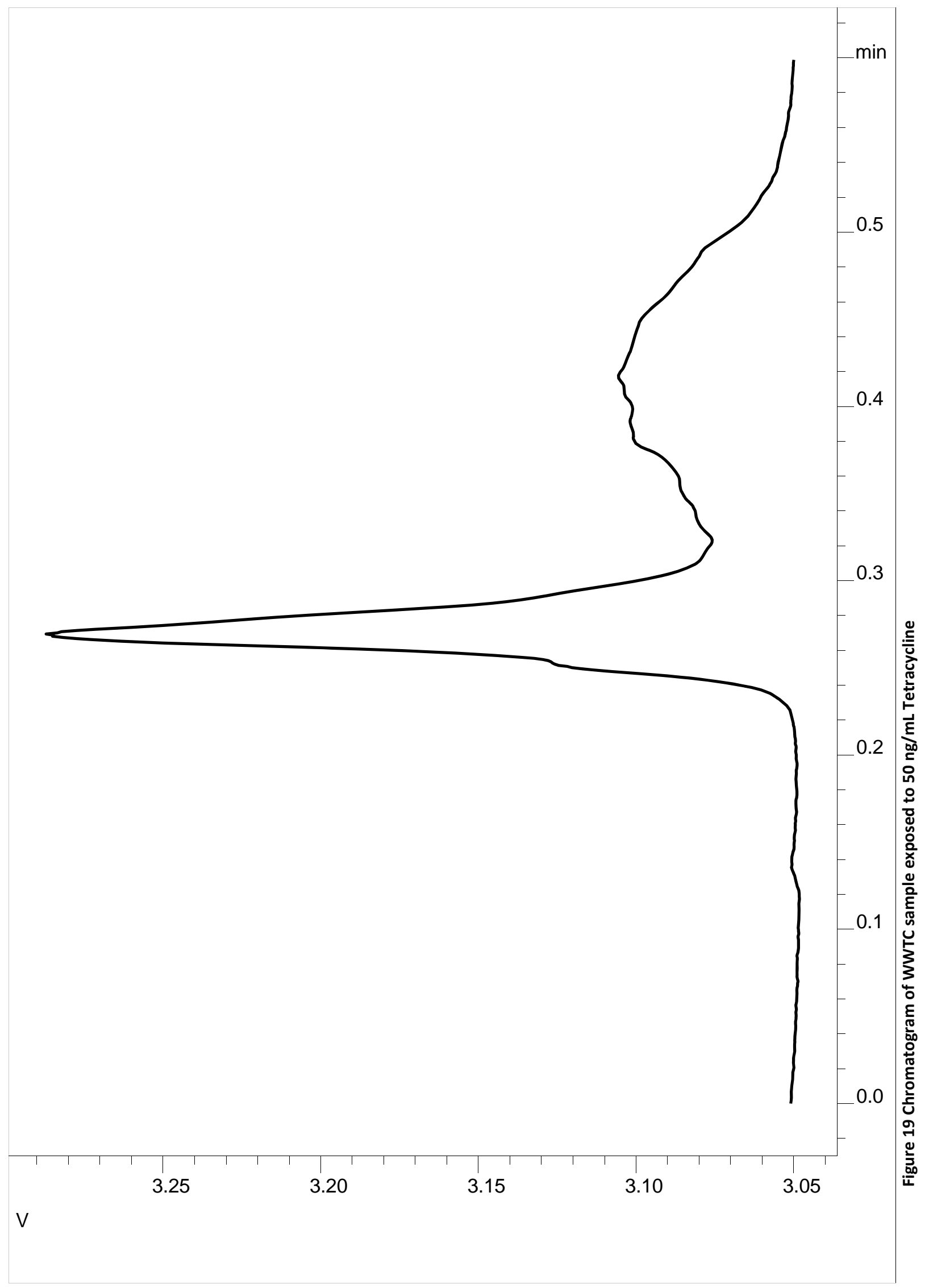




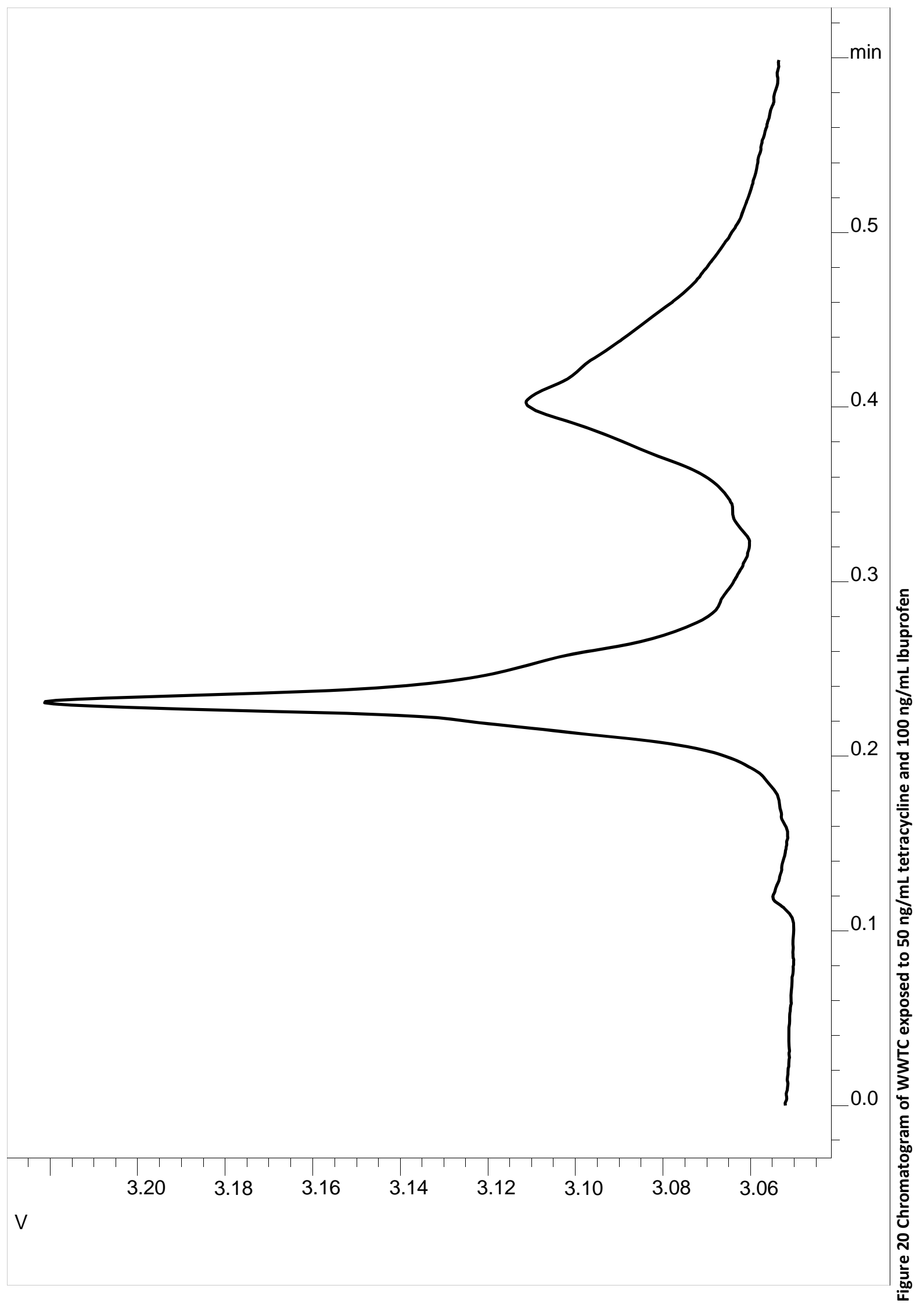




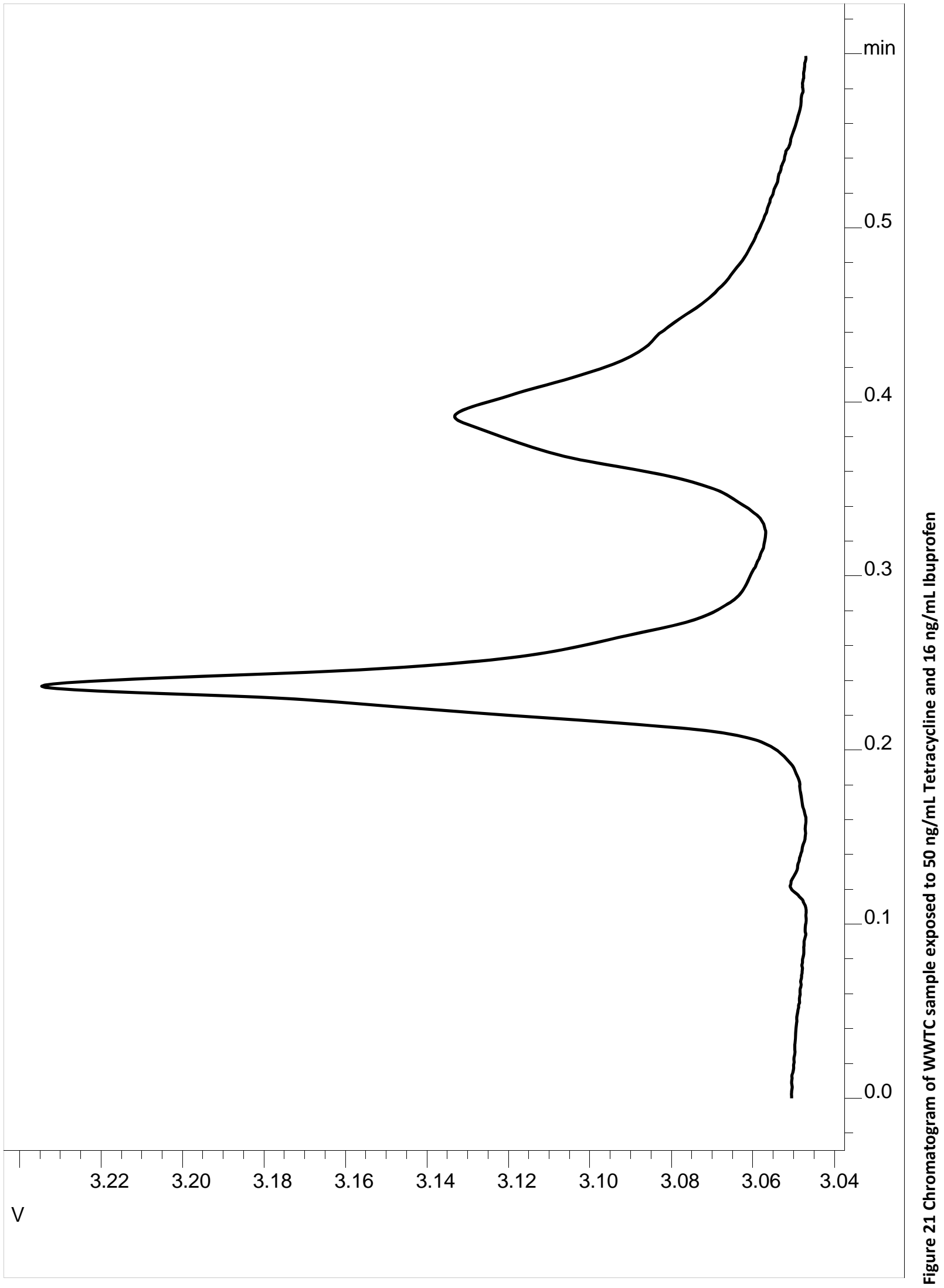




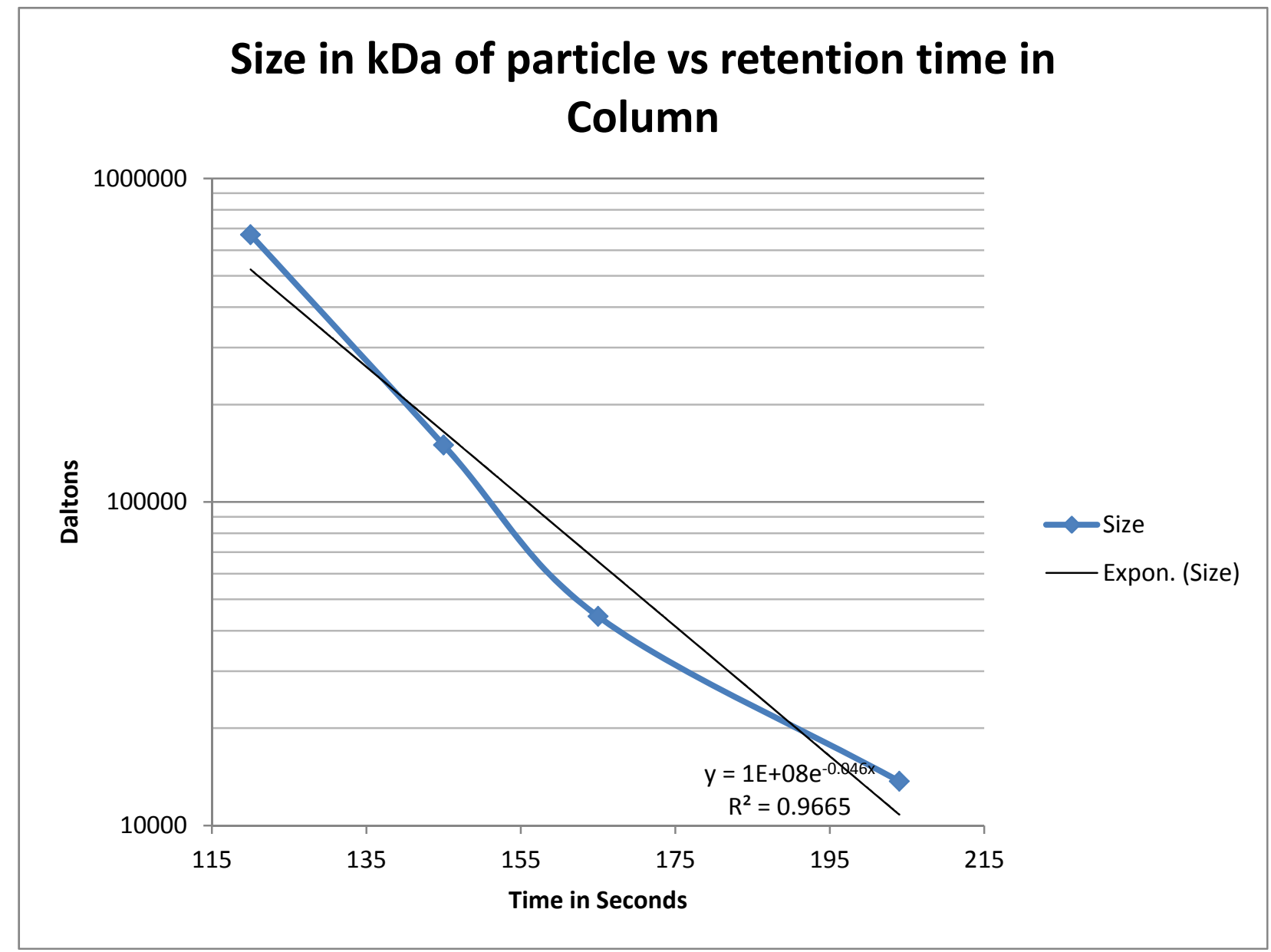

Figure 22 Protein Standard Mix 15-600 kDa run through Zorbax Bio series gf-250 column at $1 \mathrm{~mL} / \mathrm{min}$. From left to right, Thyroblobulin Bovine 670 kDa, y-globulins from bovine blood 150 kDa, Chicken egg albumin 44.3 kDa, Ribonuclease A 13.7 kDa 


\section{Appendix C - Statistics Tables}

Table 3 ANOVA table of area under chromatograms for the contaminant groups

\begin{tabular}{|c|c|c|c|c|c|c|}
\hline SUMMARY & & & & & & \\
\hline Groups & Count & Sum & Average & Variance & & \\
\hline control & 3 & 207.34 & 69.11 & 1.93 & & \\
\hline Ibuprofen group & 6 & 295.22 & 49.20 & 1.74 & & \\
\hline $\begin{array}{l}50 \mathrm{ng} / \mathrm{mL} \\
\text { Tetracycline }\end{array}$ & 3 & 266.13 & 88.71 & 19.19 & & \\
\hline $\begin{array}{l}\text { Tetracycline } \\
\text { Ibuprofen Group }\end{array}$ & 6 & 405.27 & 67.54 & 31.12 & & \\
\hline $\begin{array}{l}50 \mathrm{ng} / \mathrm{mL} \text { tet }+ \\
16 \mathrm{nl} / \mathrm{ml} \text { lbuprofen }\end{array}$ & 4 & 256.92 & 64.23 & 2.95 & & \\
\hline $\begin{array}{l}100 \mathrm{ng} / \mathrm{mL} \\
\text { Ibuprofen }\end{array}$ & 4 & 196.80 & 49.20 & 2.70 & & \\
\hline ANOVA & & & & & & \\
\hline Source of Variation & SS & $d f$ & $M S$ & $F$ & P-value & F crit \\
\hline Between Groups & 4124.82 & 5 & 824.96 & 73.82 & $3.4 \mathrm{E}-12$ & 2.71 \\
\hline Within Groups & 223.50 & 20 & 11.18 & & & \\
\hline Total & 4348.33 & 25 & & & & \\
\hline
\end{tabular}


Table 4 ANOVA table for area under peak one for chromatograms of contaminant groups

\begin{tabular}{|c|c|c|c|c|c|c|}
\hline SUMMARY & & & & & & \\
\hline Groups & Count & Sum & Average & Variance & stdev & \\
\hline control & 3 & 92.62 & 30.87 & 1.66 & 1.29 & \\
\hline Ibuprofen group & 6 & 132.66 & 22.11 & 0.46 & 0.68 & \\
\hline $\begin{array}{l}50 \mathrm{ng} / \mathrm{mL} \\
\text { tetracycline }\end{array}$ & 3 & 127.01 & 42.34 & 4.28 & 2.07 & \\
\hline $\begin{array}{l}\text { Tetracycline } \\
\text { Ibuprofen Group }\end{array}$ & 6 & 195.97 & 32.66 & 5.10 & 2.26 & \\
\hline $\begin{array}{l}50 \mathrm{ng} / \mathrm{mL} \text { tet }+ \\
16 \mathrm{nl} / \mathrm{ml} \text { lbuprofen }\end{array}$ & 4 & 125.64 & 31.41 & 1.72 & 1.31 & \\
\hline $\begin{array}{l}100 \mathrm{ng} / \mathrm{mL} \\
\text { Ibuprofen }\end{array}$ & 4 & 87.11 & 21.78 & 0.06 & 0.25 & \\
\hline ANOVA & & & & & & \\
\hline Source of Variation & SS & $d f$ & MS & $F$ & P-value & F crit \\
\hline Between Groups & 1139.48 & 5 & 227.89 & 101.27 & $1.69 \mathrm{E}-13$ & 2.71 \\
\hline Within Groups & 45.01 & 20 & 2.25 & & & \\
\hline Total & 1184.48 & 25 & & & & \\
\hline
\end{tabular}


Table 5 ANOVA table for area under peak two for chromatograms of contaminant groups

\begin{tabular}{|c|c|c|c|c|c|c|}
\hline SUMMARY & & & & & & \\
\hline Groups & Count & Sum & Average & Variance & stdev & \\
\hline control & 3 & 114.72 & 38.24 & 1.73 & 1.32 & \\
\hline Ibuprofen group & 6 & 162.56 & 27.09 & 1.58 & 1.26 & \\
\hline $\begin{array}{l}50 \mathrm{ng} / \mathrm{mL} \\
\text { tetracycline }\end{array}$ & 3 & 139.12 & 46.37 & 8.25 & 2.87 & \\
\hline $\begin{array}{l}\text { Tetracycline } \\
\text { Ibuprofen Group }\end{array}$ & 6 & 209.30 & 34.88 & 12.41 & 3.52 & \\
\hline $\begin{array}{l}50 \mathrm{ng} / \mathrm{mL} \text { tet }+ \\
16 \mathrm{nl} / \mathrm{ml} \text { lbuprofen }\end{array}$ & 4 & 131.28 & 32.82 & 1.34 & 1.16 & \\
\hline $\begin{array}{l}100 \mathrm{ng} / \mathrm{mL} \\
\text { lbuprofen }\end{array}$ & 4 & 109.68 & 27.42 & 2.20 & 1.48 & \\
\hline ANOVA & & & & & & \\
\hline Source of Variation & SS & $d f$ & $M S$ & $F$ & $P$-value & F crit \\
\hline Between Groups & 971.09 & 5 & 194.22 & 38.63 & 1.31E-09 & 2.71 \\
\hline Within Groups & 100.55 & 20 & 5.03 & & & \\
\hline Total & 1071.64 & 25 & & & & \\
\hline
\end{tabular}

Table 6 Bonferroni Post Hoc Control vs (50 ng/mL Tetracycline +100 ng/mL lbuprofen)

\begin{tabular}{|c|c|c|c|c|c|}
\hline & $\begin{array}{c}50 \mathrm{ng} / \mathrm{ml} \text { tet }+100 \\
\mathrm{ng} / \mathrm{ml}\end{array}$ & control & & & \\
\hline Mean & 64.23 & & 69.11 & & \\
\hline Variance & 2.95 & & 1.93 & & \\
\hline Observations & 4 & & 3 & & \\
\hline Pooled Variance & 2.54 & & & & \\
\hline \multicolumn{6}{|c|}{ Hypothesized Mean } \\
\hline Difference & 0 & & & & \\
\hline$d f$ & 5 & & & & \\
\hline t Stat & -4.01 & & & & \\
\hline $\mathrm{P}(\mathrm{T}<=\mathrm{t})$ one-tail & 0.0051 & & & & \\
\hline t Critical one-tail & 2.015 & & & \multicolumn{2}{|c|}{ Bonferroni } \\
\hline $\mathrm{P}(\mathrm{T}<=\mathrm{t})$ two-tail & 0.01 & & & 0.0033 & FALSE \\
\hline t Critical two-tail & 2.57 & & & & \\
\hline
\end{tabular}


Table 7 Bonferroni Post Hoc Control vs Tetracycline and Ibuprofen Group

\begin{tabular}{|c|c|c|c|c|}
\hline & Control & $\begin{array}{c}\text { Tetracycline } \\
+ \text { Ibuprofen } \\
\text { Groups }\end{array}$ & & \\
\hline Mean & 69.11 & 67.54 & & \\
\hline Variance & 1.938 & 31.12 & & \\
\hline Observations & 3 & 6 & & \\
\hline Pooled Variance & 22.78 & & & \\
\hline Hypothesized Mean Difference & 0 & & & \\
\hline$d f$ & 7 & & & \\
\hline t Stat & 0.46 & & & \\
\hline $\mathrm{P}(\mathrm{T}<=\mathrm{t})$ one-tail & 0.33 & & & \\
\hline t Critical one-tail & 1.89 & & \multicolumn{2}{|c|}{ Bonferroni } \\
\hline $\mathrm{P}(\mathrm{T}<=\mathrm{t})$ two-tail & 0.66 & & 0.0033 & FALSE \\
\hline t Critical two-tail & 2.36 & & & \\
\hline
\end{tabular}

Table 8 Bonferroni Post Hoc Control vs $50 \mathrm{ng} / \mathrm{mL}$ tetracycline group

\begin{tabular}{lrr|r} 
& Control & $\begin{array}{r}50 \mathrm{ng} / \mathrm{mL} \\
\text { tetracycline }\end{array}$ \\
\cline { 1 - 3 } Mean & 69.11 & 88.71 & \\
Variance & 1.93 & 19.19 & \\
Observations & 3 & 3 & \\
Pooled Variance & 10.56 & & \\
Hypothesized Mean Difference & 0 & & \\
df & 4 & & \\
t Stat & -7.39 & & \multicolumn{2}{|c}{ Bonferroni } \\
P(T<=t) one-tail & 0.0009 & & \\
t Critical one-tail & 2.13 & & \\
P(T<=t) two-tail & 0.0018 & & \\
t Critical two-tail & 2.78 & & \\
\hline
\end{tabular}


Table 9 Bonferroni Post Hoc $50 \mathrm{ng} / \mathrm{mL}$ tetracycline $+100 \mathrm{ng} / \mathrm{mL}$ lbuprofen vs $50 \mathrm{ng} / \mathrm{mL}$ Tetracycline $+16 \mathrm{ng} / \mathrm{mL}$ lbuprofen

\begin{tabular}{|c|c|c|c|c|}
\hline & $\begin{array}{c}50 \mathrm{ng} / \mathrm{mL} \\
\text { tetracycline } \\
+100 \\
\mathrm{ng} / \mathrm{mL} \\
\text { Ibuprofen }\end{array}$ & $\begin{array}{c}50 \mathrm{ng} / \mathrm{mL} \\
\text { tetracycline } \\
\text { and } 16 \\
\mathrm{ng} / \mathrm{mL} \\
\text { Ibuprofen }\end{array}$ & & \\
\hline Mean & 64.23 & 67.54 & & \\
\hline Variance & 2.95 & 31.12 & & \\
\hline Observations & 4 & 6 & & \\
\hline Pooled Variance & 20.56 & & & \\
\hline Hypothesized Mean Difference & 0 & & & \\
\hline$d f$ & 8 & & & \\
\hline t Stat & -1.13 & & & \\
\hline $\mathrm{P}(\mathrm{T}<=\mathrm{t})$ one-tail & 0.15 & & & \\
\hline t Critical one-tail & 1.86 & & \multicolumn{2}{|c|}{ Bonferroni } \\
\hline $\mathrm{P}(\mathrm{T}<=\mathrm{t})$ two-tail & 0.29 & & 0.0033 & FALSE \\
\hline t Critical two-tail & 2.31 & & & \\
\hline
\end{tabular}

Table 10 Bonferroni Post Hoc Ibuprofen as one group vs Ibuprofen $100 \mathrm{ng} / \mathrm{mL}$

\begin{tabular}{|c|c|c|c|c|}
\hline & Variable 1 & Variable 2 & & \\
\hline Mean & 49.20 & 49.20 & & \\
\hline Variance & 1.74 & 2.70 & & \\
\hline Observations & 6 & 4 & & \\
\hline Pooled Variance & 2.01 & & & \\
\hline Hypothesized Mean Difference & 0 & & & \\
\hline df & 8 & & & \\
\hline t Stat & 0.0051 & & & \\
\hline $\mathrm{P}(\mathrm{T}<=\mathrm{t})$ one-tail & 0.50 & & & \\
\hline t Critical one-tail & 1.86 & & \multicolumn{2}{|c|}{ Bonferroni } \\
\hline $\mathrm{P}(\mathrm{T}<=\mathrm{t})$ two-tail & 0.99 & & 0.0033 & FALSE \\
\hline t Critical two-tail & 2.31 & & & \\
\hline
\end{tabular}

Table 11 ANOVA analysis of Carbohydrate concentrations of EPS samples produced by WWTC exposed to various concentrations of Tetracycline and Ibuprofen 
Anova: Single Factor

SUMMARY

\begin{tabular}{|c|c|c|c|c|c|}
\hline Groups & Count & Sum & Average & Variance & $s t d v$ \\
\hline Control & 3 & 34.70 & 11.57 & 36.64 & 6.05 \\
\hline $50 \mathrm{ng} / \mathrm{mL}$ tetracycline & 3 & 25.99 & 8.66 & 1.67 & 1.29 \\
\hline $16 \mathrm{ng} / \mathrm{mL}$ Ibuprofen & 3 & 23.21 & 7.74 & 0.74 & 0.86 \\
\hline tet $+16 \mathrm{ng} / \mathrm{mL}$ ibu & 3 & 22.57 & 7.52 & 2.10 & 1.45 \\
\hline tet $+100 \mathrm{ng} / \mathrm{mL}$ ibu & 3 & 30.23 & 10.08 & 8.25 & 2.87 \\
\hline
\end{tabular}

ANOVA

\begin{tabular}{lccccccr}
\hline \multicolumn{1}{c}{ Source of Variation } & SS & $d f$ & MS & $F$ & P-value & F crit \\
\hline Between Groups & 34.72 & 4 & 8.68 & 0.88 & 0.51 & 3.48 \\
Within Groups & 98.81 & 10 & 9.88 & & & \\
& & & & & & \\
Total & 133.53 & 14 & & & & \\
\hline
\end{tabular}


Appendix D - Method for Calculation of chromatogram area

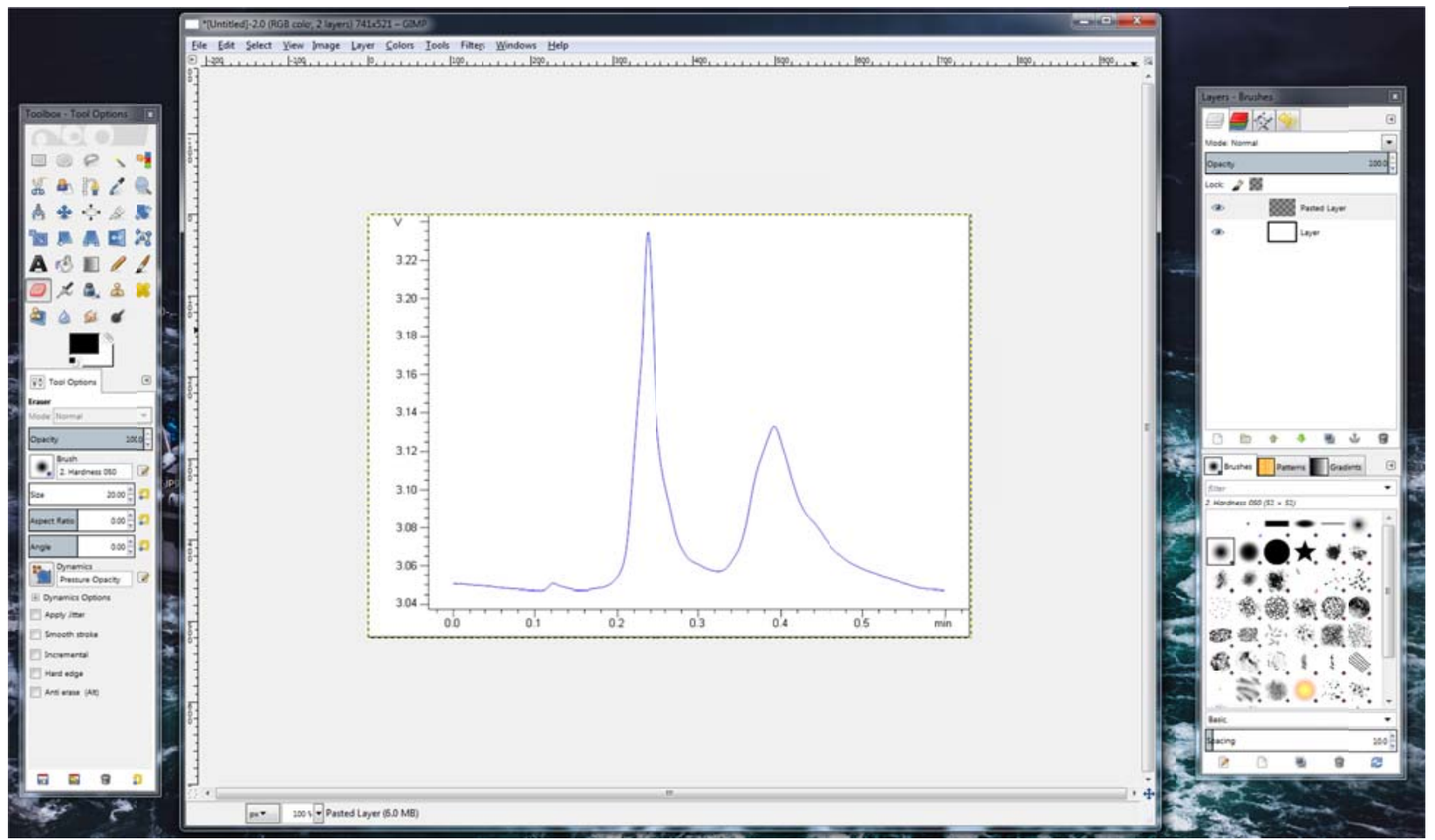

Figure 23 Step One - Open Chromatogram in GIMP 2.0 Program

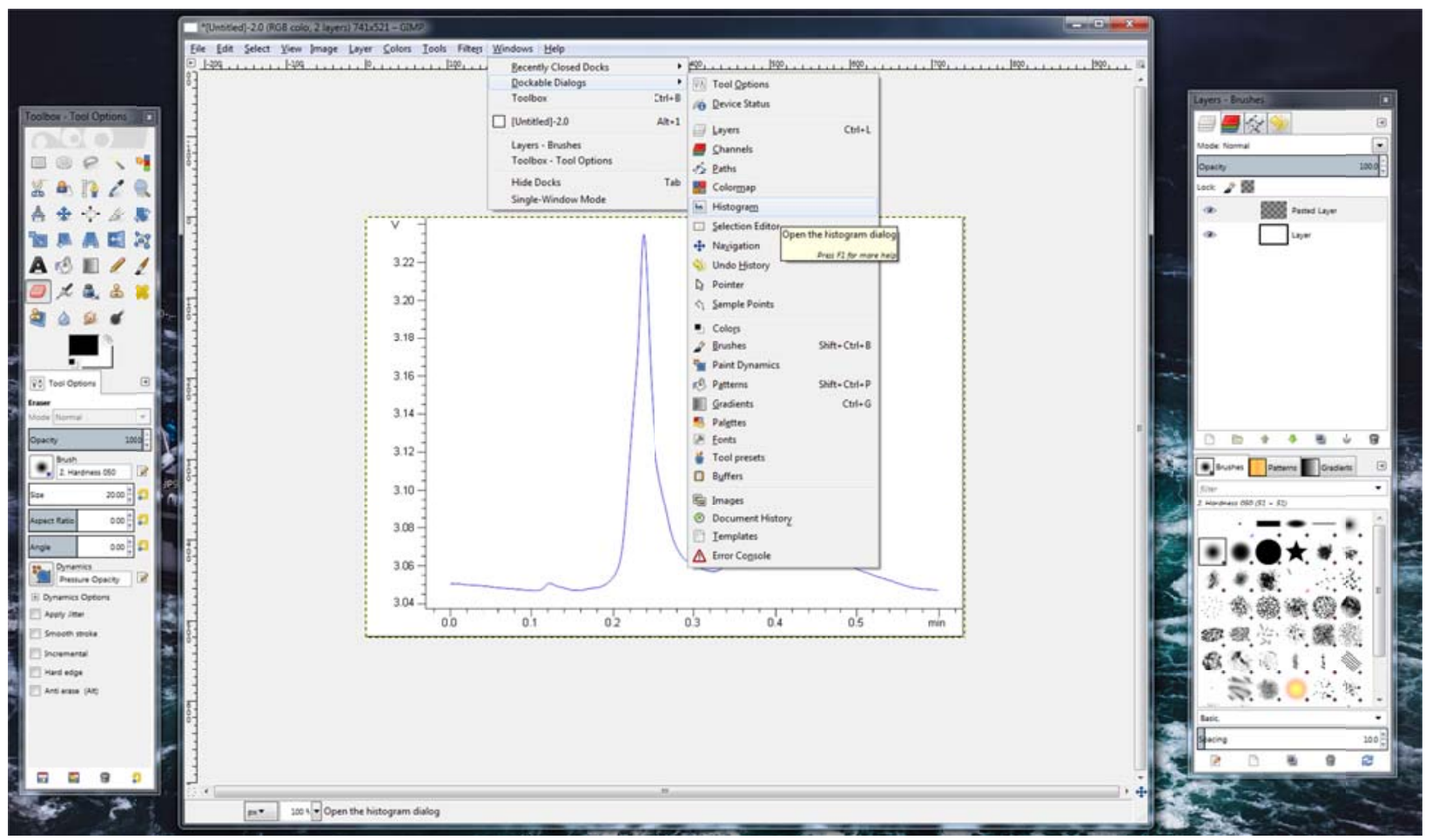

Figure 24 Step 2 - Open the Histrogram window 


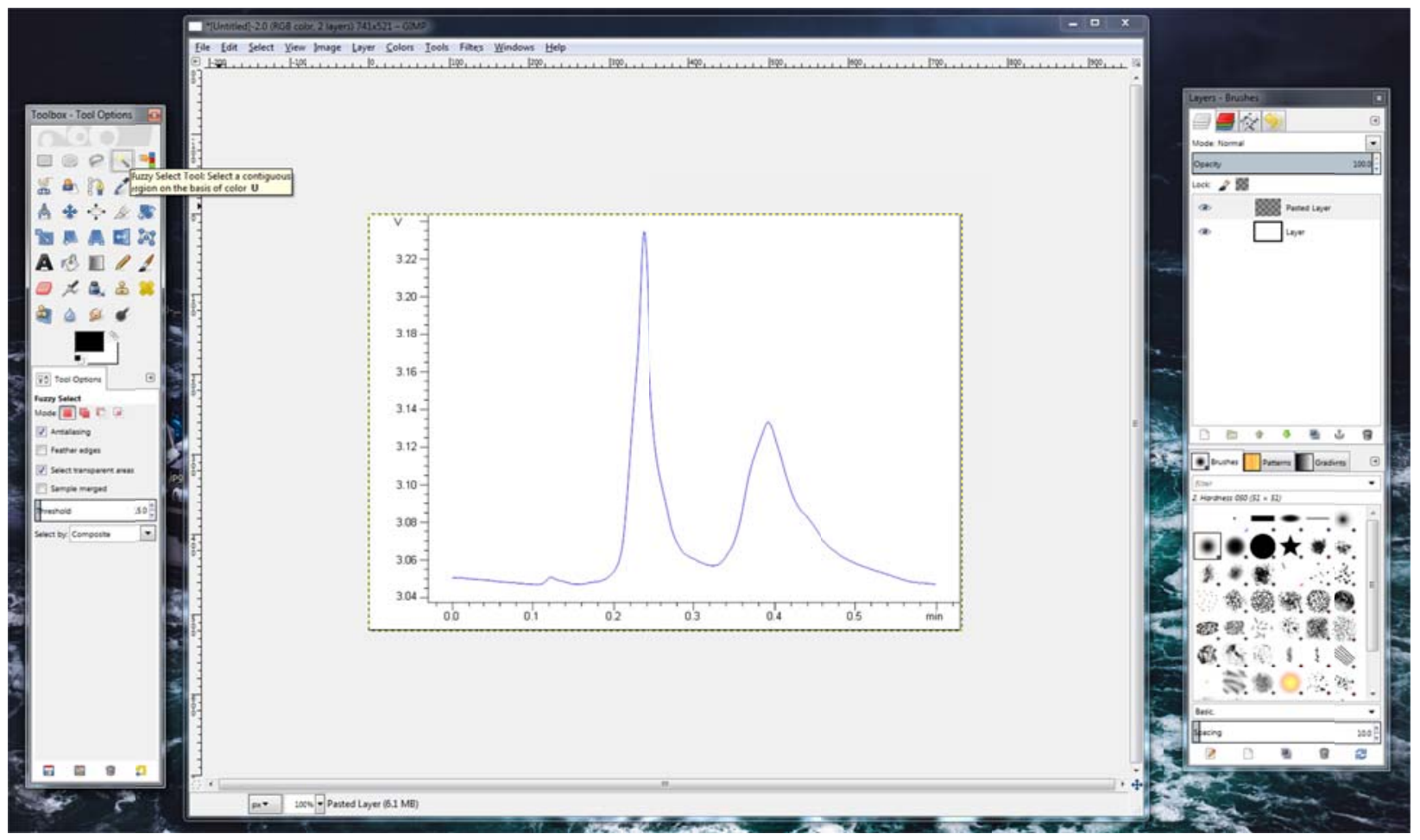

Figure 25 Step 3 - Press U key to use "Fuzzy Select" tool

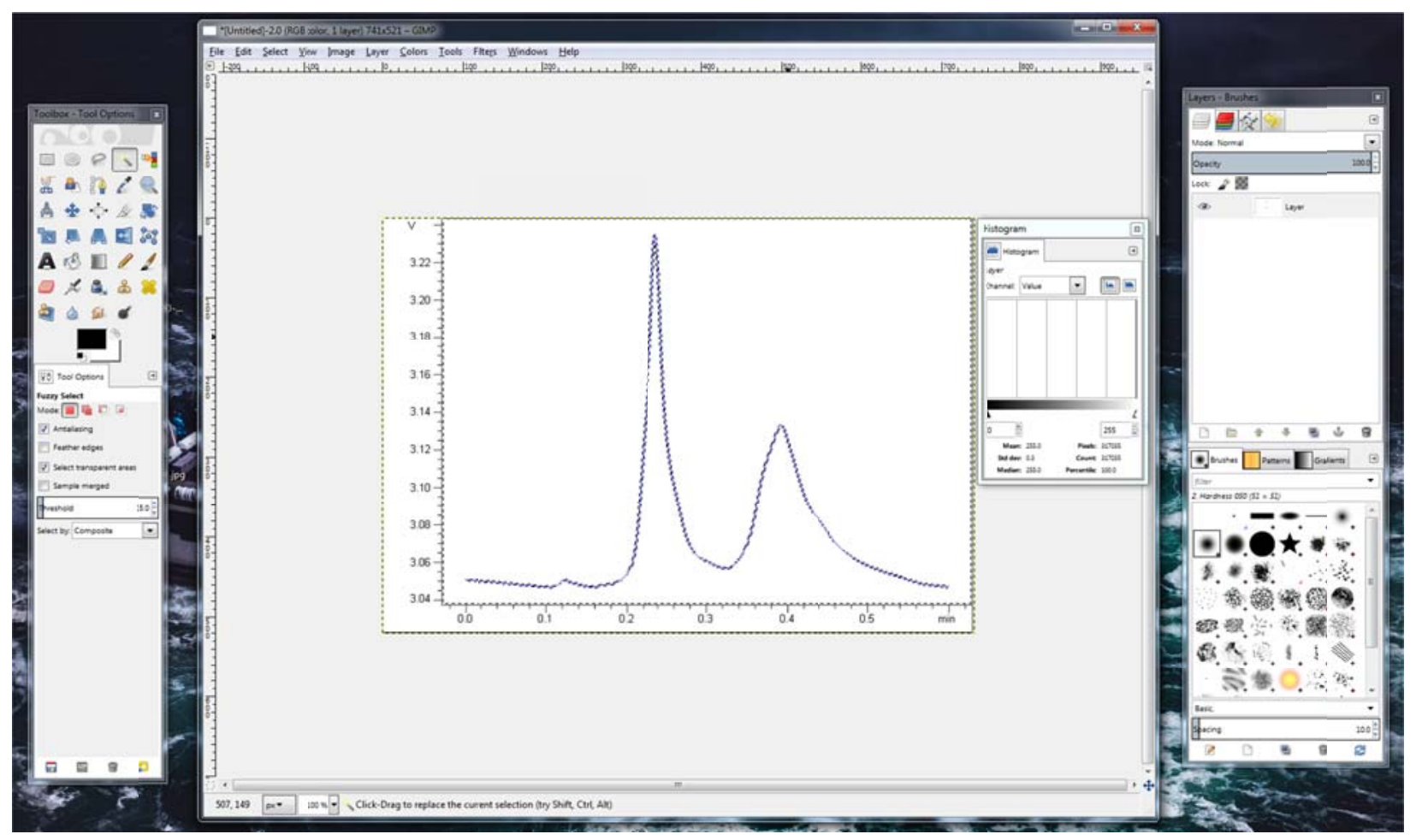

Figure 26 Step 4 - With "Fuzzy Select" tool, click anywhere within the graph boundaries, total pixels in graph will be displayed in Histogram 


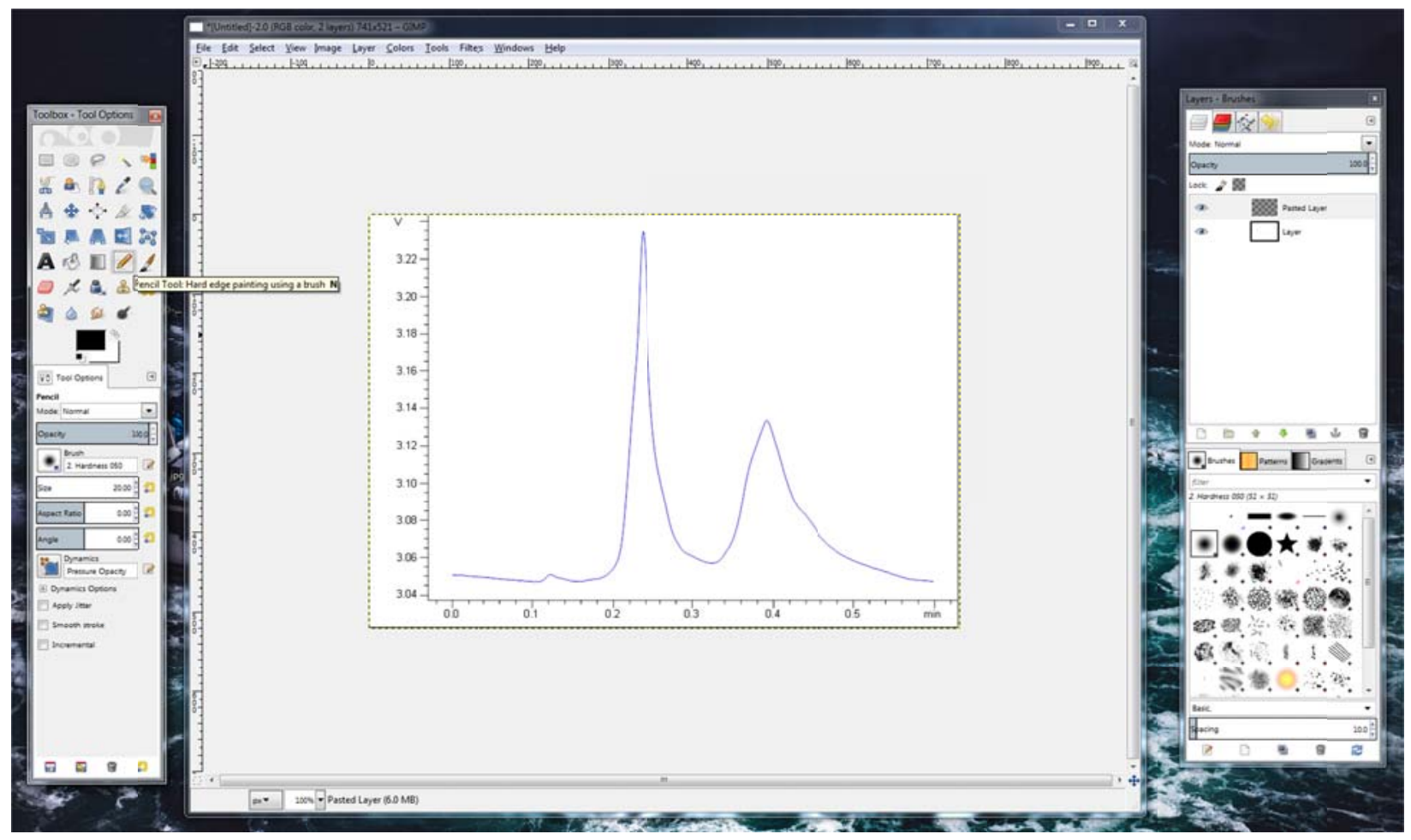

Figure 27 Step 5 - Select the pencil brush tool

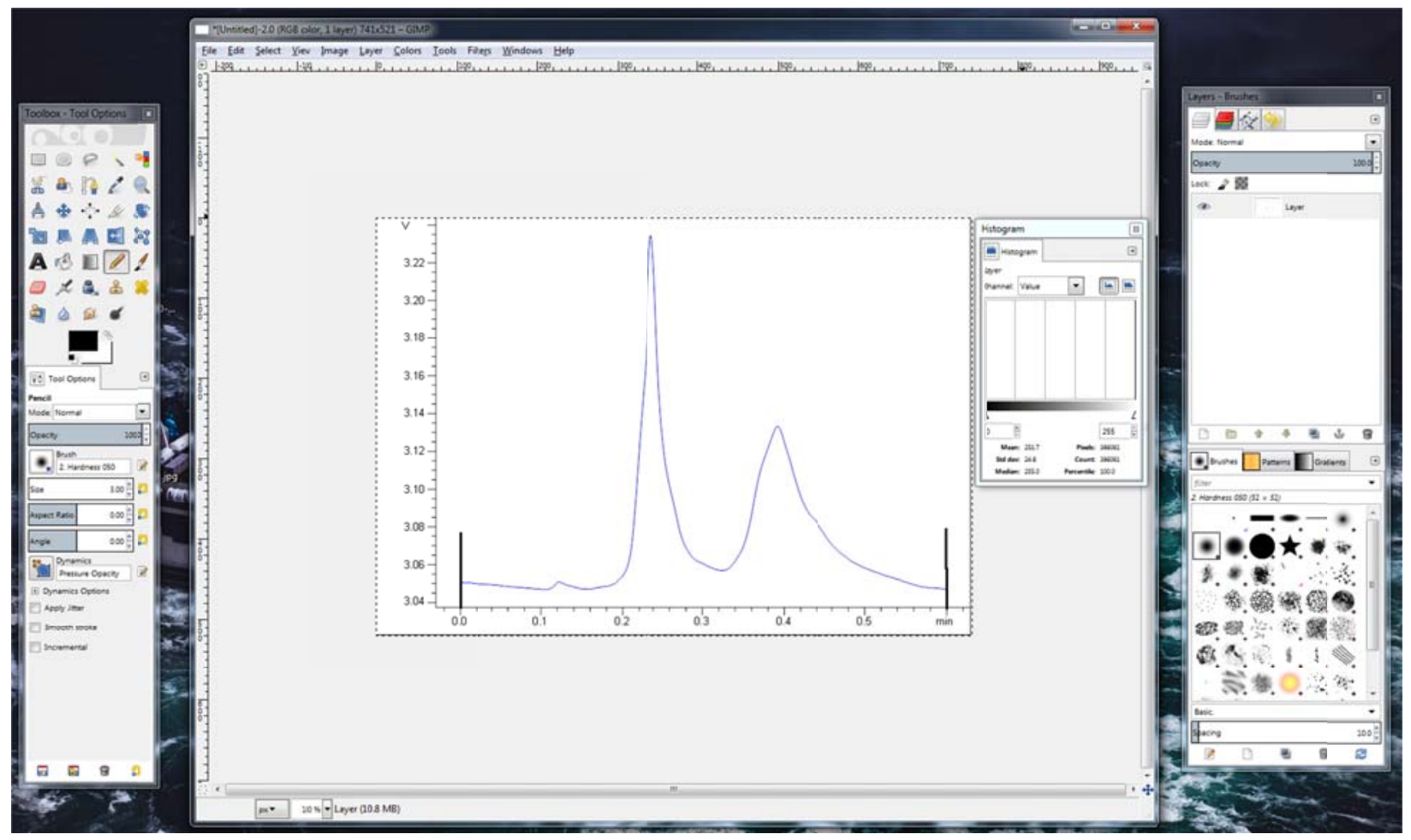

Figure 28 Step 6 - Close off the boundaries of the chromatogram using the pencil tool (Shift click to draw straight lines) 


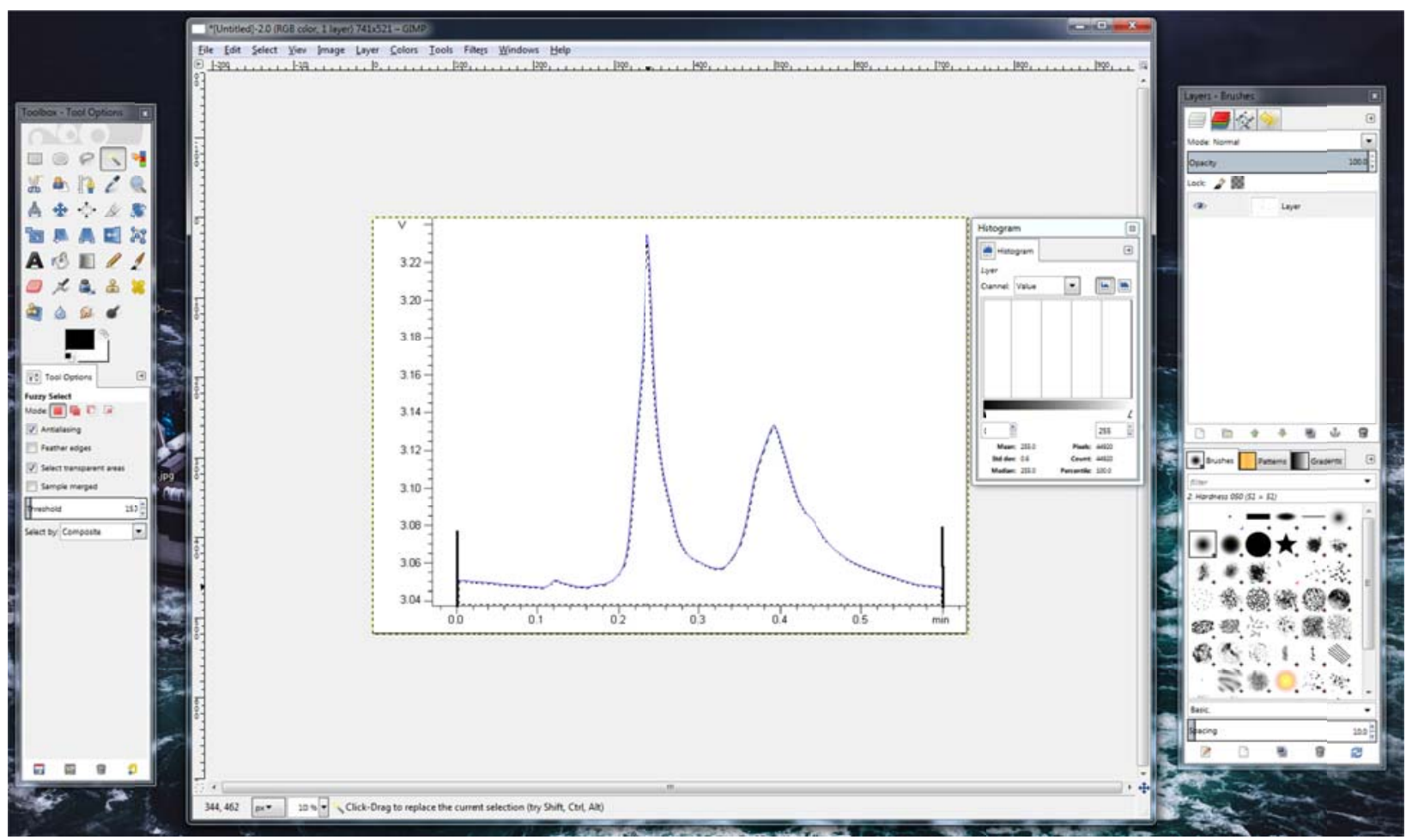

Figure 29 Step 7 - Using the "Fuzzy Select" tool once again, click under the line of the chromatogram, total pixels under the graph will be shown in the Histogram 


\section{Appendix E - Normal Q-Q plots}

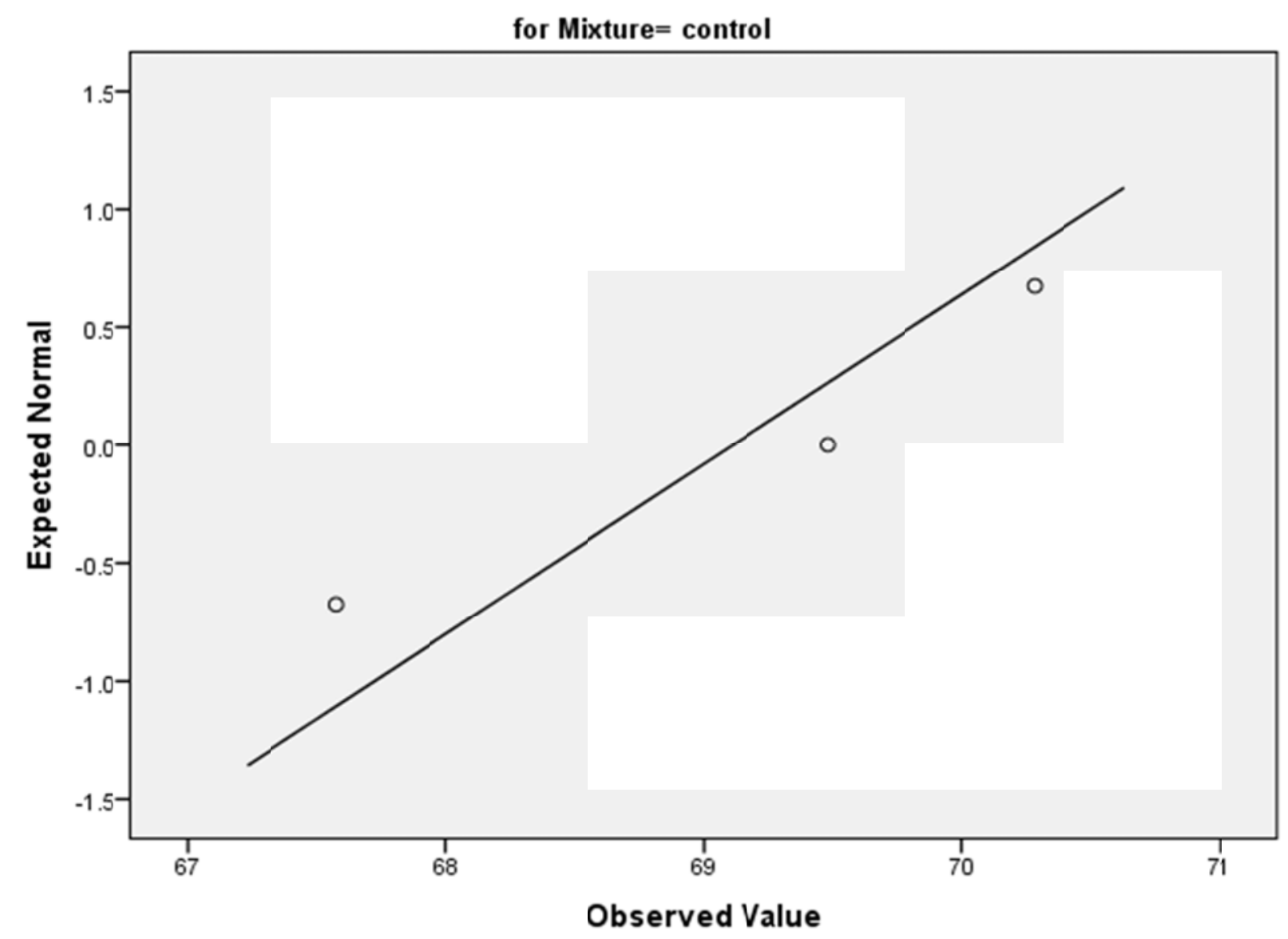

Figure 30 Normal Q-Q plot for the Area of the Chromatograms belonging to the Control Group 


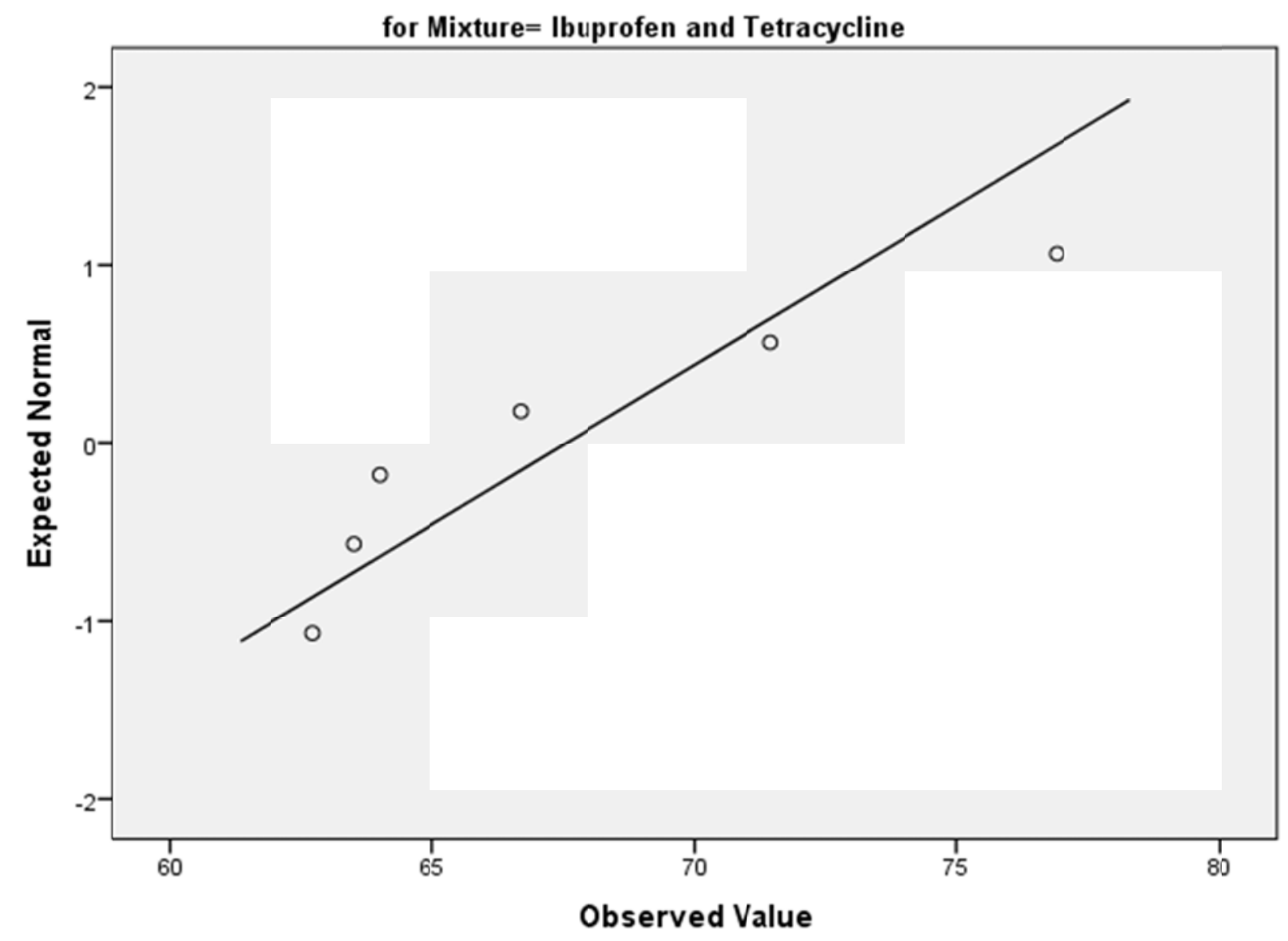

Figure 31 Normal Q-Q plot for the Area of the Chromatograms belonging to the Groups containing both Tetracycline and Ibuprofen 


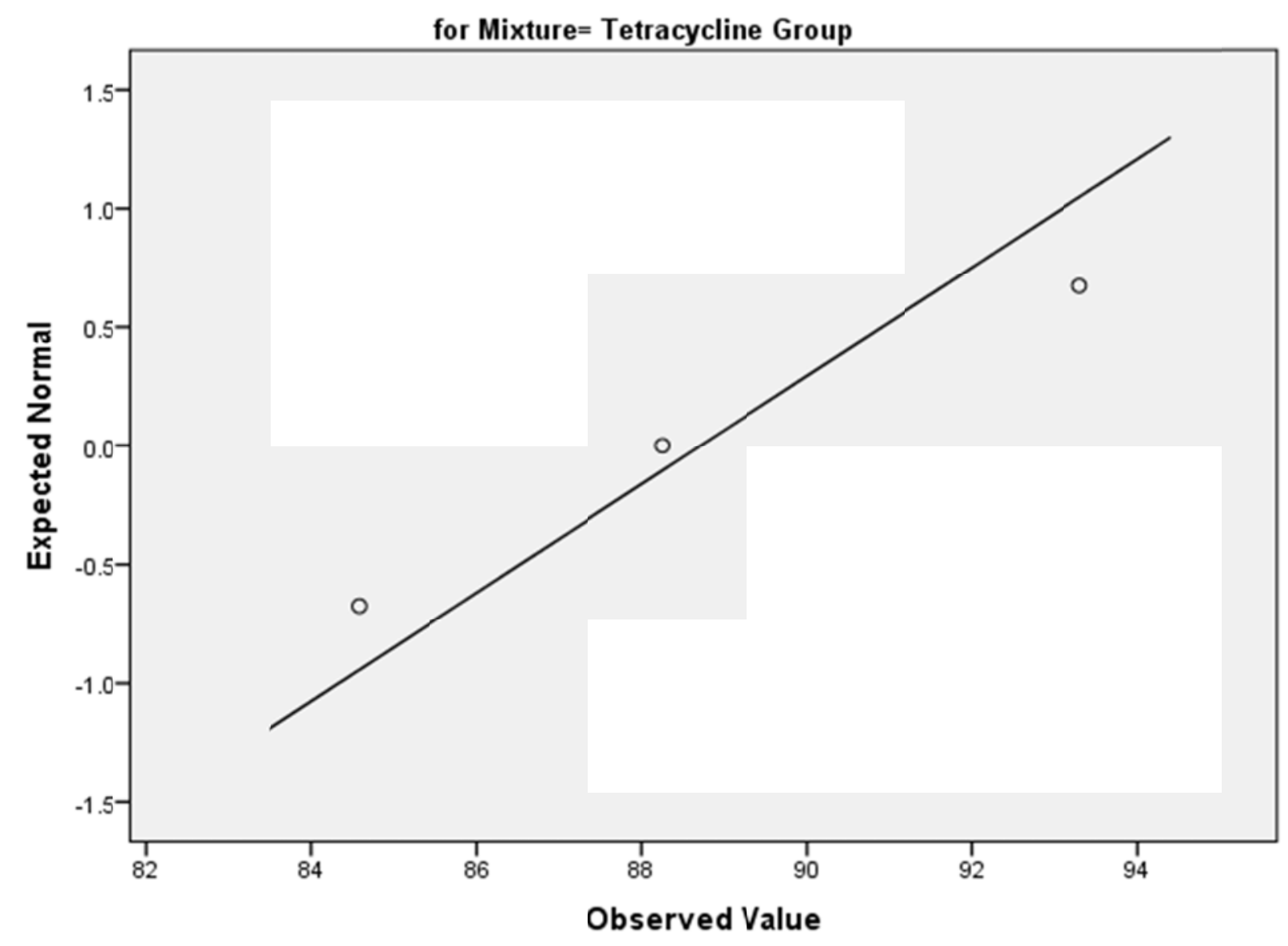

Figure 32 Normal Q-Q plot for the Area of the Chromatograms belonging to the Tetracycline Group 


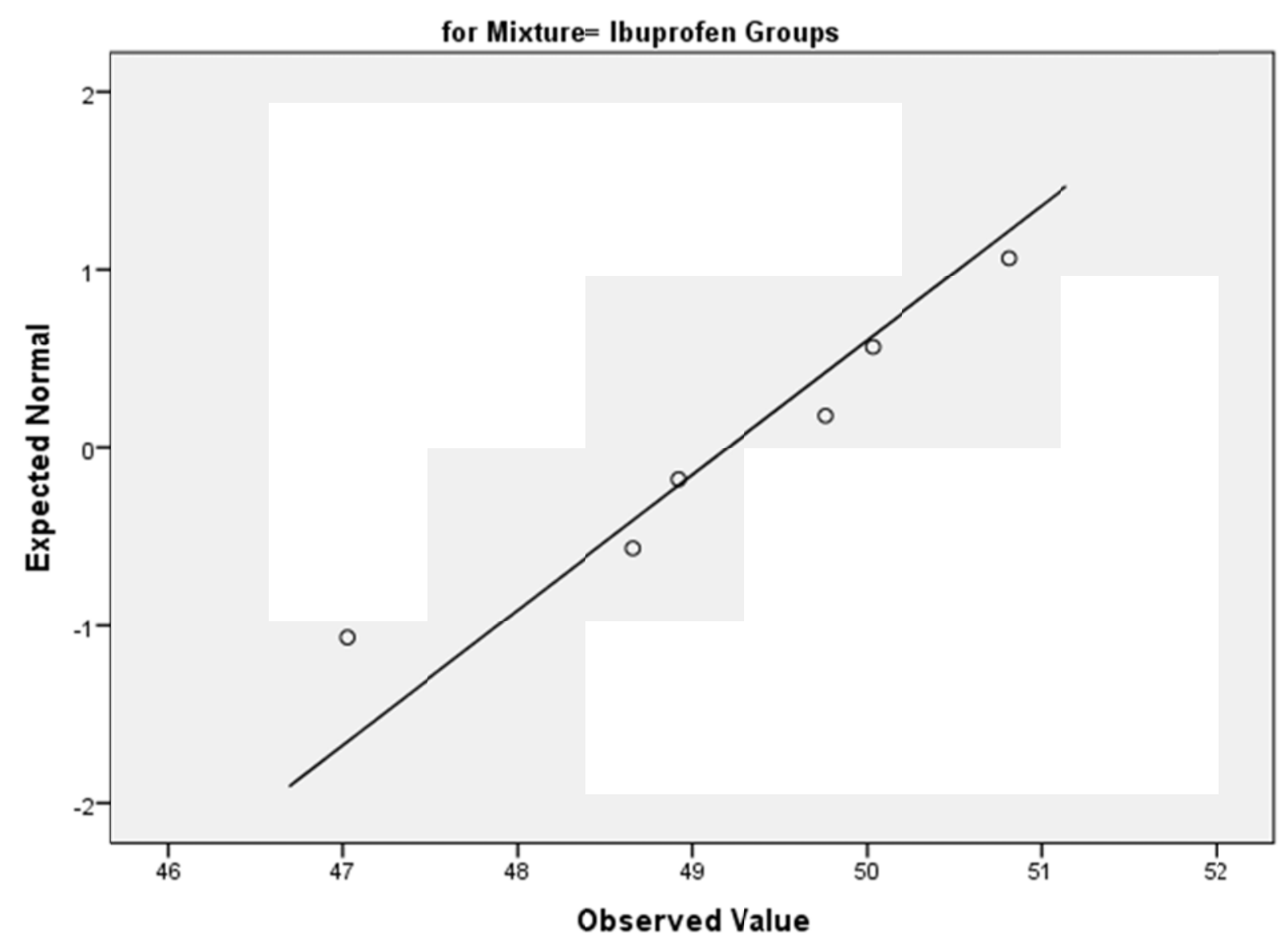

Figure 33 Normal Q-Q plot for the Area of the Chromatograms belonging to the Ibuprofen Groups 


\section{References}

Acevedo, B., Borrás, L., Oehmen, a., \& Barat, R. (2014). Modelling the metabolic shift of polyphosphate-accumulating organisms. Water Research, 65, 235-244. http://doi.org/10.1016/j.watres.2014.07.028

Actis, G. C., Pellicano, R., Fadda, M., \& Rosina, F. (2014). Antibiotics and Non-Steroidal AntiInflammatory Drugs in Outpatient Practice : Indications and Unwanted Effects in a Gastroenterological Setting, 133-137.

Alcock, R. E., Sweetman, A., \& Jones, K. C. (1998). Assessment of Organic Contaminant Fate in Wastewater Treatment Plants. Chemosphere, 38(10), 2247-2262.

Avella, a C., Essendoubi, M., Louvet, J. N., Görner, T., Sockalingum, G. D., Pons, M. N., ... de Donato, P. H. (2010). Activated sludge behaviour in a batch reactor in the presence of antibiotics: study of extracellular polymeric substances. Water Science and Technology : A Journal of the International Association on Water Pollution Research, 61(12), 3147-55. http://doi.org/10.2166/wst.2010.924

Batt, A. L., Kim, S., \& Aga, D. S. (2007). Comparison of the occurrence of antibiotics in four fullscale wastewater treatment plants with varying designs and operations. Chemosphere, 68(3), 428-35. http://doi.org/10.1016/j.chemosphere.2007.01.008

Borgmann, U., Bennie, D. T., Ball, a. L., \& Palabrica, V. (2007). Effect of a mixture of seven pharmaceuticals on Hyalella azteca over multiple generations. Chemosphere, 66(7), 12781283. http://doi.org/10.1016/j.chemosphere.2006.07.025

Brozinski, J.-M., Lahti, M., Oikari, A., \& Kronberg, L. (2013). Identification and dose dependency of ibuprofen biliary metabolites in rainbow trout. Chemosphere, 93(9), 1789-95. http://doi.org/10.1016/j.chemosphere.2013.06.018

Celander, M. C. (2011). Cocktail effects on biomarker responses in fish. Aquatic Toxicology (Amsterdam, Netherlands), 105(3-4 Suppl), 72-7.

http://doi.org/10.1016/j.aquatox.2011.06.002

Coutu, S., Wyrsch, V., Wynn, H. K., Rossi, L., \& Barry, D. a. (2013). Temporal dynamics of antibiotics in wastewater treatment plant influent. Science of the Total Environment, 458460, 20-26. http://doi.org/10.1016/j.scitotenv.2013.04.017

Deblonde, T., Cossu-Leguille, C., \& Hartemann, P. (2011). Emerging pollutants in wastewater: A review of the literature. International Journal of Hygiene and Environmental Health, 214(6), 442-448. http://doi.org/10.1016/j.ijheh.2011.08.002

EPA. (2007). OVERVIEW : OFFICE OF POLLUTION PREVENTION AND TOXICS PROGRAMS, (January).

Fent, K., Weston, A. a., \& Caminada, D. (2006). Ecotoxicology of human pharmaceuticals. Aquatic Toxicology, 76(2), 122-159. http://doi.org/10.1016/j.aquatox.2005.09.009

Frolund, B., Palmgreen, Ri., Keiding, K., \& Nielsen, P. H. (1996). Extraction of Extracellular Polymers From Activated Sludge Using a Cation Exchange Resin. Pergamon, 30(8), 1749- 
1758.

Funt, L. S. (1985). Oral ibuprofen and minocycline for the treatment of resistant acne vulgaris. Journal of the American Academy of Dermatology, 13(3), 524-525. http://doi.org/10.1016/S0190-9622(85)80375-3

Gilbride, K. A., \& Levinson, L. (2011). Detection of Melamine and Cyanuric Acid in Vegetable Protein Products Used in Food Production. Journal of Food Science, 76(4), 568-575.

Gilbride, K., \& Levinson, L. (2007). Wastewater Treatment and Emerging Pollutants in the Environment.

Guerra, P., Kim, M., Shah, a., Alaee, M., \& Smyth, S. a. (2014). Occurrence and fate of antibiotic, analgesic/anti-inflammatory, and antifungal compounds in five wastewater treatment processes. Science of the Total Environment, 473-474, 235-243. http://doi.org/10.1016/j.scitotenv.2013.12.008

Ha, J., Gélabert, A., Spormann, A. M., \& Brown, G. E. (2010). Role of extracellular polymeric substances in metal ion complexation on Shewanella oneidensis: Batch uptake, thermodynamic modeling, ATR-FTIR, and EXAFS study. Geochimica et Cosmochimica Acta, 74(1), 1-15. http://doi.org/10.1016/j.gca.2009.06.031

Holtz, S. (2006). There is no "Away", pharmaceuticals, personal care products, and endocrinedisrupting substances: Emerging contaminants detected in water.

Hoque, M. E., Cloutier, F., Arcieri, C., Mclnnes, M., Sultana, T., Murray, C., ... Metcalfe, C. D. (2014). Removal of selected pharmaceuticals, personal care products and artificial sweetener in an aerated sewage lagoon. The Science of the Total Environment, 487, 80112. http://doi.org/10.1016/j.scitotenv.2013.12.063

Hughes, S. R., Kay, P., \& Brown, L. E. (2013). Global synthesis and critical evaluation of pharmaceutical data sets collected from river systems. Environmental Science \& Technology, 47(2), 661-77. http://doi.org/10.1021/es3030148

Irsch, R. O. H. (2003). OCCURRENCE OF NEUTRAL AND ACIDIC DRUGS IN THE EFFLUENTS OF CANADIAN SEWAGE TREATMENT PLANTS, 22(12), 2872-2880.

Joshi, P. M., \& Juwarkar, A. a. (2009). In Vivo Studies to Elucidate the Role of Extracellular Polymeric Substances from. Environmental Science \& Technology, 43(15), 5884-5889.

Kim, Y., Choi, K., Jung, J., Park, S., Kim, P.-G., \& Park, J. (2007). Aquatic toxicity of acetaminophen, carbamazepine, cimetidine, diltiazem and six major sulfonamides, and their potential ecological risks in Korea. Environment International, 33(3), 370-5. http://doi.org/10.1016/j.envint.2006.11.017

Klaper, R., Associate, S., \& Welch, L. C. (2011). Emerging Contaminants and Threats in the Great Lakes.

Landers, T. F., Cohen, B., Wittum, T. E., \& Larson, E. L. (2012). A review of antibiotic use in food animals: perspective, policy, and potential. Public Health Reports, 127(1), 4-22. Retrieved from

http://www.pubmedcentral.nih.gov/articlerender.fcgi?artid=3234384\&tool=pmcentrez\&r 
endertype $=$ abstract

Le-Clech, P., Chen, V., \& Fane, T. a. G. (2006). Fouling in membrane bioreactors used in wastewater treatment. Journal of Membrane Science, 284(1-2), 17-53.

http://doi.org/10.1016/j.memsci.2006.08.019

Lee, N. M., \& Welander, T. (1996). Reducing sludge production in aerobic wastewater treatment through manipulation of the ecosystem. Water Research, 30(8), 1781-1790. http://doi.org/10.1016/0043-1354(96)00059-0

Lienert, J., Bürki, T., \& Escher, B. I. (2007). Reducing micropollutants with source control: substance flow analysis of 212 pharmaceuticals in faeces and urine. Water Science and Technology : A Journal of the International Association on Water Pollution Research, 56(5), 87-96. http://doi.org/10.2166/wst.2007.560

Limited, G. I. (2012). Granules India Intellectual Capital Report.

Lishman, L., Smyth, S. A., Sarafin, K., Kleywegt, S., Toito, J., Peart, T., ... Seto, P. (2006). Occurrence and reductions of pharmaceuticals and personal care products and estrogens by municipal wastewater treatment plants in Ontario, Canada. The Science of the Total Environment, 367(2-3), 544-58. http://doi.org/10.1016/j.scitotenv.2006.03.021

Luo, Y., Guo, W., Ngo, H. H., Nghiem, L. D., Hai, F. I., Zhang, J., ... Wang, X. C. (2014). A review on the occurrence of micropollutants in the aquatic environment and their fate and removal during wastewater treatment. The Science of the Total Environment, 473-474, 619-41. http://doi.org/10.1016/j.scitotenv.2013.12.065

Martín-González, A., Díaz, S., Borniquel, S., Gallego, A., \& Gutiérrez, J. C. (2006). Cytotoxicity and bioaccumulation of heavy metals by ciliated protozoa isolated from urban wastewater treatment plants. Research in Microbiology, 157(2), 108-18.

http://doi.org/10.1016/j.resmic.2005.06.005

McEneff, G., Barron, L., Kelleher, B., Paull, B., \& Quinn, B. (2014). A year-long study of the spatial occurrence and relative distribution of pharmaceutical residues in sewage effluent, receiving marine waters and marine bivalves. The Science of the Total Environment, 476477, 317-26. http://doi.org/10.1016/j.scitotenv.2013.12.123

McGettigan, P., \& Henry, D. (2013). Use of Non-Steroidal Anti-Inflammatory Drugs That Elevate Cardiovascular Risk: An Examination of Sales and Essential Medicines Lists in Low-, Middle, and High-Income Countries. PLoS Medicine, 10(2). http://doi.org/10.1371/journal.pmed.1001388

Metcalfe, C., Hoque, M. E., Sultana, T., Murray, C., Helm, P., \& Kleywegt, S. (2014). Monitoring for contaminants of emerging concern in drinking water using POCIS passive samplers. Environmental Science. Processes \& Impacts, 16(3), 473-81. http://doi.org/10.1039/c3em00508a

Miao, X. S., Bishay, F., Chen, M., \& Metcalfe, C. D. (2004). Occurrence of antimicrobials in the final effluents of wastewater treatment plants in Canada. Environmental Science and Technology, 38(13), 3533-3541. http://doi.org/10.1021/es030653q

Michael, I., Rizzo, L., McArdell, C. S., Manaia, C. M., Merlin, C., Schwartz, T., ... Fatta-Kassinos, D. 
(2013). Urban wastewater treatment plants as hotspots for the release of antibiotics in the environment: A review. Water Research, 47(3), 957-995.

http://doi.org/10.1016/j.watres.2012.11.027

Miège, C., Choubert, J. M., Ribeiro, L., Eusèbe, M., \& Coquery, M. (2009). Fate of pharmaceuticals and personal care products in wastewater treatment plants - Conception of a database and first results. Environmental Pollution, 157, 1721-1726. http://doi.org/10.1016/j.envpol.2008.11.045

Moore, N. (2007). Ibuprofen: a journey from prescription to over-the-counter use. Journal of the Royal Society of Medicine, 100(48), 2-6.

Moussa, M. S., Hooijmans, C. M., Lubberding, H. J., Gijzen, H. J., \& van Loosdrecht, M. C. M. (2005). Modelling nitrification, heterotrophic growth and predation in activated sludge. Water Research, 39(20), 5080-98. http://doi.org/10.1016/j.watres.2005.09.038

Mudgal, S. (BIO I. S., Toni, A. D. (BIO I. S., Lockwood, S. (BIO I. S., Salès, K. (BIO I. S., Backhaus, T. (University of G., \& Sorensen, B. H. (University of C. (2013). Study on the environmental risks of medicinal products.

Nelson, M. L. (2002). The chemistry and biology of the tetracyclines. Annual Reports in Medicinal Chemistry, 37, 105-114. http://doi.org/10.1039/c3md00325f

OECD. (2012). OECD Environmental Outlook to 2050.

Osachoff, H. L., Mohammadali, M., Skirrow, R. C., Hall, E. R., Brown, L. L. Y., van Aggelen, G. C., ... Helbing, C. C. (2014). Evaluating the treatment of a synthetic wastewater containing a pharmaceutical and personal care product chemical cocktail: compound removal efficiency and effects on juvenile rainbow trout. Water Research, 62, 271-80. http://doi.org/10.1016/j.watres.2014.05.057

Pal, A., \& Paul, a. K. (2008). Microbial extracellular polymeric substances: Central elements in heavy metal bioremediation. Indian Journal of Microbiology, 48(1), 49-64. http://doi.org/10.1007/s12088-008-0006-5

Pan, S.-F., Zhu, M.-P., Paul Chen, J., Yuan, Z.-H., Zhong, L.-B., \& Zheng, Y.-M. (2015). Separation of tetracycline from wastewater using forward osmosis process with thin film composite membrane - Implications for antibiotics recovery. Separation and Purification Technology, 153, 76-83. http://doi.org/10.1016/j.seppur.2015.08.034

Pasquini, L., Merlin, C., Hassenboehler, L., Munoz, J.-F., Pons, M.-N., \& Görner, T. (2013). Impact of certain household micropollutants on bacterial behavior. Toxicity tests/study of extracellular polymeric substances in sludge. The Science of the Total Environment, 463464, 355-65. http://doi.org/10.1016/j.scitotenv.2013.06.018

Pereira, S., Micheletti, E., Zille, A., Santos, A., Moradas-Ferreira, P., Tamagnini, P., \& De Philippis, R. (2011). Using extracellular polymeric substances (EPS)-producing cyanobacteria for the bioremediation of heavy metals: Do cations compete for the EPS functional groups and also accumulate inside the cell? Microbiology, 157(2), 451-458. http://doi.org/10.1099/mic.0.041038-0

Petrie, B., McAdam, E. J., Scrimshaw, M. D., Lester, J. N., \& Cartmell, E. (2013). Fate of drugs 
during wastewater treatment. TrAC Trends in Analytical Chemistry, 49, 145-159. http://doi.org/10.1016/j.trac.2013.05.007

Prosser, R. S., \& Sibley, P. K. (2015). Human health risk assessment of pharmaceuticals and personal care products in plant tissue due to biosolids and manure amendments, and wastewater irrigation. Environment International, 75, 223-233.

http://doi.org/10.1016/j.envint.2014.11.020

Report, F. (2009). Guelph Wastewater Treatment Master Plan, (April).

Richard, M., \& Ph, D. (2003). Michael Richard, Ph.D. Sear-Brown Fort Collins, CO, 1-21.

Russell, R. I. (2001). Non-steroidal anti-inflammatory drugs and gastrointestinal damage--problems and solutions. Postgraduate Medical Journal, 77(904), 82-88. http://doi.org/10.1136/pmj.77.904.82

Sanchez, W., Sremski, W., Piccini, B., Palluel, O., Maillot-Maréchal, E., Betoulle, S., ... Porcher, J.M. (2011). Adverse effects in wild fish living downstream from pharmaceutical manufacture discharges. Environment International, 37(8), 1342-8. http://doi.org/10.1016/j.envint.2011.06.002

Schlüter, A., Szczepanowski, R., Pühler, A., \& Top, E. M. (2007). Genomics of IncP-1 antibiotic resistance plasmids isolated from wastewater treatment plants provides evidence for a widely accessible drug resistance gene pool. FEMS Microbiology Reviews, 31(4), 449-477. http://doi.org/10.1111/j.1574-6976.2007.00074.x

Shapiro, S. S., \& Wilk, M. B. (1965). An Analysis of Variance Test for Normality (Complete Samples). Biometrika, 52(3), 591-611. http://doi.org/10.1093/biomet/52.3-4.591

Sheng, G.-P., Yu, H.-Q., \& Li, X.-Y. (2010). Extracellular polymeric substances (EPS) of microbial aggregates in biological wastewater treatment systems: a review. Biotechnology Advances, 28(6), 882-94. http://doi.org/10.1016/j.biotechadv.2010.08.001

Stuart, M., Lapworth, D., Crane, E., \& Hart, A. (2012). Review of risk from potential emerging contaminants in UK groundwater. The Science of the Total Environment, 416, 1-21. http://doi.org/10.1016/j.scitotenv.2011.11.072

Vasquez, M. I., Lambrianides, a, Schneider, M., Kümmerer, K., \& Fatta-Kassinos, D. (2014). Environmental side effects of pharmaceutical cocktails: what we know and what we should know. Journal of Hazardous Materials, 279, 169-89. http://doi.org/10.1016/j.jhazmat.2014.06.069

Verlicchi, P., Al Aukidy, M., \& Zambello, E. (2012). Occurrence of pharmaceutical compounds in urban wastewater: removal, mass load and environmental risk after a secondary treatment--a review. The Science of the Total Environment, 429, 123-55. http://doi.org/10.1016/j.scitotenv.2012.04.028

Wong, R. C., Kang, S., Heezen, J. L., Voorhees, J. J., \& Ellis, C. N. (2015). Oral ibuprofen and tetracycline for the treatment of acne vulgaris. Journal of the American Academy of Dermatology, 11(6), 1076-1081. http://doi.org/10.1016/S0190-9622(84)80192-9

Woodruff, T. J., Burke, T. a, \& Zeise, L. (2011). The need for better public health decisions on 
chemicals released into our environment. Health Affairs (Project Hope), 30(5), 957-67. http://doi.org/10.1377/hlthaff.2011.0194

Wunder, D. B., Tan, D. T., LaPara, T. M., \& Hozalski, R. M. (2013). The effects of antibiotic cocktails at environmentally relevant concentrations on the community composition and acetate biodegradation kinetics of bacterial biofilms. Chemosphere, 90(8), 2261-6. http://doi.org/10.1016/j.chemosphere.2012.10.031

Yin, Z., Wang, Y., Whittell, L. R., Jergic, S., Liu, M., Harry, E., ... Oakley, A. J. (2014). DNA Replication Is the Target for the Antibacterial Effects of Nonsteroidal Anti-Inflammatory Drugs. Chemistry \& Biology, 21(4), 481-487. http://doi.org/10.1016/j.chembiol.2014.02.009

Zenker, A., Cicero, M. R., Prestinaci, F., Bottoni, P., \& Carere, M. (2014). Bioaccumulation and biomagnification potential of pharmaceuticals with a focus to the aquatic environment. Journal of Environmental Management, 133, 378-87. http://doi.org/10.1016/j.jenvman.2013.12.017

Zhang, H., Du, M., Jiang, H., Zhang, D., Lin, L., Ye, H., \& Zhang, X. (2014). Environmental Science Processes \& Impacts Occurrence, seasonal variation and removal wastewater treatment plants , Jiulongjiang River. Environmental Science: Processes \& Impacts, 17, 225-234. http://doi.org/10.1039/C4EM00457D

Zhang, T., Ye, L., Tong, A. H. Y., Shao, M.-F., \& Lok, S. (2011). Ammonia-oxidizing archaea and ammonia-oxidizing bacteria in six full-scale wastewater treatment bioreactors. Applied Microbiology and Biotechnology, 91(4), 1215-25. http://doi.org/10.1007/s00253-0113408-y 